\title{
HOW FACEBOOK GAVE ME 'FRIENDS': THE IMPACT OF FACEBOOK IMPORTANCE ON ENGAGEMENT AND PSYCHOLOGICAL \\ WELL-BEING
}

\author{
By \\ Jessica Moorman \\ A thesis submitted to \\ the Faculty of Graduate and Postdoctoral Affairs \\ in partial fulfillment of the requirements for the degree of \\ Master of Arts \\ in \\ Psychology
}

Carleton University

Ottawa, Canada

(C2012 Jessica Moorman 
Library and Archives

Canada

Published Heritage

Branch

395 Wellington Street

Ottawa ON K1A ON4

Canada
Bibliothèque et

Archives Canada

Direction du

Patrimoine de l'édition

395 , rue Wellington

Ottawa ON K1A ON4

Canada
Your file Votre référence

ISBN: 978-0-494-93604-7

Our file Notre référence

ISBN: 978-0-494-93604-7
NOTICE:

The author has granted a nonexclusive license allowing Library and Archives Canada to reproduce, publish, archive, preserve, conserve, communicate to the public by telecommunication or on the Internet, loan, distrbute and sell theses worldwide, for commercial or noncommercial purposes, in microform, paper, electronic and/or any other formats.

The author retains copyright ownership and moral rights in this thesis. Neither the thesis nor substantial extracts from it may be printed or otherwise reproduced without the author's permission.
AVIS:

L'auteur a accordé une licence non exclusive permettant à la Bibliothèque et Archives Canada de reproduire, publier, archiver, sauvegarder, conserver, transmettre au public par télécommunication ou par l'Internet, prêter, distribuer et vendre des thèses partout dans le monde, à des fins commerciales ou autres, sur support microforme, papier, électronique et/ou autres formats.

L'auteur conserve la propriété du droit d'auteur et des droits moraux qui protege cette thèse. $\mathrm{Ni}$ la thèse ni des extraits substantiels de celle-ci ne doivent être imprimés ou autrement reproduits sans son autorisation.
In compliance with the Canadian Privacy Act some supporting forms may have been removed from this thesis.

While these forms may be included in the document page count, their removal does not represent any loss of content from the thesis.
Conformément à la loi canadienne sur la protection de la vie privée, quelques formulaires secondaires ont été enlevés de cette thèse.

Bien que ces formulaires aient inclus dans la pagination, il n'y aura aucun contenu manquant. 


\begin{abstract}
The objective of the study was to investigate the use of Facebook by first year undergraduate students as it relates to their sense of belief in the importance of Facebook, Facebook Engagement and overall well-being. Also examined was how collective selfesteem might moderate this relationship. Participants included 431 first year students $(M=20.4, S D=1.67)$ from Carleton University. Results from the study indicated Facebook Importance was significantly and positively related to both Facebook usage and Facebook Engagement Factors. Facebook variables, specifically Facebook Importance and the three Facebook Engagement Factors, were significantly related to negative aspects of well-being (i.e. depression and loneliness), and several of these relationships were moderated by collective self-esteem. For example, the effect of Facebook Importance on depression was strongest for individuals higher on collective self-esteem. However, the effect of Managing Conflict on depression was strongest for individuals lower on collective self-esteem. These findings have important implications for understanding Facebook usage and maintenance of friendships online.
\end{abstract}




\section{FACEBOOK IMPORTÁNCE, ENGAGEMENT AND WELL-BEING}

\section{Acknowledgements}

I wish to express my most sincere gratitude to the many people who have helped me in realizing my ability and purpose in working towards and achieving this monumental goal. First and foremost I would like to give my profound thanks to my advisor Dr. Anne Bowker, my ever-diligent mentor. You encouraged me to think like a researcher, always trying to get me to a deeper level of understanding. You helped me realize that this research was only the beginning, not the final thing I will ever create. The enthusiasm you had for your research was contagious and motivational for me, and I can't thank you enough for this experience: To my committee members, for your limitless generosity, for giving your time and providing valuable insights as the project took shape, my sincerest thanks. To my lab mates, there is a piece of you in each step of this research and I am ever indebted to you for your supportive criticism, your kind words of encouragement, and for all of your juju. It helped more than you will know. To my best of friends, you shared with me your stories, your optimism and your belief in my ability to carry out this project, and for this, I owe you an impossible debt of gratitude. All of you have contributed enormously to making my years at Carleton some of the most enjoyable, meaningful and successful years of my life. To Etelle Bourassa, thank you for treating me with insurmountable kindness and concern for all of my problems, big and small. Your relentless sense of care always brought me a kind of ease that was so very reassuring. To the many students who participated in this research, thank you, without your willingness to further research in this field, this study would not have been possible. To Moe, thank you for being patient with me throughout this process and for supporting me in a way that no one else could. Your reassurance on those long nights grounded me 


\section{FACEBOOK IMPORTANCE, ENGAGEMENT AND WELL-BEING}

and made me appreciate this wonderful journey. You have been a source of inspiration, and I am especially grateful for the laughs you always knew I needed. To my family, especially my grandparents and my two loving brothers, Scott and Peter, thank you for your enthusiasm and belief in my strengths. I hope you recognize this accomplishment as one that is shared between us all. Last but never least, to my dear parents, there are no words to thank you for the kind of support that you have given me, not only during these past two years, but also throughout my entire life. You have seen me at my best and my worst and your enduring love and encouragement has never waivered. You instilled in me a strong work ethic and taught me the value in pursuing a passion. I appreciate you for always having a loving piece of optimism to share. My profound thank you for being my rock during this process. This is for you. 


\section{Tables of Contents}

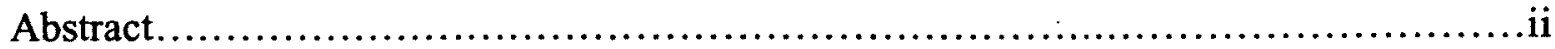

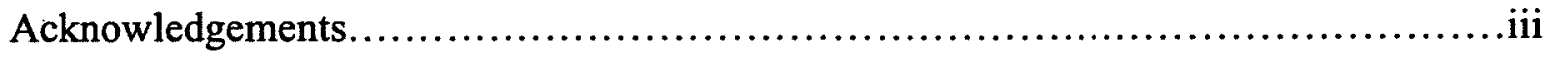

Table of Contents..................................................................

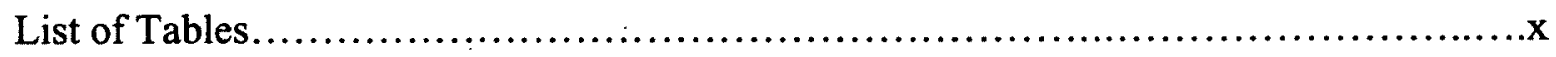

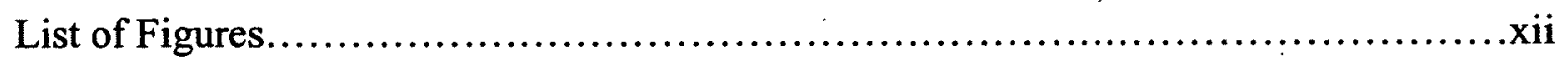

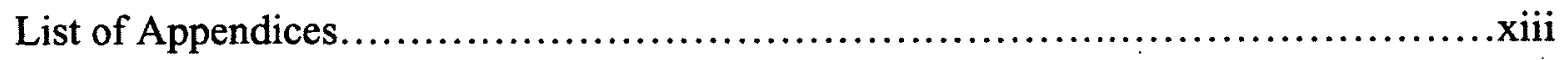

How Facebook Gave Me 'Friends': The Impact of Facebook Importance on

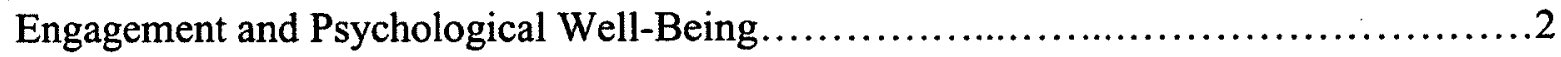

Statement of the Problem.........................................................

Contemporary Communication and Emerging Adults..............................5

Emerging Adults.......................................................

Benefits and drawbacks of social networking sites..........................8

The importance of social networking sites...............................11

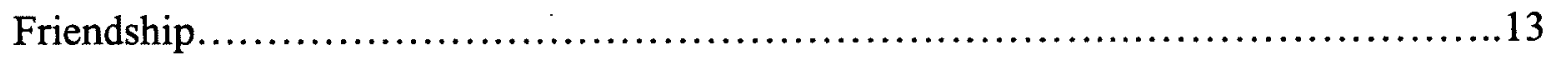

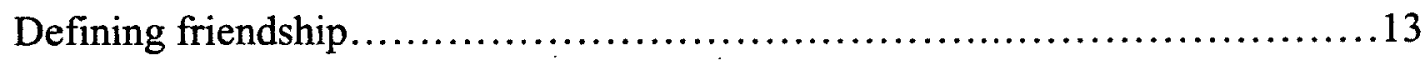

Online friendships................................................... 14

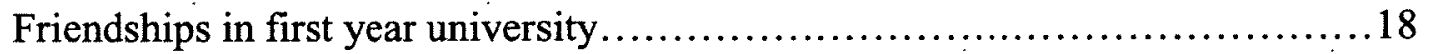

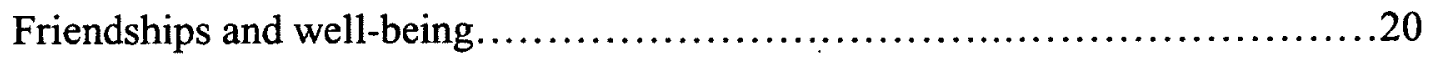

The Emergence of Facebook and Online Friendships.............................23

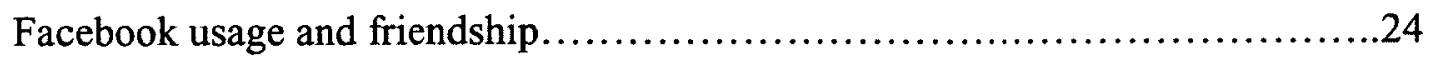

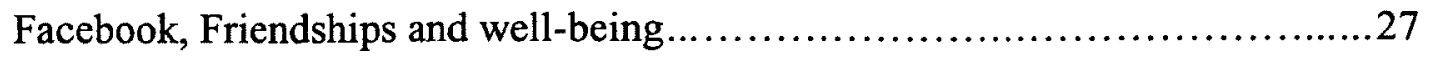

Proposed Main Effects...................................................... 30 


\section{FACEBOOK IMPORTANCE, ENGAGEMENT AND WELL-BEING}

Proposed Moderator (Collective self-esteem) ....................................32

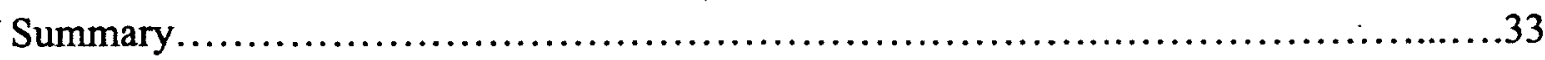

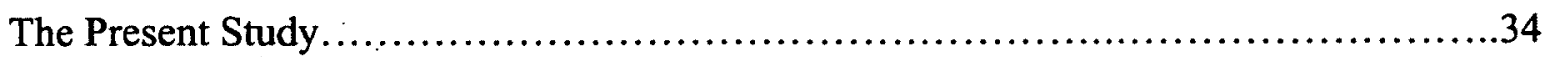

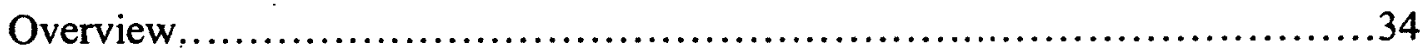

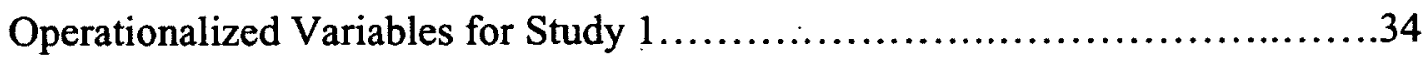

Facebook Engagement..............................................

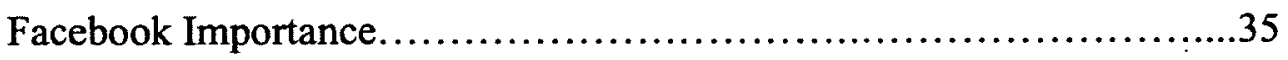

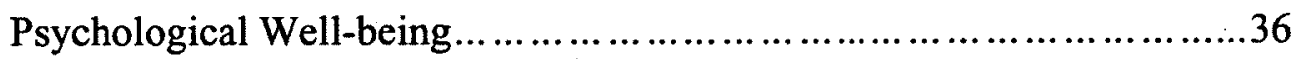

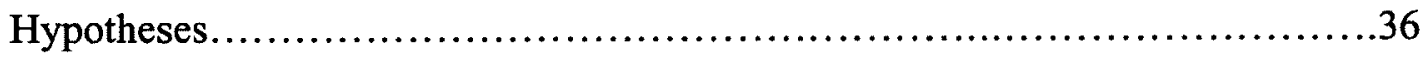

Sub-Hypotheses......................................................

Main Hypotheses..................................................... 38

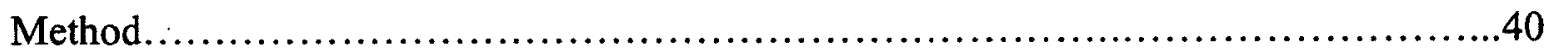

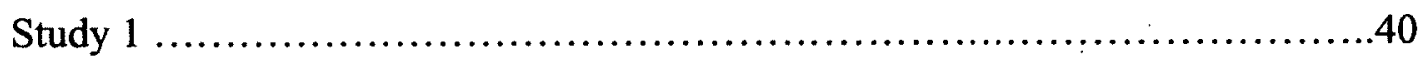

Participants......................................................... 40

Procedure and Design............................................40

Measures......................................................... 41

Background information ............................................41

Facebook...................................................41

Facebook Engagement Questionnaire.......................41

Facebook Importance Questionnaire .........................43

Collective Self-Esteem........................................... 44

Psychological well-being ..........................................44

Depression................................................44 


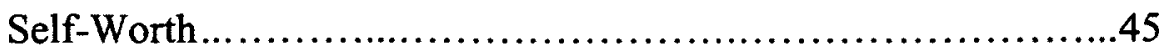

Loneliness...............................................45

Satisfaction with Life Scale ..................................46

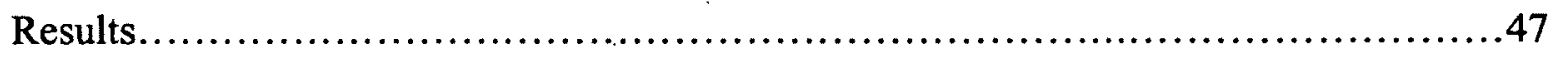

Preliminary Analyses.............................................................

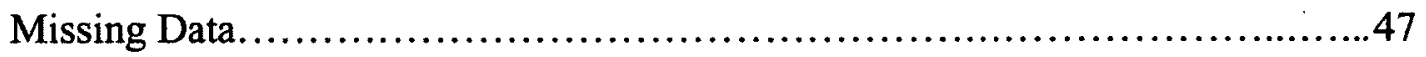

Testing of Assumptions................................................... 48

Potential Control Variables. ..............................................48

Descriptive Statistics..................................................49

Categorization of Socio-Demographic and Facebook Variables.................53

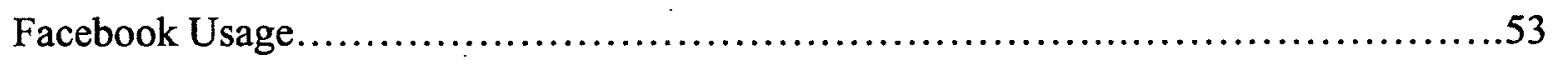

Descriptive Analyses by Age and Gender...................................53

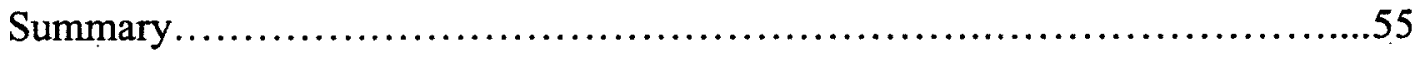

Hierarchical Regression Analyses..............................................56

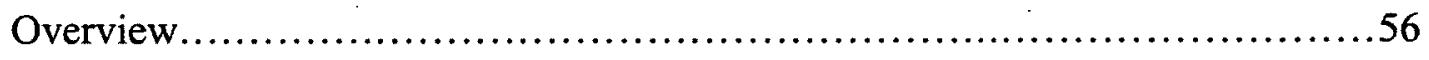

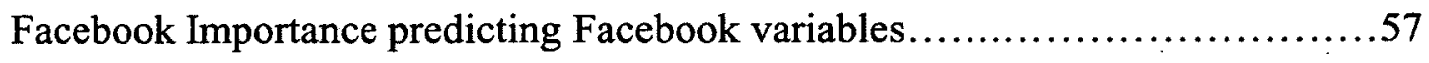

Predicting Facebook hours and Facebook friends............................57

Predicting communication methods......................................57

Collective self-esteem predicting Facebook variables........................57

Collective self-esteem predicting Facebook hours and Facebook friends.........57

Collective self-esteem predicting communication methods......................58

The relationship between Facebook Importance and Facebook Engagement.............58

Collective self-esteem as a moderator ......................................59 
Predicting Facebook Preference (Factor 1) ...............................59

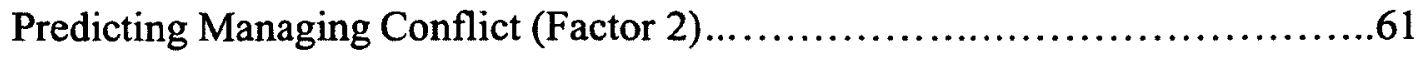

Predicting Monitoring Social Ties (Factor 3) ..............................63

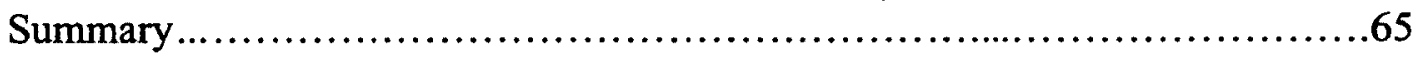

The relationship between Facebook importance, Facebook engagement and indices of psychological well-being. ...........................................67

Predicting depression....................................................68

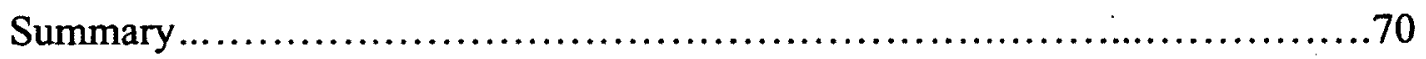

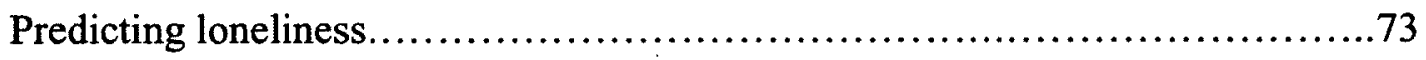

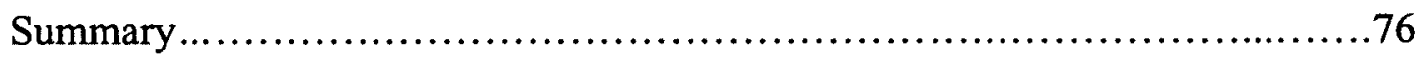

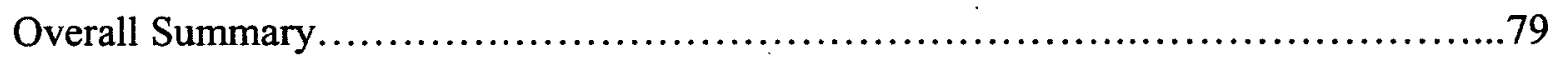

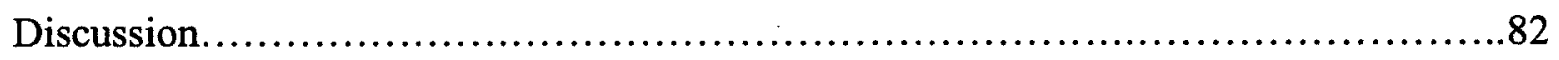

Individual Difference Factors (Age and Gender) $\ldots \ldots \ldots \ldots \ldots \ldots \ldots \ldots \ldots \ldots \ldots \ldots \ldots \ldots$

The relationship between Facebook Importance and Facebook Engagement..............86

Facebook Importance and Facebook preference $\ldots \ldots \ldots \ldots \ldots \ldots \ldots \ldots \ldots \ldots \ldots . \ldots 6$

Facebook Importance and Managing Conflict..............................8 87

Facebook Importance and Monitoring Social Ties............................89

The Relationship between Facebook Importance, Facebook Engagement and

Indices of Psychological Well being ............................................. 90

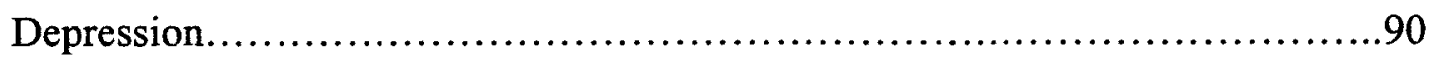

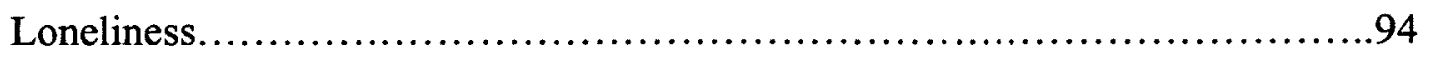

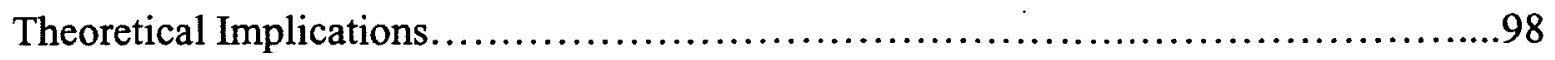

Limitations and Future Research............................................. 101 
FACEBOOK IMPORTANCE, ENGAGEMENT AND WELL-BEING

Conclusion............................................................... 104

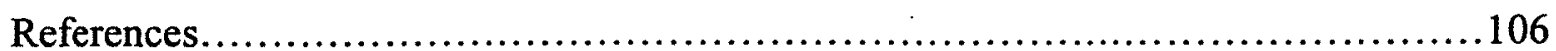

Appendices................................................................. 123

Appendix A. Informed Consent..................................... 123

Appendix B. Debriefing .............................................. 125

Appendix C. Measures..................................................127

Appendix D. Facebook Engagement Questionnaire.......................128

Appendix E. Facebook Importance Questionnaire........................131

Appendix F. Collective self-esteem Scale............................... 133

Appendix G. Centre for Epidemiological Studies Depression Scale............134

Appendix H. The Self-Perception Scale for Adolescents-Self Worth Subscale..136

Appendix I. Revised UCLA Loneliness Scale ..........................................141

Appendix J. Satisfaction With Life Scale.............................. 143 
FACEBOOK IMPORTANCE, ENGAGEMENT AND WELL-BEING

\section{List of Tables}

Table

Description

Page

Descriptive statistics for the independent, dependent and moderating variables for females and males .50

Correlations between Facebook Importance and Facebook

Engagement Factors.

Correlations between Facebook Importance, Facebook

Engagement Factors, Collective self-esteem and the four indices of psychological well-being

Hierarchical Regression Analyses of Facebook Importance on

Facebook Preference (Facebook Engagement Factor 1) and the Moderating Effects of Collective self-esteem (controlling for

Facebook variables)

Hierarchical Regression Analyses of Facebook Importance on Managing Conflict (Facebook Engagement Factor 2) and the Moderating Effects of Collective self-esteem (controlling for

Facebook variables)

6

Hierarchical Regression Analyses of Facebook Importance on Monitoring Social Ties (Facebook Engagement Factor 3) and the Moderating Effects of Collective self-esteem (controlling for Facebook variables) .64

Hierarchical Regression Analyses of Facebook Importance and Facebook Engagement Factors on depression scores and the 
FACEBOOK IMPORTANCE, ENGAGEMENT AND WELL-BEING

Moderating Effects of Collective self-esteem (controlling for

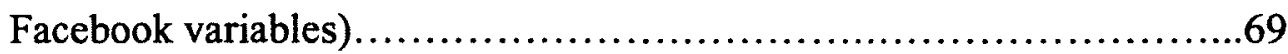

$8 \quad$ Hierarchical Regression Analyses of Facebook Importance and

Facebook Engagement Factors on loneliness and the Moderating

Effects of Collective self-esteem (controlling for Facebook

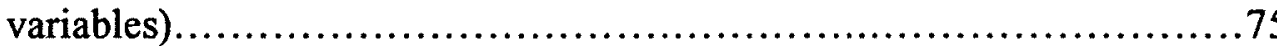


FACEBOOK IMPORTANCE, ENGAGEMENT AND WELL-BEING

\section{List of Figures}

Figure Description

Page

1

The relationship between Facebook Importance and

Monitoring Social Ties on Facebook as a function of

Collective self-esteem........................................66

2. The relationship between Facebook Importance and depression

scores as a function of Collective self-esteem.....................71

3 The relationship between Managing Conflict on Facebook and

depression scores as a function of Collective self-esteem............72

4 The relationship between Facebook Preference and loneliness

scores as a function of Collective self-esteem......................77

5 The relationship between Monitoring Social Ties and loneliness

scores as a function of Collective self-esteem.......................78 


\section{List of Appendices}

Appendix

A

B

C

D

$\mathrm{E}$

F

G

$\mathrm{H}$

I

J
Description

Page

Appendix A. Informed Consent..................................123

Appendix B. Debriefing........................................... 125

Appendix C. Measures.......................................127

Appendix D. Facebook Engagement Questionnaire................128

Appendix E. Facebook Importance Questionnaire..................131

Appendix F. Collective self-esteem Scale.

Appendix G. Centre for Epidemiological Studies Depression Scale...134

Appendix H. The Self-Perception Scale for Adolescents-Self Worth

Subscale.

.136

Appendix I. Revised UCLA Loneliness Scale.

Appendix J. Satisfaction With Life Scale 
How Facebook Gave Me 'Friends': The Impact of Facebook Importance On Engagement and Psychological Well-Being

\section{Statement of the Problem}

Over the course of our lives we will all experience a variety of interpersonal changes; meeting new friends, leaving old friends and now more than ever, collecting and maintaining everyone in between. With the rise of online social networking communities such as Facebook, our definition of friendship has shifted away from traditional face-toface interactions with close friends, to online chatting with hundreds of acquaintances. Long gone are the days of afternoon coffee dates and late movie nights with a few close school friends; friendships have now taken a digital turn and ended up online. Online social networking sites have created a digital platform from which we can collect, establish and maintain friendship ties. The traditional definitions of friendship have been overwhelmingly changed by the structural nature of the medium itself and have subsequently challenged the conventional norms of what we expect from a friendship.

Friendships, particularly in adolescence and young adulthood, are one of those essential, and increasingly beneficial, components of human existence and interpersonal connectivity (Weiss, 1974). In exploring friendship's developmental and interpersonal significance, researchers have become sensitive to the potentially different provisions afforded by friendships. Yet the literature remains quite sparse with regard to friendships in late adolescence, and in the relatively new field of emerging adulthood (Bowker \& Ramsay, 2012). While the importance of friendship remains apparent in emerging adulthood, the qualities and benefits of such maturing relations, and how they are established both in the traditional sense and now more recently, online, is still largely 
unexplored within this developmental period.

The purpose of the current research was to examine how university students used Facebook - its perceived importance, the nature of their online engagement and how this affected their psychological well-being. The transition to university is a particularly challenging time for many young adults both in terms of their adjustment to a new environment as well as their ability to maintain both old and new friendships (Barry \& Madsen, 2009). Specifically, the current research aimed to explore the usage and purposes of online friendship interactions ${ }^{1}$, individual attitudes towards the importance of online networks (i.e. Facebook Importance), and the impact of Facebook use and Engagement behaviours on well-being. Of additional interest to the current study was how perceived social group identity/status, or collective self-esteem, affected the relationship between Facebook Importance, Facebook Engagement and psychological well-being.

For all our research into friendships, we know relatively little about what actually happens within a friendship and how such relationships actually enhance positive adjustment outcomes (Bowker \& Ramsay, 2012). This is particularly true of more predominant and contemporary ideals of friendship, with specific reference to online friendships (Bowker \& Ramsay, 2012). There is, in fact, a growing debate in the literature as to whether or not online friendships should be categorized as 'real friendships' and whether or not they result in the kind of genuine interaction and positive outcomes often attributed to offline friendships. As well, it has been argued that online

\footnotetext{
${ }^{1}$ In the present thesis, interaction refers to the intended exchanges between individuals, which may or may not be reciprocated online.
} 
friendships tend to lack social and emotional cues (Lee \& Boyer, 2007; Mesch \& Talmud, 2006), as well as the physical closeness that comes with interacting in traditional face-toface friendships. Some researchers even believe that it is precisely the lack of traditional social cues that makes social networking sites ideal for forming genuine personal relationships. For example, Suler (1996) suggests that some people even believe that they are more directly encountering the mind, heart, and even soul of another person when they are not being distracted by the physicality of the person. Whether friendships are developed online or offline however, there remains a lack of understanding on how these bonds are formed and what it is that occurs interpersonally within these dyads.

The relatively new field of emerging adulthood gives us an opportunity to consider developmental trends in friendship relationships as individuals move out of adolescence and into emerging adulthood, particularly through the lens of contemporary online networking tools. The extent to which online social networking sites, specifically Facebook, impede or enhance the social well-being of individuals in various aspects of their interpersonal lives, in particular among friendships, has only begun to be studied. An important element to also consider in researching emerging adults, is how highly regarded friendships are within this developmental period (Buote, Pancer, Pratt, Adams, Lefcovitch, \& Polivy, 2007). Richey and Richey (1980), Tokuno (1986), and Weiss (1974), have suggested that friends fulfill a number of key functions in helping emerging adults accommodate to their new environment when they start university. Friends for first year students provide a sense of belonging, give both emotional support and tangible assistance when needed, offer advice and counsel, and serve as role models with regard to appropriate behavior in the campus environment (Buote et al., 2007). New friends are 
also a source of fun and enjoyment, balancing out the many stressors that students experience in adjusting to university life (Pancer, Hunsberger, Pratt, \& Alisat, 2005; Pratt, Danso, Arnold, Norris, \& Filyer, 2001), and as such, it appears to be necessary for individuals to continue to maintain and develop these friendships for their well-being during transitional times.

Given that emerging adulthood is viewed as a time of transition (Buote et al., 2007) (e.g., starting university, beginning new jobs, and moving from one community to another), the present research aimed to explore how pertinent, and arguably, necessary, online mediums, such as Facebook, could be as an important tool in connecting and further developing friendships during this developmental period. The use of Facebook and similar social networking websites is a relatively recent phenomenon, so the growth of Facebook's influence (Hoffman, 2008) on how users experience and maintain friendships online has not been explored yet in great detail in the literature (Hoffman, 2008).

In the sections that follow, I will review literature on a) contemporary communications b) friendships; c) the emergence of Facebook and characteristics of online friendships; d) proposed linked between Facebook Importance and reasons for engaging in social networking and (proposed main effects) e) literature on collective selfesteem and social networking (potential moderating variable) of interest to the current study.

\section{Contemporary Communication and Emerging Adults}

Technology does indeed create new social norms. It has transformed the way people think of the global community and as such, the world is both smaller and larger. 
for young adults today (Vitak, 2008). The world is smaller because of rapid transportation, telecommunications, the emergence of an international culture, and not least, the Internet (Vitak, 2008). The world is larger in the sense that many more young adults grow up thinking in broader, international terms; in ways that their parents, a generation ago, did not (Vitak, 2008). The opportunity to reach out and connect with friends and family on a global scale is something that online networking sites have afforded for recent generations. In addition, online social networking sites offer a dynamic way for a young adult to play with his or her budding personality and social identity, as well as a chance to continue to expand their growing connectedness with others (Vitak, 2008). This new digital paradigm not only shapes the way in which people communicate, but also how they use language and create digital norms (Mitrano, 2006). Social networks intersect with all that is edgy about innovative networking technologies and have created a systemic shift in the way perceptions, language, and interpersonal culture is created and understood (Mitrano, 2006). Facebook, albeit arguably not a permanent fixture in technological advancements, is what is happening right now in the way of young adults, in colleges and universities, and it is setting the current standard of communication for both personal and professional use; most notably among the younger generations (Mitrano, 2006).

With Facebook becoming an increasingly mainstream staple in a digitally based society, greater value has been placed on encouraging and fostering technologies, online communities and social structures that better serve the growing digital globalization of interpersonal growth (Mitrano, 2006). In many cases, online participation in social media and within digital communities has become a necessity to remain connected and be 
successful in all aspects of our lives (Mitrano, 2006).

Increasing participation in online friendships however, has seen a vast increase and desire for virtual spaces where communication is easily accessible and quickly attainable, prompting the belief that this movement to online spaces for interaction improves the human limitations of the real world (Bingham, Holloway, \& Valentine, 1999). McKenna, Green and Gleason (2002) proposed that the Internet has become a leading venue for social interaction, where aspects of our daily lives are shared and relationships forged, replacing the need for traditional face-to-face venues; arguably, in particular for emerging adults caught within transitional periods developmentally, academically and socially. Clearly, increasing online maintenance of friendships and social contacts have certainly become important concerns with possible uncertain implications for emerging adults, as their importance has started to shape the nature of these interactions and has become a primary mode of communication for some (Gangadharbatla, 2008).

Emerging adults. An area of development that is of particular interest to the current study in looking at online friendships is emerging adulthood. Changes over the past half century with respect to greater rates of education and delayed onset of marriage (Arnett, 2000) have altered the nature of development in the late teens and early twenties for young people in industrialized societies, and as such it is no longer normative for the late teens and early twenties to be a time of entering and settling into long-term adult roles (Arnett, 2000). On the contrary, these years are more typically a period of frequent change and exploration (Arnett, 1998; Rindfuss, 1991) and offer a unique opportunity to look at the nature of friendships during this time of interpersonal discovery. In addition, 
the majority of university students fall within this developmental period and represent some of these individuals who are currently going through a transitional phase both socially, academically and interpersonally (Arnett, 2000); creating a rich source for examining friendships.

Largely, emerging adulthood typically requires a minimum of two years to complete but can last anywhere up to eight years or more (Kenniston, 1970). This period can be described as the time between adolescence and adulthood, but does not fall neatly into either category. Defined as "youth" in previous sociological research by Kenniston (1970), Arnett (2000) recently identified this transitional phase as "emerging adulthood" to better identify this group of individuals. More clearly defined, emerging adulthood is said to take place between the ages of approximately 18 to 25 and is typically characterized by greater independence from parents and the exploration of more challenging life choices concerning education, work, and interpersonal relationships (Arnett, 2000). Regardless of how this transitional phase between adolescence and adulthood is defined or the experiences that each individual has during this time, most theorists could agree that for young people, this is a period of experimentation and personal growth, characterized by many important milestones, changes in academic profiles, and often more importantly, changing dynamics between friends particularly in the transition from high school to post-secondary.

Benefits and drawbacks of social networking sites. Social networking sites may be one way to help emerging adults remain connected with friends, as it tends to facilitate mixed-mode relationships where, through an initial meeting offline, individuals continue to interact socially with the same people both offline and online (Tong, Van Der 
Heide, \& Langwell, 2008). In the case of social networking sites, we may see many relationships vacillating between the virtual and physical world quite frequently (Donath \& Boyd, 2004). As a result, Donath and Boyd (2004) argue that online social networking sites can help individuals to maintain a larger number of close ties than people can typically maintain without such technology, such as groups of friends from different environments. Instead of simply connecting with those in close physical proximity to themselves, today's emerging adults now can easily connect with their circle of friends from various social/geographic environments in a way that previous generations could not. In addition, social networking sites are proving to be a unique way for incoming first year students to initially create contact and a basis for friendship within their new environment (Mauk, 2011). In the case of individuals transitioning from one social environment to another, for example moving from high school to university, online communities may foster different features and play different roles in emerging adults' lives, as compared to the mostly face-to-face friendships that they had in high school (Mauk, 2011). It is through this innovative network of connectivity that individuals in transition can not only keep in touch with their old group of friends, but also rapidly and effectively create a social network of individuals within their new environment (Mauk, 2011), and in this way, the capabilities of these networks becomes an important benefit to their use. Arguably then, this ease in the social maintenance of new and close friends could be considered a crucial bridging platform for individuals during transitional phases of life; a clear way to stay in with the old and close to the new.

With each of these unprecedented and often multi-modal online relationships contributing to the total number of friends however, the size of one's apparent friend 
network on a system such as Facebook, can easily become much larger than in offline settings, and it remains unclear as to how these online relations replicate friendship characteristics and interactions found within traditional offline affiliations. Yet, research has suggested that it is the medium which is impacting the perceived nature of these relations (Tong et al., 2008), creating a biased and digitally mastered belief in the importance of its use and how it can make friendships come into existence.

Nevertheless, social networking sites, such as Facebook, make it seem as though online friendships may be easier to maintain than offline ones; yet, monitoring friendships online may lead to more superficial, asynchronous relationships, whereby you can follow your friend's life, without ever having to interact with him/her offline. Seligman (2011) suggests that some drawbacks of social networking sites like Facebook bring out the natural human inclinations toward voyeurism and narcissism. The site's public quality, such as the ability to see friends' photos, posts, and activities exploits voyeurism, such that many teens spend hours "Facebook stalking" (Seligman, 2011); recognizing in turn that all of their friends can see what they are doing and therefore are feeding their sense of narcissism. The expression of this narcissism is often subtle. Seligman (2011) found that many adolescents and emerging adults agree that they would not change the essential content of what they say, but rather change the way they said it. They agreed that they often posted links or started conversations for the recognition they would get as a result, rather than creating meaningful and substantial interpersonal connections (Seligman, 2011). Nevertheless, the allure of these frivolous qualities in addition to the site's communication value keeps us logged on with friends, peers and family online. 
The importance of social networking sites. More recently there has been an increasing interest in studying the use and effects of Facebook. Numerous empirical studies have been conducted to examine patterns of university students' use of Facebook. These focused on a variety of academic interests including Facebook usage profile and also time spent on Facebook (Ellison, Steinfield, \& Lampe, 2007; Pempek, Yermolayeva, \& Calvert, 2009; Vasalou, Joinson, \& Courvoisier, 2010), purposes of Facebook usage (Ellison et al., 2007; Vasalou et al., 2010), effects of Facebook use on college adjustment (DeAndrea, Ellison, LaRose, Steinfield, \& Fiore, 2011) and also self-esteem, social and emotional adjustment (Kalpidou, Costin, Morris, 2011), and the effects of Facebook use on sociability and social capital (Ellison et al., 2007; Keenan \& Shiri, 2009). Despite the numerous studies examining social networking sites, there is little information on how important Facebook might be for maintaining online friendships.

Facebook Importance, for the purposes of this study, was defined as the degree to which people felt attached to Facebook and their attitude towards the sense of importance they attribute to this form of media and its subsequent capabilities with respect to maintaining friendships online. Little is known about attitudes towards the importance of social networking sites, but researchers exploring the importance of other types of media, such as television and the Internet, have shown that it can generally affect the amount of media use, the kinds of social interaction, and perceptions of media choice (Rubin, 1981; Rubin \& Rubin, 1992). In a study of Internet use, affinity, or belief in the importance of the Internet was positively related to using the Internet for interpersonal-related motives (Papacharissi \& Rubin, 2002). Scholars who have conducted research on attitudes toward computers, in general, have found that these attitudes are related to various 
computer-related outcomes. For example, in a study by Sensales and Greenfield (1995) regarding attitudes about computers and technology, they found that people make negative attributions to computers concerning individual-psychological and socialpsychological matters. Shamp (1991) found that people tended to "transpose" their attitudes about computers onto persons with whom they communicated via computer; in other words, the perceptions that respondents had about computers were similar to the perceptions that they had about the kinds of interactions they had with others online. Therefore, it can be reasoned that perhaps the orientation towards Facebook, a contemporary Internet medium, may elicit similar consistencies; that is, that people's orientations towards using Facebook will be positively related to perceptions and attitudes concerning the importance Facebook plays in maintaining friendships among emerging adults.

In addition, research has shown that the reasons for using Internet mediums increase when usage levels and familiarity with the technology itself increases (Gangadharbatla, 2008). That is, usage and adoption of web technologies; such as social networking sites like Facebook, depends on a user's "confidence in their ability to successfully understand, navigate, and evaluate content online" (Daugherty, Eastin, \& Gangadharbatla 2005, p. 71). With this in mind, the greater the ease with which a person can perform those tasks online, the greater should be his or her ability and willingness to join and participate in user-generated content sites (Gangadharbatla, 2008). In addition, research has also shown that as beliefs regarding the purpose of these mediums increases, the attitudes toward the importance of those beliefs also should increase (Ajzen \& Sexton 1999), which suggests that persons with higher levels of importance beliefs in the 
purpose of these mediums should have more favourable attitudes toward them (Gangadharbatla, 2008). The area of research examining Facebook and friendships within emerging adulthood is quite limited but the aforementioned research suggests that this idea of the importance placed on the medium itself can have a direct impact on usage and the kinds of interactions that occur among users. With this in mind, the current study hoped to gain greater insight into how the belief regarding the importance of Facebook would shape the online content and types of interactions among friends.

\section{Friendship}

Defining friendship. Prior to attempting to define friendship, it is necessary to note that in general, developmental theorists have argued that maintaining relationships constitutes an essential human need; being cared for and actively belonging to a social group enhances the likelihood of survival and differs significantly from one person to the next (Voss, Markiewicz, \& Doyle, 1999). Arriving at a definition for this heavily weighted developmental and social construct however, is difficult. The lack of consensus among researchers is a result of several characteristics of the friendship relationship (Osborn, 2000). With the idea that friendship is a voluntary dyad rather than defined by external social structures, the burden of defining the characteristics of friendship rests primarily with the members in each friendship (Auhagen, 1996; Bowker \& Ramsay, 2012). Nevertheless, several characteristics have been consistent across studies and form a universal understanding of friendship. Auhagen (1996) categorizes the characteristic features of a friendship to be mutual, voluntary, charged with positive emotion, and valued by the friends. This set of definitive guidelines provides an outlined framework for friendship composed of elements that can be easily measured and observed. Other 
scholars however, have been reluctant to form specific definitions of friendship and rather have chosen to examine essential elements of the relationship. Davis and Todd (1985) sought to examine close friendships and concluded that there are nine essential elements; equal eligibilities (members as being both equal in the friendship), enjoyment, trust, mutual assistance, acceptance, respect, spontaneity, understanding and intimacy.

There is a general consensus in the literature however, that friendships can be defined as close dyadic reciprocal relationships, with a shared history, a sense of commitment and a general enjoyment of each others company (Bowker \& Ramsay, 2012). Adolescent friendships are one of the central social relationships of this developmental period, perhaps the most important relationship to study during adolescence (Arnett, 2000; Bowker \& Ramsay, 2012). According to Sullivan (1953), the friendships which develop during early adolescence provide opportunities for interpersonal intimacy, a validation of one's own self-worth as well as a context for the acquisition of social and relationship skills such as increased sensitivity to another's needs and desires. All of the aforementioned characteristics and benefits of friendship have largely been based on research on traditional offline friendships, but what is not as widely researched is whether online friendships provide these same opportunities to produce similar quality outcomes as offline friendship.

Online friendships. It has become quite evident that young adults are continuously looking to improve the methods by which they communicate, share knowledge, and most importantly, manage their ever-expanding social groups (Subrahmanyam, Reich, Waechter \& Espinoza, 2008; Gangadharbatla, 2008); particularly between their existing and newly formed friendship groups. Although the 
existence of friendships that are sustained primarily online is well supported, little consensus has emerged regarding the nature of these friendships and how they compare to offline friendships. Research has shown that online friendships and offline friendships are not rated as significantly different with respect to factors such as depth and personalized communication, but rather are rated as significantly different with respect to understanding, commitment, and interdependence (Parks \& Floyd, 1996; Parks \& Roberts, 1998). In addition, Walther $(1993,1996)$ offers a similar perspective, which suggests that online friendships can reach levels of development similar to their offline counterparts when adequate time is offered for their development. This implies that with adequate time and in-depth interactions online, such relationships may be quite similar to traditional offline friendships, and contribute similarly to positive outcomes.

With the rise of the Internet and computer mediated communication, recent research has looked at the impact of online social ties. Activities that connect individuals directly to one another on a digital level (e.g. email, online chat) tend to have positive correlations with social ties, while those activities that are more solitary in nature, such as web surfing, tend to be more negatively associated with strong social ties (Zhao, Grasmuck, \& Martin, 2008). As mentioned, it has been suggested that online friendships lack the verbal and non-verbal cues that accompany non-digital interactions, leading to potentially less in-depth interactions (Zhao et al., 2008). Yet, Walther and D'Addario (2001) argue however, that individuals adapt their behaviour to cues present within online interaction, including content and language strategies.

Further research within this area found that individuals communicating solely through online social networks can, and will, form intimate friendships comparable to 
friendships formed through traditional methods of communication (Tidwell \& Walther, 2002); despite the growing argument that relations established online are often not suitably categorized as "real" friendships. Furthermore, research has also shown that a physical link is not necessary to form a strong and lasting relationship (Rheingold, 1993; Wellman \& Gulia, 1999). Therefore, online friendships could be considered similar to offline friendships, as users have now learned to adapt and accommodate for digital shortcomings by modifying and accepting a new wave of social interaction.

Experiencing this digitalized shift in social interaction has propelled friendships and peer groups into a stage of constant re-evaluation. Much of the early research on online communities assumed that individuals using these systems would be connecting with others outside their pre-existing social group, permitting them to form communities around shared interests, as opposed to shared physical geography (Wellman, Salaff, Dimitrova, Garton, Gulia, \& Haythornthwaite, 1996). A hallmark of this early research is the presumption that when online and offline social networks overlapped, the eventual directionality was from online interaction to offline meeting; or rather online connections resulted in face-to-face meetings (Wellman et al., 1996). Now, however, among the new generation of emerging adults, the online medium by which friendships are established and maintained presents itself as a vehicle that fosters both friendship convenience and perceived relational success and quality in and of itself.

Some literature suggests however, that the idea of online friendships comes with a price; that it remains a constant quantity versus quality debate. In offline settings, there seems to be no negative implications associated with the number of friendships one has; the greater the number of friends, the higher ratings of positive characteristics attached 
(e.g. you must be a kind, trustworthy, likable person) (Way \& Greene, 2006). However, in the digital social networking realm, beyond a certain point, negative judgments begin to take shape regarding the excessive amount of online friendships (Tong et al., 2008). An individual with a high number of online friendships (e.g. typically more than 100) tends to be viewed as a user that, according to Donath and Boyd (2004), spends time superficially "friending" (Donath \& Boyd, 2004) other users beyond a plausible extent; thereby establishing the idea that the profile user is spending an inordinate amount of time towards friend collecting rather than obtaining or maintaining quality relationships (Tong et al., 2008). As always, the challenge remains in understanding how these online relations present themselves, what these online interactions look like, and whether they are capable of truly replicating the kinds of qualities that offline friendships provide for individuals.

In summary, some researchers (Parks \& Floyd, 1996; Parks \& Roberts, 1998; Walther, 1993, 1996; Tidwell \& Walther, 2002) have suggested that online friendships, if given adequate time and interaction, are quite similar to the quality of offline friendships, and do not significantly differ in terms of interaction and positive interpersonal outcomes, while other researchers (Tong et al., 2008; Donath \& Boyd, 2004) suggest that online friendships lack the necessary cues, physical proximity and closeness that accompany positive outcomes.

Given this discrepancy among researchers on the benefits and potential limitations of online friendships, it is important to gain further information on what it is that is occurring online within these dyads and how factors related to friendships may play a role in turning to online methods for interaction. For instance, it's important to delve 
deeper into what emerging adult's online engagement looks like. Does it include increased time spent online, varying methods of communication (i.e. public wall posting or private messaging), managing conflict online, sharing positive information about their lives, or is it used to merely passively look into the lives and daily events of our weak ties. Furthermore, the current study aimed to explore how emerging adults are beginning to value the importance of this new medium and its subsequent impact on the amount of time spent online interacting with friends, and how this has shaped the way they perceive their friendships. Finally, to better understand the maintenance of contemporary friendships between emerging adults, the current study focused solely on interactions among friends online to separate out these unique interactions from online romantic relations, as well as to capture outcomes and characteristics apart from well-documented offline friendship interactions.

Friendships in first year university. Given the many transitions that emerging adults face, it is not surprising that their friendships change as well. Transformations in friendships and friendship networks often relate to life stage rather than age (Barry \& Madsen, 2009). Emerging adulthood is a ubiquitous time of considerable development at both the social and interpersonal level (Arnett, 2000). The choices and decisions made by adolescents during these transitional years are often related to their immediate desires, gratifications and general peer acceptance (Arnett, 2000). University in particular, is a time of interpersonal change, both in terms of remaining connected to close friendships and in establishing new social groups, and can be quite overwhelming for many students as they attempt to navigate their search for their self-identity, and in understanding the role that their relationships play in this life task (Arnett, 2000). According to Arnett 
(2000), emerging adults are highly self-focused, and therefore, it is not surprising that they struggle with determining the criteria that reflect a real commitment to others. For many, emerging adulthood remains a time of interpersonal reflection and reconsideration, and Arnett (2000) believes that emerging adulthood allows more stable close interpersonal relationships with individuals outside of the family unit to be established. Therefore, friendships can fill a critical role as emerging adults separate from their families and move towards establishing themselves independently.

Relatively few studies have focused on friendship development in a university student population, however two studies indicate that friendships undergo significant changes during this period. Hays $(1984,1985)$ found that approximately $60 \%$ of the friendships that were just budding at the beginning of university students' first semester became defined as close friendships by the end of the semester. While this research speaks to offline friendships, research is limited with respect to discovering changes in relational patterns online in a first year population.

In addition, few studies have highlighted the importance of a balance in maintaining both new and old groups of friends and how Facebook could act as an important mechanism from which individuals can maintain their friendships and positive interpersonal outcomes. Pratt et al. (2001) established a program that focused on the development of friendships and social support during the first year of university. Students participating in the intervention met weekly in small groups for the first nine weeks of their first year of university to discuss things such as how to make new friends at university and how to balance their "old" and "new" friendships (Pratt et al., 2001). An evaluation of the program indicated that those involved in the program had higher 
levels of social support and adjusted significantly better to university, as compared to individuals randomly assigned to a control group (Pratt et al., 2001). Such interventions may be particularly beneficial and useful when considering how contemporary methods of interacting may further these results and aid in bridging the gap between old and new social environments during times of transition, and aid in enabling a stronger sense of connectedness and social membership.

While the majority of the aforementioned research speaks specifically to offline friendships, research is quite limited in terms of mapping out changes in relational patterns for emerging adults in the first year of university. Furthermore, there is little to no research which examines what it is that makes certain relations in university closer than others, and how emerging adults utilize these friendships in terms of sharing, communicating and forming a social group.

Friendships and well-being. Several researchers, such as Sullivan (1953) have argued that friendships during early adolescence play an important, if not essential, role in the development of several aspects of competence and well-being (Gross, Juvonen, \& Gable, 2002). In particular, early friendships provide experiences that cannot be found in relations with parents. Specifically, whereas parent-child relationships are defined by a hierarchy of social "unequals," early friendships consist of interactions among "equals" (Gross et al., 2002). As a consequence, friendships give adolescents important opportunities to experience acceptance, validation, and closeness, and it can be argued that these friendships make a profound contribution to a young adult's early sense of well-being (Gross et al., 2002).

Moving into early adulthood, research has found that feeling close and connected 
to others outside of the family unit on a daily basis is associated with higher daily wellbeing, and in particular, feeling understood and appreciated and sharing pleasant interactions are especially strong predictors of well-being (Reis, Sheldon, Gable, Roscoe, \& Ryan, 2000; Gross et al., 2002). As outlined by Reis and Shaver (1988), intimacy is developed and sustained through social exchanges with responsive others (e.g., pleasant interactions and feeling understood). Intimacy emerges as an expectation for friendships in early adolescence (Buhrmester \& Furman, 1987; Sullivan, 1953), and the expectations and meanings of friendships remain constant throughout adolescence and adulthood. Therefore, intimate and meaningful interactions with friends are likely to be at least as important to adolescent well-being as they are to adult well-being (Gross et al., 2002). Friendship constitutes an important aspect in many people's lives and is considered an essential correlate of happiness and general well-being, in particular for early adults (Argyle, 2001; Peterson, 2006). Recent research suggests that even though one might have several close friends (Bliesner \& Adams, 1992), it is the quality of these close friendships that uniquely contributes to one's happiness and individuals are happier when they experience high quality friendships (Demir, Ozdemir, \& Weitekamp, 2007). Feelings of self-worth are not only the result of interactions with others, but also provide a filter through which an individual views and responds to the behaviors of others (Berndt \& Keefe, 1995). While this suggests that friendships contribute to positive selfperception, it is equally reasonable to assume that an individual's feelings of self-worth affect the capacity to establish positive relationships with others (Berndt \& Keefe, 1995; Bohrnstedt, \& Felson, 1983). This may be especially true during emerging adulthood: In the period of late adolescence and early emerging adulthood, social group and friends 
become increasingly important (Mauk, 2011). Having a friend is a significant social achievement for adolescents and an indicator of social competence (Buote et al., 2007). The multiple functions that friends fulfill, and their provisions of support and well-being, suggests that having strong friendships during periods of transition certainly helps individuals cope and provides a sense of social support and perceived positive feelings of worth (Buote et al., 2007; Kenny, 1987). An emerging adult who develops a positive sense of self-evaluation may be more able than an emerging adult with feelings of low self-worth to form such friendships and may be more prepared to disclose thoughts and feelings (Buote, et al., 2007; Kenny, 1987). In other words, feelings of self-worth may facilitate the development of satisfactory and quality friendships.

In summary, research has shown that solid friendships foster and create increased feelings of happiness, self-worth, and help emerging adults cope during transitional periods (Buote, et al., 2007; Kenny, 1987; Berndt, 1982; Bohrnstedt \& Felson, 1983; Demir et al., 2007). It is this sense of support and worth within the friendships that help to develop and establish positive qualities within established friendships. These research findings are based primarily on friendships within traditional face-to-face contexts, and demonstrate the benefits of being in close, high quality friendships. With the recent move to online interpersonal interactions however, it is necessary to examine how friendships maintained predominantly online could potentially result in similar outcomes for emerging adults, and how online interactions and what aspects of online communities benefit or impede interpersonal success and overall well-being. 


\section{The Emergence of Facebook and Online Friendships}

In just six years, social networking has gone from an insignificant curiosity to becoming the primary mode of electronic communication for many (Sheldon, 2008). As the fastest growing social network all over the world, Facebook encourages users to embrace the ubiquitous social networking world (Sheldon, 2008). Millions of users are logging on to reconnect with college friends, tap into alternative communities and forge new relationships (Sheldon, 2008). Beginning in 2004 as a social network site only for Harvard students, it quickly encompassed users at over 2,000 other university and college campuses in the United States (Lampe, Ellison, \& Steinfield, 2007). Initially Facebook was designed with only college students in mind (Freiert, 2007); however in 2005 high schools were added to the Facebook community in order to reach a wider range of users (Lampe et al., 2007). In the following year, almost 22,000 commercial organizations had a presence online (Freiert, 2007). It was the third most popular site on the web in August 2007 with over 22 million unique visitors and over 15 billion pages viewed (Freiert, 2007). Now, with over 800 million users, Facebook is now used by 1 in every 13 people on earth, with over 250 million of them (over 50\%) who log in every day (Facebook.com, 2012). The average user has about 130 friends, but this number will continue to expand past 2011 (Facebook.com, 2012).

At the most basic level, online social networking sites are Internet centers which collectively foster interactive and personal connections between multiple users (Sheldon, 2008). Social networks represent one of three main types of online communities (aside from chat systems, such as instant messaging, and blogs) (Coley, 2006). The main purpose of social networks is to aid.in the forging of new friendships or to maintain those 
relations that already exist (Coley, 2006; Sheldon, 2008). Social networking sites typically provide users with a host of interactive tools such as a profile space, capability for facilitating uploaded content (such as music and photos), messaging in various forms and the ability to make connections to other people through similar interests and shared friendships (Joinson, 2008). These rapid online connections are the foundational structure of a social network site; although most social networking sites provide opportunities for new communication, the construction of interest groups, and entertaining components structural compliments to further engagement (Joinson, 2008).

Facebook usage and friendships. While individuals may use Facebook for different reasons, Lampe et al. (2007) suggest, through empirical evidence, that Facebook is mostly used to maintain or reinforce existing offline relationships, as opposed to establishing new ones online. Characteristically, there is usually some common offline activity among individuals who 'friend' one another, such as a shared class or extracurricular activity (Lampe, et al., 2007). Boyd (2008) asserts that Facebook enables young adults in the United States to socialize with friends even when unable to do so in offline situations; resulting in relying on online interaction as opposed to face-to-face connections to socialize among peers. Another potential 'perk' for social networking site users is the ability to create an illusion of popularity through the sheer volume of "friends" one has accumulated on their profile.

In one study of Facebook users' messaging habits, researchers found that being a friend on Facebook should be considered a necessary, but not a sufficient, requirement for being a friend offline (Golder, Wilkinson, \& Huberman, 2006). These findings suggest that, for some individuals at least, the quantity of connections one has ranks 
higher than the quality of those relations. Because Facebook now allows for relationships to take place in a virtual world, individuals looking for this form of gratification from a social networking site need merely alter their profile accordingly in order to accrue more "friends".

Online social networking site researchers have drawn a distinction between the use of Facebook for a) 'social searching', finding out information about offline contacts and b) 'social browsing', the use of online networking sites to foster new connections, sometimes with the aim of connecting offline afterwards (Joinson, 2008). A survey of over 2,000 University students found suggestive evidence that the primary use for Facebook was for 'social searching'; that is, to find out more information about and make connections with people who they have met briefly offline, in class, or current friends (Joinson, 2008).

As noted earlier, on Facebook, the meaning of 'friend' is not always consistent with traditional definitions of friendship (Tong et al., 2008). It can mean several things. First, it often reflects that individuals have some form of acquaintance-relation that is based in offline interactions which will develop more extensively online, however grounded in the offline setting (Tong et al., 2008). Social networking sites can therefore facilitate mixed-mode relationships where, through a foundational basis of friendship offline, individuals interact socially with the same people both offline and online (Tong et al., 2008). In the case of social networking systems therefore we may see many relationships that vacillate between the virtual and physical world quite frequently. Yet, Donath and Boyd (2004) argue that online social networking systems can help individuals to maintain a larger number of close ties than people can typically maintain 
without such technology.

At the same time, a "friend" on Facebook often does not correspond with the same contextual label as it does offline (Tong et al., 2008). "Friending" someone on Facebook, particularly large numbers of people, has been shown to be one of the, if not the, main activities of Facebook, according to Lampe, Ellison, and Steinfield (2006). Although Lampe et al. (2006) found that a large network of weak social ties via Facebook transforms into a generative source of social capital, they also found that almost half of survey respondents had either neutral feelings or felt disconnected from their friends on Facebook, despite continued usage as a means of mediating relationships.

Additionally, Lee and Boyer (2007) report that Facebook can play a role in maintaining long-distance friendships but that university students do not need Facebook to maintain most of their close friendships. In fact, some of the friendships they have on Facebook may be quite superficial in nature, with students reporting having friends that they have encountered only briefly outside of Facebook (Lee \& Boyer, 2007). As such, with each of these basic and unprecedented online relationships contributing to the total number of friends, the size of one's apparent friend network on a system such as Facebook, can easily become much larger, yet, as some researchers argue, less concrete in terms of meaningfulness and quality, than traditional offline networks.

The Facebook experience however, may also assist in maintaining relationships that may otherwise be transient, and it may in fact connect people who would not otherwise communicate (Christofides, Muise, \& Desmarais, 2009). In many instances, online interactions facilitate the development of relationships with those whom you have shared a common connection, but would not likely further pursue offline (Lampe et al., 
2006). In this way, Facebook can be considered a medium to strengthen bonds and enhance opportunity to become connected. In some sense, this very debate on the availability for labeling options (friend, close friend, acquaintance) and whether online friendships produce the same friendship quality outcomes as offline friendships often overshadow some of the larger questions within this field of literature. Perhaps it isn't the directionality of the friendship or the degree of closeness with Facebook friends that is proving to be problematic in understanding friendships for this developmental period, but rather the belief in the importance and necessity of interacting on Facebook, that is shaping online usage and interpersonal content. With the interpersonal flexibility that Facebook affords, a more pertinent question should be why and how is Facebook an important vehicle through which friendships can develop; and how do attitudes towards this contemporary social tool structure online interactions between people, and subsequently, how is this impacting our well-being?

Facebook, friendships and well-being. Although social networking sites have become tremendously popular among young adults, there remains little research that specifically focuses on the psychological consequences of using such sites. This is remarkable because social networking sites lend themselves exceptionally well to the investigation of the social consequences of Internet communication (Valkenburg, Peter, \& Schouten, 2006). After all, group acceptance and interpersonal feedback on the self, both important features of social network sites, are vital predictors of social self-esteem and well-being (Harter, 1999). Therefore, if the Internet has the potential to influence adolescents' social self-esteem and well-being, it is likely to occur via their use of friendship networking sites and the interactions that occur within them (Valkenburg et al., 
2006).

The relationship between psychological well-being and Internet usage is never an afterthought in computer-mediated communication research, but rather a foundational departure point for many studies (Kim, LaRose, \& Peng, 2009). Research on excessive forms of Internet usage has shown that overzealous Internet use has been known to have negative effects on psychological well-being; such as on one's degree of depression and loneliness (Morgan, \& Cotton, 2003). Conversely, opposing camps argue that it is depression and loneliness, which may in fact be predictors of habitual and problematic overexposure and usage of the Internet (Kim et al., 2009). More recently, a longitudinal study argues that the relationship between Internet usage and psychological well-being may in fact be bidirectional (Kim et al., 2009).

Individuals who have a greater propensity and higher preference for online interaction, feel that online communication is relatively less risky and easier than face-toface communication because of its greater anonymity (Kim et al., 2009). That is, they perceive that online communication might be the necessary catalyst for social communication and acceptance in certain circumstances (Morahan-Martin \& Schumacher, 2000). As these individuals devote a continuous amount of time to their online social interactions, many fail to properly regulate their overall usage, which consequently, disengages them from their offline social communities (Morgan \& Cotton, 2003; Morahan-Martin \& Schumacher, 2000). This limits their physical contact with offline community members and leads to potentially lower levels of psychological well-being due to individual isolation (Morahan-Martin \& Schumacher, 2000).

Thus, excessive time spent online may be related to decreased opportunities for 
face-to-face contact with others. Further, this relationship between time spent online and relationship quality may be affected by an individual's current level of well-being. For example, Lampe et al. (2007) found evidence that self-esteem may operate as a moderator of social network site use. That is, young people with lower self-esteem appeared to benefit more from their use of Facebook than those with higher self-esteem.

Despite the plethora of research on Internet use in general, research examining the potential relationship between psychological well-being and interaction with friends online is currently lacking. In a notable exception, Valkenburg et al. (2006) found that the more people used social network sites, the greater the frequency of interaction with friends, which had positive benefits on respondents' self-worth and ultimately their reported satisfaction with life (Steinfield, Ellison, \& Lampe, 2008).

Therefore, there is conflicting evidence, with some researchers (Valkenburg et al., 2006; Steinfield et al., 2008) reporting a positive relationship between Internet use and well-being, while others suggesting that excessive online interactions decrease relationship quality and well-being (Morgan \& Cotton, 2003; Morahan-Martin \& Schumacher, 2000). In the past decade, a number of studies have explored how Internet use might be related to psychological and social well-being, with mixed results (Kraut, Patterson, Lundmark, Kiesler, Mukhopadhyay, \& Scherlis, 1998; Kraut, Kiesler, Boneva, Cummings, Helgeson, \& Crawford, 2002; McKenna \& Bargh, 2000; Nie, 2001; Shaw \& Gant, 2002; Valkenburg \& Peter, 2007). Kraut et al. (1998) found that greater Internet use was associated with various measures of loneliness, depression and stress. They argued that this was due to the fact that weaker ties generated online were displacing stronger offline ties with family and friends, and this was largely impacting the level of 
individual self-confidence (Kraut et al., 1998).

In a follow-up study, Kraut et al. (2002) found that when examined over a longer period of time, Internet use was no longer associated with decreased communication and involvement with family (and the associated measures of loneliness and depression); in fact, the effects were generally positive. In an attempt to reconcile the aforementioned studies, the present study will explore how the content and purposes of interactions online between friends affects psychological well-being; an approach not yet examined in this field of study. While the above studies suggest that it is the amount of time spent online, and the frequency of these online interactions that predicts an individual's psychological well-being, in the current study, the aim was to examine how the belief in the importance of Facebook and Facebook Engagement (e.g. what they are doing online and how they are doing so) with friends on Facebook potentially affected overall psychological wellbeing.

\section{Proposed Main Effects}

The main focus of the current study was to examine the relationship between individuals' attitude towards the importance of Facebook (Facebook Importance) as a predictor and Facebook Engagement as an outcome, and how this varies as a function of collective self-esteem. While it appears that emerging adults use social networking sites to connect with others, it is imperative to consider the importance of the online phenomena of these networks, primarily Facebook, that allow for this constant and ever evolving connection to friends (Subrahmanyam et al., 2008). As such, it was anticipated that the importance of Facebook would positively affect the kinds of engagement activities in which users participate. Gathering feedback from peers and strengthening 
the bonds of friendship are also part of the developmental challenges of emerging adulthood. In fact, some researchers argue that self-disclosure and sharing interpersonal information with friends may promote personal identity and intimacy (Buhrmester \& Furman, 1987). If so, then the types of communication with friends that occur on Facebook may help young adults resolve key developmental issues that may be present during emerging adulthood, including both identity and intimacy development. To the extent that this is true, Facebook use and the belief in the importance of it as a social medium may therefore have a positive effect on friendship development (Subrahmanyam et al., 2008), by increasing users' likelihood of interacting online with their friends.

Additionally, maintaining your perceived feeling of group membership can also be understood on the basis of a fundamental interpersonal relations orientation, which suggests three basic needs underlie people's group-seeking behavior online (Gangadharbatla, 2008): inclusion, which pertains to the need to belong to or include others in a circle of acquaintances; affection, or the need to love or be loved by others; and control, which encompasses the need to exert power over others or give power over the self to others (Schutz, 1966). Joining social networking sites such as Facebook, can meet all three of these needs and can increase the likelihood of particular behaviours online; specifically, people may join user-generated content sites such as Facebook to remain "in the loop" and maintain relationships with friends and others, irrespective of time and physical space (Gangadharbatla, 2008). Therefore, it was anticipated that higher collective self-esteem would positively predict greater Facebook Engagement, as it was expected that a need to maintain or create a greater perceived sense of social status/identity would be the driving force behind the Facebook Engagement. 
Subsequently, the second set of analyses examined Facebook Importance and Facebook Engagement, as predictors, of indices of psychological well-being, as outcomes, with collective self-esteem as a moderator.

\section{Proposed Moderator (Collective self-esteem)}

Collective self-esteem, which is also referred to as social identity in psychology literature, is defined as "that aspect of the individuals' self-concept which derives from their knowledge of their membership in a social group together with the value and emotional significance attached to that membership" (Tajfel, 1981, p. 255; as cited in Crocker \& Luhtanen, 1990). Most collective self-esteem research appears in the area of psychology, including studies that link collective self-esteem to individual general wellbeing, often represented by variables such as life satisfaction, depression, and hopelessness. However, the relationship among collective self-esteem, group membership, and participation in online communities remains under-researched. Luhtanen and Crocker (1992) suggest however, that active members of social groups score higher on the collective self-esteem scale than do less active members. In other words, researchers do not know if people are more likely to join organizations or groups such as social networking sites when they score higher on the collective self-esteem scale. The current study examined collective self-esteem as a potential moderator in the relationship between the attitudes towards the importance of Facebook (i.e. Facebook Importance), Facebook Engagement and indices of psychological well-being.

\section{Summary.}

As demonstrated by a review of the literature, online social networking sites, namely Facebook, have transformed friendships in a digital swoop within western society. 
Although the prevalence of research on online friendships appears to be limited, the number of individuals using Facebook as a medium to continuously change and shape their interpersonal relations is growing every year (Mauk, 2011). Because friendships include a multitude of psychological, individual and sociocultural factors, examining friendships solely within an online context and highlighting the nature of interactions among friends online may serve to expand the literature on the development of contemporary friendships in general, and online, and the subsequent outcomes with respect to psychological well-being.

Research has yielded an abundance of evidence with conflicting patterns of how Facebook is used, for what purposes, and how, if at all, online friendships differ from offline friendships (Parks \& Floyd, 1996; Parks \& Roberts, 1998; Walther, 1993, 1996; Tidwell \& Walther, 2002; Tong et al., 2008; Donath \& Boyd, 2004). This will be the first time that attitudes towards the importance of actively managing these friendships online, or Facebook Importance, and context of online interactions will be examined in the same study. In addition, this study hoped to determine how this impacted psychological well-being, solely within an online context.

\section{The Present Study}

Overview. The current research examined the relationship between Facebook specific variables, such as Facebook usage (i.e. time spent online, number of Facebook friends and communication methods) and Facebook Importance, Facebook Engagement and indices of psychological well-being. The research focused on Facebook Importance (i.e. the belief in the importance that Facebook plays in maintaining friendships online) Facebook Engagement, collective self-esteem and their relationship to psychological 
well-being. Of interest was how Facebook Importance affects how online friendships are being maintained online using Facebook Engagement measures (e.g. number of wall posts) and their online engagement and how this affects the psychological well-being of the participants. Specifically, I plan to explore how Facebook Importance influences current Facebook Engagement trends and how this impacts psychological well-being, varying as a function of collective self-esteem, among first year university students.

\section{Operationalized variables.}

Facebook Engagement. This variable will be operationally defined in three ways including a) Facebook usage; the amount of time and number of Facebook friends, b) Facebook Communication methods; the types of online communication method (i.e. wall postings and private messages) c) Engagement; the kinds of online interactions among friends and how they use Facebook to maintain their friendships. Part B of the Facebook Engagement questionnaire (i.e. Engagement) will be factor analyzed, as part of the study, to determine if there are sub factors that quantify this concept. Facebook Engagement, as defined above, will be measured using scores from the Facebook Engagement Questionnaire, a two-part questionnaire measuring both demographics of online maintenance of friends, or Facebook usage (i.e. total time online, friend count,) and Facebook Engagement.

This measure is based on the results from my honours thesis (Moorman \& Bowker, 2011) and has shown evidence of being an appropriate index for Facebook Engagement (Cronbach's alpha $=.81$; Moorman \& Bowker, 2011). Based on the results of my honours thesis, this measure aims to capture general Facebook usage (i.e. time spent online and number of Facebook friends), and Facebook communication methods 
(i.e. number of wall postings and private messages), and Facebook Engagement (i.e. the kinds of online interactions among friends) rather than solely capturing time spent online as a measure of Facebook usage or engagement. A total score will be calculated for overall time on Facebook, Facebook friend count, types of communication methods and each Facebook Engagement.

Facebook Importance. Facebook Importance will be operationally defined as the degree to which people feel attached to Facebook and their attitude towards the sense of importance they attribute to this form of media and its subsequent capabilities with respect to maintaining friendships online. Facebook Importance, as defined above, will be measured using the Facebook Importance Questionnaire, a 6-point Likert scale designed for the current study to measure participant responses towards the importance of 22 online Facebook activities in maintaining friendships online. A total score will be given by adding up scores for each item, where higher scores indicated greater Facebook Importance.

Psychological well-being. Psychological well-being will be operationally defined and measured using four subscales; the Centre for Epidemiological Studies Depression Scale (CES-D; Radloff, 1977), The Self-Perception Profile for Adolescents (SPPA), developed by Harter (1988), Revised UCLA Loneliness Scale (Hays \& DiMatteo, 1987) and the Satisfaction with Life Scale (SWLS), developed by Diener, Emmons, Larsen, and Griffin (1985). These four measures we chosen to replicate and include some of the previous research done on negative concepts of well-being, such as depression and loneliness, both of which have been linked in the literature with Facebook usage (Gross et al., 2002), and positive evaluations of well-being, with respect to how Facebook usage 
impacts perceived self-worth, and our overall satisfaction with life (Perry, 2010).

\section{Hypotheses.}

Sub-hypotheses. Prior to conducting the main regression analyses, several subhypotheses were tested to examine how the independent variables and moderating variable predict general Facebook usage, specifically the amount of time spent on Facebook, the number of Facebook friends, and differences in communication methods (i.e., public communication vs. private communication).

Hypothesis 1. It was hypothesized that Facebook Importance would predict greater Facebook usage (i.e. the amount of time per day spent on Facebook, as well as the number of Facebook friends). This was expected due to past research that has suggested that as Internet self-efficacy (i.e., beliefs) increase, then attitudes and behaviours toward the object of those beliefs will also increase (Ajzen \& Sexton 1999). Following this logic, it was therefore expected that the greater the belief in the importance of Facebook (i.e. Facebook Importance), the more likely individuals would spend a greater amount of time online and have an increased number of Facebook friends because of this greater amount of time spent online interacting.

Hypothesis 2. It was also expected that Facebook Importance would predict greater Facebook communication between friends, including the number of wall posts between friends per day, as well as the number of private messages between friends per day. While there is little research on Facebook Importance and methods of communication between online contacts, past research has suggested that, usage and 
adoption of behaviours on social networking sites depends on their "confidence in their ability to successfully understand, navigate, and evaluate content online' (Daugherty et al., 2005, p. 71). As such, the greater the ease with which a person can perform those tasks online, the greater should be an individual's ability to interact and communicate with others. Therefore, the greater the belief in the importance of Facebook, the more it was expected that individuals would participate in greater communication methods on Facebook (i.e. more wall posts and private messages).

Hypothesis 3. It was expected that collective self-esteem scores would predict greater Facebook usage. As research has shown that the level of social belonging and perceived group membership varies among people (Baumeister \& Leary, 1995), their effect emerges in varying levels of attitudes and willingness by different people to join and participate in user-generated content sites (Gangadharbatla, 2008). In other words, there is a greater chance that people will join and participate in social networking sites, or spending a greater amount of time and participate in the sites' behaviours, if they rate high on their perceived group membership. As such, for the current study, it was expected that higher scores on collective self-esteem would be related to spending a greater amount of time on Facebook and subsequently, having a greater number of friends.

Hypothesis 4. It was also hypothesized that collective self-esteem would predict more varied ways of communicating using Facebook. Research has shown that social networking sites offer a space in which people can address this need to be socially 
accepted by using services provided by the sites that enable conversations and information gathering (Gangadharbatla, 2008). In addition, because of the many ways online in which users can communicate (Pempek et al., 2009), there are varied avenues from which individuals can approach sharing information with their online contacts (Pempek et al., 2009). As such, it was expected that the greater the level of collective self-esteem, the more likely individuals would be willing to participate in more varied ways of communicating (i.e. privately (private messaging) and publically (wall postings)).

\section{Main hypotheses.}

Hypothesis 1. It was hypothesized that higher scores on Facebook Importance would predict greater overall Facebook Engagement. This hypothesis supports previous research which has shown that the belief in the importance of Internet mediums was found to be positively related to using these mediums for increased interpersonal-related motives (Papacharissi \& Rubin, 2002), and that joining social networking sites may allow people to remain "in the loop" and maintain relationships with friends and others (Gangadharbatla, 2008). In other words, there is a greater chance that people will join and participate on Facebook if they have a strong need to belong (Gangadharbatla, 2008) and increase their perceived social group status.

Hypothesis 1(a). It was also anticipated that this relationship would be moderated by collective self-esteem, such that higher collective self-esteem would strengthen the relationship between Facebook Importance and Facebook Engagement. This was expected as previous research (Ridings \& Gefen, 2004) has shown that social networks 
support the importance and ease of staying in touch with friends, social support, and friendship (Gangadharbatla, 2008), and as such, arguably; Facebook is a good means for continuing to maintain these friendships. While the research is limited in this area, this finding was also expected due to the fact that those with higher collective self-esteem would want to uphold their perceived group membership (Gangadharbatla, 2008) and as such would want to utilize all avenues to participate in further friendship interactions.

Hypothesis 2. It was hypothesized that both Facebook Importance and Facebook Engagement together as an interaction, would predict less positive scores for depression, loneliness, self-worth, and satisfaction with life.

Hypothesis 2 (a). It was expected that this relationship would be stronger for those lower on collective self-esteem. While there is little to no research to directly support this claim, people who may not feel secure in their social group may frequently participate in user-generated content sites and online communities that reflect this need to belong, as they can have increased usage amount as well as a bigger membership group (Gangadharbatla, 2008). 


\section{Method}

\section{Participants}

Participants for the current study were drawn from a sample of first year students from the Introductory Psychology participant pool at Carleton University. A total of 431 participants (306 females and 125 males) were recruited and received $.5 \%$ course credit for participating. Participants ranged in age from 17 to 45 years $^{1}(M=20.4, S D=1.67)$.

\section{Procedure and Design}

Participants who wished to participate in the study were provided with an html weblink via the SONA recruitment system. The web-link automatically took participants to an online consent form. This consent form (see Appendix A) informed participants that the experiment concerns Facebook use, friendships and psychological well-being. Upon granting consent, participants were asked to complete a battery of self-reporting questionnaires. They first completed a short background questionnaire (see Appendix C), which will include items regarding their student number, age, and gender. Participants then completed a two-part Facebook Engagement Questionnaire (see Appendix D) in order to gather a sense of how much time participants are spending online, how many friends they have, and what Facebook Engagement Methods they are using to interact with and maintain friendships online. Participants also completed the Facebook Importance Questionnaire (see Appendix E), which aimed to capture responses to the level of Facebook Importance attributed to a variety of Facebook activities they use in maintaining their friendships online. Following the Facebook questionnaires, participants completed a measure asking questions regarding collective self-esteem (see Appendix F).

\footnotetext{
' Participants that were older than 25 years of age were left within the sample because while they exceed the typical age range for emerging adults, they were within the normal ranges for Facebook variables, and self-identified as being in first year (i.e. the transitional period looked at within the current study).
} 
Finally, participants completed a battery of self-reporting psychological well-being measures (see Appendix G, H, I, J). Finally, participants were fully debriefed (see Appendix B).

\section{Measures}

Background information. Participants were asked to provide demographic information specifying the following information: age, gender, student number, ethnic background, language and academic profile (see Appendix C).

\section{Facebook. ${ }^{1}$}

Facebook Engagement questionnaire. Part A of this measure aimed to gather basic Facebook usage trends among participants (e.g. how many hours a day they spend, on average, how many friends they have on Facebook, etc.). Part B of the measure asked participants to evaluate their preference for using Facebook as a way to maintain friendships and other methods for engaging with their friends online. To assess whether participants preferred to manage their interpersonal relationships through Facebook or offline, participants were asked to rate the degree to which they agreed/disagreed with the 16 presented Facebook interactions and situations in Part B of the Facebook Engagement Questionnaire (MFF) (Moorman \& Bowker, 2011). Each item was ranked using a 6point Likert scale ranging from 1 (Strongly Disagree) to 6 (Strongly Agree). Higher scores indicated Facebook as the preferred means to maintain friendships (Moorman \& Bowker, 2011) (see Appendix D).

\footnotetext{
${ }^{1}$ There are no previous published measures on Facebook Importance or Engagement, therefore the measures were used from a study conducted in 2010 (Moorman \& Bowker, 2011) and modified to best capture the goals of the current study.
} 
A factor analysis was conducted on both the Facebook Engagement and Facebook Importance scales. The 16 items of the Facebook Engagement scale were subjected to a principal components analysis (PCA): Prior to performing PCA the suitability of data for factor analysis was assessed. Inspection of the correlation matrix revealed the presence of many coefficients of .3 and above. The Kaiser-Meyer-Oklin value was .87 exceeding the recommended value of .6 (Kaiser, 1970, 1974) and the Barlett's Test of Sphericity (Bartlett, 1954) reached statistical significance, supporting the factorability of the correlation matrix. Principal components analysis revealed the presence of four components with eigenvalues exceeding 1, explaining 27.6 per cent, 11.3 per cent, 8.2 per cent, and 6.3 per cent of the variance respectively. An inspection of the scree plot revealed a clear break after the third component. Using Catell's (1966) scree test, it was decided to retain three components for further investigation. This was further supported by the results of parallel analysis, which showed only three components with eigenvalues exceeding the corresponding criterion values for a randomly generated data matrix of the same size. To aid in the interpretation of these three components, a varimax rotation was performed. The rotated solution revealed the presence of three components showing a number of strong loadings and all variables. Subsequently, the results of this analysis support the use of the Facebook Engagement scale with three component factors. Tests of reliability on the factors yielded a three factor model; Facebook Preference (e.g. "Facebook is the easiest way to communicate with my friends"; percentage of total variance accounted for $=31.47 \%$, Cronbach's alpha $=.82$ ); Managing Conflict (e.g. "I have blocked a friend on Facebook when we have been in a fight with each other"; percentage of total variance accounted for $=12.45 \%$, Cronbach's alpha $=.72 ;$ and 
Monitoring Social Ties (e.g. "I have Facebook friends I don't talk to but I still keep them on my friend's list", percentage of total variance accounted for $=9.28 \%$ Cronbach's alpha $=.62)$.

Facebook Importance questionnaire. Participants were asked to evaluate the ways in which they feel Facebook is important (i.e. Facebook Importance) in maintaining certain interpersonal activities online. To assess which online activities participants view as highly important and their attitudes towards these activities, participants were asked to rate the degree to which they agreed/disagreed with the 22 presented interpersonal engagement activities on Facebook using the Facebook Importance Questionnaire (FIQ), designed for the present study (Moorman \& Bowker, 2011). Each item was ranked using a 6-point Likert scale ranging from 1 (Strongly Disagree) to 6 (Strongly Agree). Higher scores indicated greater Facebook Importance (see Appendix E).

The 22-question Facebook Importance scale was also subjected to principal components analysis (PCA). Prior to performing PCA the suitability of data for factor analysis was assessed. Inspection of the correlation matrix revealed the presence of many coefficients of .3 and above. The Kaiser-Meyer-Oklin value was .87 exceeding the recommended value of .6 (Kaiser, 1970, 1974) and the Barlett's Test of Sphericity (Bartlett, 1954) reached statistical significance, supporting the factorability of the correlation matrix. Principal components analysis revealed the presence of only one component with eigenvalues exceeding 1 , explaining 47.6 per cent of the variance. An inspection of the scree plot revealed a clear break after this first component as well. Subsequently, the Facebook Importance scale was examined for its reliability and with a 
Cronbach's alpha of .946 , it was decided to leave the Facebook Importance scale as it was.

Collective self-esteem. The collective self-esteem scale (CSES) is a 16-item, 7point Likert-type measure asking respondents to consider their perceptions and feelings related to social group memberships. The CSES aims to conceptualize four aspects: 1) Membership Esteem: an individual's judgments of how worthy they are as members of their social groups; 2) Private Collective Self Esteem: personal judgments of how good one's social groups are; 3) Public Collective Self Esteem: one's perceptions of how positively other people evaluate one's social groups; and 4) Importance to Identity: the importance of one's social groups memberships to one's self-concept. Luhtanen and Crocker (1992), reported sub-scale alphas in the range of $a=.71$ to $a=.88$ (see Appendix F). The sum of all items were calculated as the participants' overall collective selfesteem.

Psychological well-being. To assess participant overall psychological wellbeing, participants were asked to complete the Centre for Epidemiological Studies Depression Scale (CES-D; Radloff, 1977), The Self-Perception Profile for Adolescents (SPPA), developed by Harter (1988), Revised UCLA Loneliness Scale (Hays \& DiMatteo, 1987) and the Satisfaction with Life Scale (SWLS), developed by Diener, Emmons, Larsen, and Griffin (1985). These measures were chosen to capture some negative concepts of well-being, such as depression and loneliness, both of which have been linked in the literature with Facebook usage, and positive evaluations of well-being with respect to how it impacts perceived self-worth, and our overall satisfaction with life. 
Depression. Participants completed the 20-item Centre for Epidemiological Studies Depression Scale to determine their depression scores (CES-D; Radloff, 1977). This method was used previously by Nelson and McNamara-Barry (2005) to detect depressive symptoms among emerging adults. The CES-D has been shown to be a reliable measure for assessing the number, types, and duration of depressive symptoms across racial, gender, and age categories (Knight, Williams, McGee, \& Olaman, 1997; Radloff, 1977; Roberts, Vernon, \& Rhoades, 1989). High internal consistency has been reported with Cronbach's alpha coefficients ranging from .85 to .90 across studies (Radloff, 1977). Participants were asked to rate how they felt or behaved in accordance to each item. Participants were instructed to rate each item (e.g. "I enjoyed life") on a 4point scale, ranging from 1 (Rarely or none of the time) to 4 (Most or all of the time). The sum of all items were calculated as the participants' overall individual score, such that higher scores indicated higher depression levels in participants (see Appendix G).

Self-worth. The Self-Perception Profile for Adolescents (SPPA), developed by Harter (1988), is a 45-item self-report instrument containing nine subscales, each containing five items. Eight subscales are designed to measure self-perceptions in relation to specific areas of ones life. These subscales include: scholastic competence; athletic competence; social acceptance; physical appearance; job competence; close friendship; romantic appeal; and behavioral conduct. One is designed to measure perception of self in general: global self-worth. For the purposes of this study, the total scoring of the global self-worth subscale was used as a measure of self-worth contributing to overall psychological well-being. Items were structured in a 4-point structured-alternative format to offset socially desirable responding. Harter (1988) reported an internal 
consistency reliability for global self-worth as $a=.85$ (see Appendix $H$ ).

Loneliness. Participants completed the Revised UCLA Loneliness Scale (Hays \& DiMatteo, 1987) as a measure of loneliness. It was developed to assess subjective feelings of loneliness or social isolation and has an alpha reliability of .84 (Hays \& DiMatteo, 19.87). The general format of the self-report consisted of 10 statements regarding self-worth and self-acceptance. Participants were instructed to rate each statement (e.g. "All in all, I am inclined to feel that I am a failure") according to a 4-point scale, ranging from 1 (Often this way) to 4 (Never). Some of the items were reverse coded, such that lower scores indicated higher levels of loneliness in participants. All items will then be aggregated, with higher scores indicating less loneliness. Scoring: Items $1,4,5,6,9,1015,16,19,20$ are reverse coded (see Appendix I).

Satisfaction with life scale. The Satisfaction with Life Scale (SWLS), developed by Diener et al. (1985), is a widely used measure of subjective well-being. The scale contains 5 items and employs a 7-point Likert scale with higher values corresponding to a higher degree of satisfaction. A total score was calculated to represent the level of satisfaction, ranging from 5 to 35 . The internal reliability, test-retest reliability coefficients of the SWLS were generally higher than 0.80 across different reports (Pavot \& Diener, 1993) (see Appendix J). 


\section{Results}

The first goal of the present study was to examine Facebook usage in a university population - how Facebook is used, how important Facebook is perceived to be, student level of engagement, and whether or not there are any age and sex differences in the usage of Facebook. The second goal was to examine the relationship between the perceived importance of Facebook (Facebook Importance) and differential Facebook uses (Facebook Engagement). The third goal this study was to examine the relationship between Facebook Importance, Facebook Engagement Factors and four indices of psychological well-being; and the role of collective self-esteem as a moderator. The data were validated by examining maximum and minimum scores to ensure that each item was scored correctly and within the proper scoring range. Subscale scores and total scores for each scale were also examined to ensure that the data were not skewed by participants' inaccurate responding.

\section{Preliminary Analyses}

Missing data. After ensuring that all data had been entered within an appropriate range for each of the measures of interest to the present study, a missing value analysis (MVA) was conducted. Among the ten variables of interest, the MVA indicated that four of the variables had a missing rate of $1 \%$ or less. One of the Facebook Engagement Factors, Managing Conflict, had a missing rate of $4.3 \%$ and one of the moderating variables, social acceptance had a missing rate of 6.2\%. A Little's MCAR test was performed to further explore the missing data. Results from this test $(p=.539)$ revealed that the data met criteria for missing completely at random. Therefore, cases with 
missing data remained in the dataset and mean substitution was performed where scale item scores were missing.

Testing of assumptions. The assumptions for all multiple regression models were examined. The normality assumption was verified by assessing the distribution of model residuals. For all models, the distribution was not discordant from the normal distribution. The linearity and homoscedasticity assumptions were confirmed by inspecting scatterplots of model residuals versus predicted values. The scatterplots revealed no systemic patterns, suggesting model assumptions were met.

Potential control variables. Prior to testing the hypotheses, socio-demographic (age, academic year and geographic proximity between hometown and university town) and Facebook demographic variables were tested to examine their relatedness to the dependent variables. All variables that had a significant effect on the three Facebook Engagement factors and the four indices of psychological well-being were statistically controlled for in this study. None of the socio-demographic variables were significantly related to the dependent variables so they were not statistically controlled for. A number of Facebook variables however were found to have a significant relationship with the dependent variables and were subsequently controlled for in the main regression analyses.

Time spent on Facebook per day $(p<.01)$ was significantly related to all Facebook Engagement factors: Facebook Preference, $r(398)=.29, p<.001$; Managing Conflict on Facebook, $r(398)=.25, p<.001$ and Monitoring Social Ties on Facebook $r(398)=.14, p<.01$. Time spent on Facebook per day was also positively correlated with depression, $r(431)=.17, p<.001$, and loneliness, $r(431)=.10, p<.05$, although these relationships were quite weak. 
In addition, there was a positive relationship between the number of Facebook friends and Managing Conflict, $r(398)=.30, p<.001$, as well as Monitoring Social Ties, $r(398)=.30, p<.001$. Additionally, number of Facebook friends was also positively correlated with depression, $r(431)=.15, p<.001$. In the main regression analyses, time spent on Facebook per day and the number of Facebook friends were controlled for in models predicting the three factors of Facebook Engagement. Time spent on Facebook per day and the number of Facebook friends were also controlled for in models predicting depression, and loneliness.

Descriptive statistics. Descriptive statistics for all measures of interest in the current study are presented in Table 1. A correlation matrix of bivariate correlations among the variables of interest for the first set of regressions predicting Facebook Engagement are presented in Table 2. An examination of Table 2 indicated that variables of interest were correlated in the expected direction. A correlation matrix of bivariate correlations among the variables of interest for the second set of regressions predicting the four indices of psychological well-being are presented in Table 3. An examination of Table 3 indicated that variables of interest were correlated in the expected direction. However, two indices of psychological well-being, self worth and life satisfaction, were not correlated with any of the independent variables or the moderator, collective selfesteem, therefore no subsequent analyses were run with these dependent variables. 
Table 1

Descriptive Statistics for the Independent, Dependent and Moderating Variables for Females $(n=306)$ and Males $(n=125)$ :

\begin{tabular}{lrccccc}
\hline & \multicolumn{2}{c}{ Females } & Males & \multicolumn{2}{c}{ Females } & \multicolumn{2}{c}{ Males } \\
\hline & $M(S D)$ & $M(S D)$ & Min & Max & Min & Max \\
\hline FB Pref. & $19.67(7.23)$ & $20.09(7.38)$ & 8 & 47 & 8 & 37 \\
Manag Confl. & $11.15(5.08)$ & $9.91(4.28)$ & 4 & 24 & 4 & 20 \\
Mon. Social. & $12.73(3.16)$ & $12.45(3.11)$ & 3 & 18 & 3 & 18 \\
Facebook Imp. & $2.80(.88)$ & $2.90(.97)$ & 1 & 5.50 & 1 & 5 \\
Collective S.E & $54.45(6.60)$ & $54.26(2.80)$ & 16 & 76 & 16 & 76 \\
Depression & $11.23(2.01)$ & $10.88(1.96)$ & 5.25 & 18.25 & 5.25 & 18 \\
Loneliness & $11.13(1.80)$ & $11.16(1.69)$ & 2.25 & 18.50 & 2.25 & 15 \\
Self-Worth & $2.38(.61)$ & $2.39(.61)$ & 1.17 & 3.83 & 1 & 3.50 \\
Satisfaction & $23.89(6.91)$ & $23.38(7.25)$ & 5 & 35 & 5 & 35 \\
& & & & & & \\
\hline
\end{tabular}

Note: The standard deviation is shown in the brackets; FB Pref. =Facebook Preference (Factor 1); Manag Confl. = Managing Conflict $($ Factor 2); Mon. Social. = Monitoring Social Ties (Factor 3); Facebook Imp.=Facebook Importance; Collective S.E.=Collective self-esteem; Satisfaction $=$ Satisfaction with Life 
Table 2

Correlations between Facebook Importance and Facebook Engagement Factors.

FB Imp. FB Pref. Man. Conf. Mon. Soc.

FB Imp. 1

FB Pref. $* * .55$ 1

Man. Conf.

**.31

**.36 1

Mon. Soc.

$* * .43$

$* * .46$

$* * .30$

1

Note: FB Imp.=Facebook Importance FB Pref. =Facebook Preference (Factor 1); Man.

Conf. $=$ Managing Conflict $($ Factor 2); Mon. Soc. $=$ Monitoring Social Ties (Factor 3)

${ }^{* * *} \mathrm{p}>0.001 ;{ }^{* *} \mathrm{p}>.01 ;{ }^{*} \mathrm{p}>.05$ 
Table 3

Correlations between Facebook Importance, Facebook Engagement Factors, Collective self-esteem and the four indices of psychological well-being.

FB Imp. FB Pref. Man.Conf Mon.Soc. CSE CESD LS SW SWL

\begin{tabular}{|c|c|c|c|c|c|c|c|c|c|}
\hline FB Imp. & 1 & & & & & & & & \\
\hline FB Pref. & $* * .55$ & 1 & & & & & & & \\
\hline Man.Conf. & $* * .31$ & $* * .36$ & 1 & & & & & & \\
\hline Mon. Soc. & $* * .43$ & $* * .46$ & $* * .30$ & 1 & & & & & \\
\hline CSE & $* * .38$ & $* * .27$ & $* .10$ & $* * .18$ & 1 & & & & \\
\hline CESD & $* * .19$ & $* * .19$ & $* * .26$ & $* .12$ & $* .15$ & 1 & & & \\
\hline LS & $* .23$ & $* .21$ & $* .15$ & $* .11$ & $* .17$ & $* .15$ & 1 & & \\
\hline SW & -.04 & .02 & .08 & -.09 & .06 & .04 & .07 & 1 & \\
\hline SWL & -.08 & -.04 & -.03 & -.09 & -.03 & .06 & -.03 & $* .20$ & 1 \\
\hline \multirow{2}{*}{\multicolumn{10}{|c|}{$\begin{array}{l}\text { Note: FB Imp.= Facebook Importance; Fac1 = Facebook Preference; Fac2 = Mar } \\
\text { Conflict; Fac3 = Monitoring Social Ties; CSE = Collective self-esteem; CESD= }\end{array}$}} \\
\hline & & & & & & & & & \\
\hline \multicolumn{10}{|c|}{ Depression Scale; LS= UCLA Loneliness Scale; $\mathrm{SW}=$ Self-Worth subscale; $\mathrm{SWL}=$} \\
\hline Satisfaction & with Life & Subscale & & & & & & & \\
\hline
\end{tabular}


Categorization of socio-demographic and Facebook variables. Gender was categorized into two groups ( $1=$ male, and $2=$ female), and age was categorized into four categories with (1) 17-20 (N=204), (2) 21-24 (N=171), (3) 25-30 (N=52), and (4) 31 and older $(N=4)$. Both Facebook usage time and Facebook friends were measured on a continuous scale. However, for the current study, these measures were categorized into smaller groups. Participant responses regarding the number of Facebook friends were grouped into one of three Facebook friend groups based on a frequency analysis: (1) 0199 friends, (2) 200-499 friends, and (3) Greater than 500. In terms of time spent on Facebook, participants were grouped into one of three usage groups: (1) an hour or less, (2) between 1-4 hours and (3) More than 4 hours.

\section{Facebook Usage}

Descriptive analyses by age and gender. A multivariate analysis of variance (MANOVA) was conducted to examine the relationship between age and gender as independent variables, individual difference factors (time spent on Facebook, number of Facebook friends and communication methods (i.e. private messaging vs. wall posts)) Facebook Importance and Facebook Engagement Factors as dependent variables.

Results indicated a significant multivariate main effect for age, Wilks $\lambda=.529, F$ $(11,391)=1.82, \mathrm{p}<.001$, partial eta squared $=.056$, but no multivariate main effects for gender or any significant age by gender interactions. Given the significance of the overall test, the univariate main effects were examined for age. The univariate results indicated significant between-subject effects for time spent on Facebook, $F(16,391)=$ $1.69, \mathrm{p}<.05$, partial eta squared $=.063$, total number of Facebook friends, $F(16,391)=$ $2.88, \mathrm{p}<.001$, partial eta squared $=.103$, Facebook Importance, $F(17,391)=1.86, \mathrm{p}<$. 
01 , partial eta squared $=.073$, and Monitoring Social Ties, $F(17,391)=3.03, \mathrm{p}<.001$, partial eta squared $=.114$. There were no significant univariate effects for Facebook Preference (Factor 1) or Managing Conflict (Factor 2).

Given the results of the multivariate main effects, significant age pairwise differences were obtained for time spent on Facebook, total number of Facebook friends, Facebook Importance, and Monitoring Social Ties. With respect to time spent on Facebook, post-hoc tests (LSD) indicated that the youngest age group (aged 17-20) $(M=3.98)$ reported a significantly greater amount of time spent online as compared to individuals aged $25-30(M=2.66, p=.043)$ and those in the highest age category (aged 31 and older $)(M=2.50, p=.009)$. Participants aged 17-20 and 21-24 did not significantly differ.

With respect to the number of Facebook friends, post-hoc comparisons (LSD) revealed that the youngest participants reported $(M=6.95)$ a greater number of Facebook friends as compared to those age 21-24 (M=5.70), those aged 25-30 (M=4.67), and those aged 31 and older $(M=2.17)$.

With respect to Facebook Importance, post-hoc (LSD) comparisons revealed that participants aged 17-20 $(M=4.09)$ and 21-24 $(M=4.02)$ rated Facebook as being significantly more important as compared to participants aged 25-30 (M=2.41, $p=.032)$ and 31 and older $(M=2.07, p=.028)$. The two younger age categories did not significantly differ from one another.

Finally, with respect to Monitoring Social Ties on Facebook, post-hoc (LSD) comparisons revealed that participants aged 17-20 $(M=23.76)$ and $21-24(M=24.25)$ reported a significantly greater amount of monitoring social ties as compared to 
participants aged 25-30 $(\mathrm{M}=19.54, p=.021)$ and participants that were 31 and older $(\mathrm{M}=18.96, p=.029)$.

A second MANOVA was conducted to examine the relationship between age and gender as independent variables and indices of well-being as dependent variables.

Results indicated a significant multivariate main effect for the age categories Wilks $\lambda=.889, F(18,411)=2.73, p<.001$, partial eta squared $=.039$, and a significant multivariate main effect for gender, Wilks $\lambda=.943, F(12,413)=2.03, p<.001$, partial eta squared $=.049$ but no significant age by gender interactions. Given the significance of the overall test, the univariate main effects were examined for age and gender.

Results indicated a significant univariate main effect of age on depression scores $F(16,391)=2.21, p<.01$, partial eta squared $=.038$, and gender on depression scores, $F$ $(12,411)=2.56, p<.05$, partial eta squared $=.041$.

Significant age category pairwise differences were obtained for depression. Posthoc (LSD) indicated that participants aged 17-20 $(M=11.10)$ reported greater depression scores as compared to participants aged 25-30 $(M=9.50, p=.25)$ and the oldest age category $(M=8.79, p=.29)$. There were no significant differences between participants aged 17-20 and participants aged 21-24.

Significant gender pairwise comparisons were also obtained for depression. Posthoc (LSD) indicated that females $(M=12.41)$ reported significantly greater depression scores as compared to the males $(M=10.10, p=.31)$.

Summary. Results showed a statistically significant main effect for age when considering the individual difference factors (time spent on Facebook and number of Facebook friends) and Facebook Importance and the three Facebook Engagement Factors 
(Facebook Preference, Managing Conflict and Monitoring Social Ties on Facebook). Specifically, and not surprisingly, pairwise comparisons indicated that younger participants, those aged 17-20, reported the most amount of time spent on Facebook and the greatest number of Facebook friends. With respect to Facebook Importance, participants aged 17-20 and 21-24 reported Facebook as being higher in importance as compared to the two older age categories. Finally, with respect to Monitoring Social Ties, participants aged 21-24 reported the greatest amount of time spent Monitoring Social Ties on Facebook as compared to all other groups. There were no significant multivariate main effects for gender or age by gender interactions.

In the second set of MANOVA analyses, results demonstrated a significant multivariate main effect for age and gender. Specifically, pairwise comparisons indicated that younger participants (aged 17-20) reported greater depression scores as compared to participants aged 25-30 and the oldest age category, participants aged 31 and older. There were no significant differences with respect to depression scores between the two younger age categories: Finally, significant gender pairwise comparisons demonstrated that females reported significantly higher depression scores as compared to males. There were no significant age by gender interactions.

\section{Hierarchical Regression Analyses}

Overview. Prior to conducting the main regression analyses, several subhypotheses were tested to examine how the independent variables and moderating variable predict general Facebook usage, specifically the amount of time spent on Facebook, the number of Facebook friends, and differences in communication methods 
(i.e., public communication (wall postings) vs. private communication (private messaging).

\section{Facebook Importance predicting Facebook variables.}

Predicting Facebook hours and Facebook friends. It was expected that Facebook Importance would predict the amount of time per day spent on Facebook, as well as the number of Facebook friends. Consistent with hypotheses, Facebook Importance was a significant predictor $(\beta=.26, p=.001)$ of time spent online, indicating that Facebook Importance was positively associated with the number of hours spent on Facebook per day. Furthermore, as predicted, Facebook Importance was also a significant predictor $(\beta=.15, p=.01)$ of the number of friends online, indicating that Facebook Importance was positively associated with the number of Facebook friends.

Predicting communication methods. It was also expected that Facebook Importance would predict communication methods between friends on Facebook, including the number of wall posts between friends per day, as well as the number of private messages between friends per day. Contrary to predictions, Facebook Importance was not a significant predictor of the number of wall posts between friends online. As predicted however, Facebook Importance was a significant predictor $(\beta=.19, p=.001)$ of the number of private messages between friends on Facebook, indicating that Facebook Importance was positively associated with private messaging friends on Facebook.

\section{Collective self-esteem predicting Facebook variables.}

Collective self-Esteem predicting Facebook hours and Facebook friends. It was expected that collective self-esteem scores would predict the amount of time per day spent on Facebook, as well as the number of Facebook friends. Consistent with 
hypotheses, collective self-esteem was a significant predictor $(\beta=.10, p=.05)$ of time spent online, indicating that individuals whose self-esteem was more closely associated with acceptance by their social group spent more hours on Facebook per day than those with lower collective self-esteem scores. Furthermore, as predicted, collective selfesteem was also a significant predictor $(\beta=.13, p=.01)$ of the number of friends online, indicating that collective self-esteem was positively associated with the number of Facebook friends.

Collective self-esteem predicting communication methods. It was also hypothesized that collective self-esteem would predict communication methods between friends on Facebook, including the number of wall posts between friends per day, as well as the number of private messages between friends per day. Contrary to predictions, collective self-esteem was not a significant predictor for either the number of wall posts between friends online or the number of private messages between friends on Facebook.

The relationship between Facebook Importance and Facebook Engagement.

The goal of these hierarchical regression analyses was to examine the main effect of Facebook Importance on the three Facebook Engagement Factors; Facebook Preference, Managing Conflict, and Monitoring Social Ties. Additionally, collective self-esteem was added to each regression model to test for the presence of moderating effects.

To avoid multicollinearity and ease in interpreting potential moderating effects, collective-self-esteem was standardized prior to analyses. For each regression model, unstandardized regression coefficients and the significant levels are reported for each model. Results were considered statistically significant if alpha was $<.05$. 
Collective self-esteem as a moderator. Collective self-esteem is a measure related to participants' perceptions and feelings related to social group identity/status. Control variables (time spent on Facebook and number of friends on Facebook) were entered on Step 1. Facebook Importance was entered on Step 2. Collective self-esteem was entered on Step 3. Facebook Importance by collective self-esteem was entered on Step 4. Regressions were performed separately using the same set of independent variables to predict each Facebook Engagement Factor: a) Facebook Preference (indicating a preference for Facebook over other forms of communication), b) Managing Conflict on Facebook (indicating the extent to which friendship conflict is dealt with on Facebook), and c) Monitoring Social Ties on Facebook (indicating the use of Facebook to keep in touch with one's social network and the events going on in their lives).

Predicting Facebook Preference (Factor 1). On Step 1, consistent with hypotheses, time spent on Facebook was a significant predictor $(\beta=.33, p=<.001)$, indicating that time spent on Facebook was positively associated with a preference for using Facebook to communicate with others. Number of Facebook friends was not a significant predictor. On Step 2, as predicted, Facebook Importance was also a significant predictor of Facebook Preference $(\beta=.55, p=<.001)$, indicating that Facebook Importance has a positive impact on using Facebook as a preferred means of communicating with friends. On Step 3, contrary to predictions, collective self-esteem did not significantly predict Facebook Preference. On Step 4, the interaction term was non-significant (see Table 4). 
Table 4

Hierarchical Regression Analyses of Facebook Importance on Facebook Preference

(Facebook Engagement Factor 1) and the Moderating Effects of collective self-esteem (controlling for Facebook variables).

Predictor Variable

Step 1

Time Spent Online

Facebook Friends

Step 2

Facebook Importance

Step 3

Collective self-esteem

Step 4

Facebook Importance $\mathrm{X}$

Collective self-esteem
$\mathbf{R}^{2}$

.09

$\Delta \mathrm{R}^{2}$

Beta

$.33^{* * *}$

.08

.32

.23

$.55^{* * *}$

.32

.00

.03

.32

.00

${ }^{* * *} \mathrm{p}<.001,{ }^{* *} \mathrm{p}<.01,{ }^{*} \mathrm{p}<.05$

.00 
Predicting Managing Conflict (Factor 2). On Step 1, consistent with hypotheses, both time spent on Facebook $(\beta=.20, p=<.001)$ and the number of Facebook friends ( $\beta$ $=.13, p=<.01$ ), were significant predictors of Managing Conflict on Facebook. On Step 2, Facebook Importance was a significant predictor $(\beta=.25, p=<.001)$, indicating that Facebook Importance was positively associated with Managing Conflict on Facebook. That is, the more important Facebook was perceived to be, the more likely individuals were to manage conflict with friends on Facebook. On Step 3, contrary to predictions, collective self-esteem was not found to significantly predict Managing Conflict on Facebook. On Step 4, the interaction term was non-significant (see Table 5). 
Table 5

Hierarchical Regression Analyses of Facebook Importance on Managing Conflict

(Facebook Engagement Factor 2) and the Moderating Effects of Collective self-esteem (controlling for Facebook variables).

Predictor Variable

Step 1

Time Spent Online

Facebook Friends

Step 2

Facebook Importance

Step 3

Collective self-esteem

Step 4

Facebook Importance X

Collective self-esteem
$\mathrm{R}^{2}$

.09

.15

$5 \quad .06$

$.25^{* * *}$

.15

.00

$-.07$

.16

.01

$20 * * *$

$.13^{* *}$

$5 \quad .00$

$16 \quad .0$

${ }^{* * *} \mathrm{p}<.001,{ }^{* *} \mathrm{p}<.01,{ }^{*} \mathrm{p}<.05$ 
Predicting Monitoring Social Ties (Factor 3). On Step 1, consistent with hypotheses, time spent on Facebook $(\beta=.22, p=<.001)$ was a significant predictor of Monitoring Social Ties on Facebook, but number of Facebook friends was not. On step 2, Facebook Importance was a significant predictor $(\beta=.38, p=<.001)$ indicating that Facebook Importance was positively associated with Monitoring Social Ties on Facebook. On Step 3, contrary to predictions, collective self-esteem was not found to significantly predict Facebook Engagement factor 3. On Step 4, a significant interaction was found between Facebook Importance and collective self-esteem $(\beta=.13, p=<.01)$ (see Table 6).

A follow up simple slopes analysis was conducted, with two categories for the moderator, collective self-esteem. The levels chosen corresponded to a low level (one standard deviation below the mean) and a high level (one standard deviation above the mean). The values for these levels for collective self-esteem were 47.29 and 61.49 , respectively. Simple slopes analysis indicated that the treatment effect of Facebook Importance on Monitoring Social Ties was the strongest for individuals low on collective self-esteem (see Figure 1.). 
Table 6

Hierarchical Regression Analyses of Facebook Importance on Monitoring Social Ties

(Facebook Engagement Factor 3) and the Moderating Effects of Collective self-esteem (controlling for Facebook variables).

Predictor Variable

Step 1

Time Spent Online

Facebook Friends

Step 2

Facebook Importance

Step 3

Collective self-esteem

Step 4

.19
$.22 *$

.05

.18

.11

$.38^{* * *}$

.18

.00

.02

.01

Facebook Importance X

Collective self-esteem 
Summary. In summary, time spent on Facebook was a significant predictor of Facebook Preference, Managing Conflict on Facebook and Monitoring Social Ties, while number of Facebook friends was only a significant predictor of Managing Conflict on Facebook. Facebook Importance was also a significant predictor of all three Facebook Engagement Factors, yet collective self-esteem was not significantly related to any of the Facebook engagement indices. Finally, the only significant interaction was between Facebook Importance and collective self-esteem for Monitoring Social Ties, where the relationship between Facebook Importance and Monitoring Social Ties was strongest for individuals low on collective self-Esteem. That is, monitoring social ties on Facebook was a particularly important element of Facebook usage for individuals who felt less secure about their social group status/membership. 


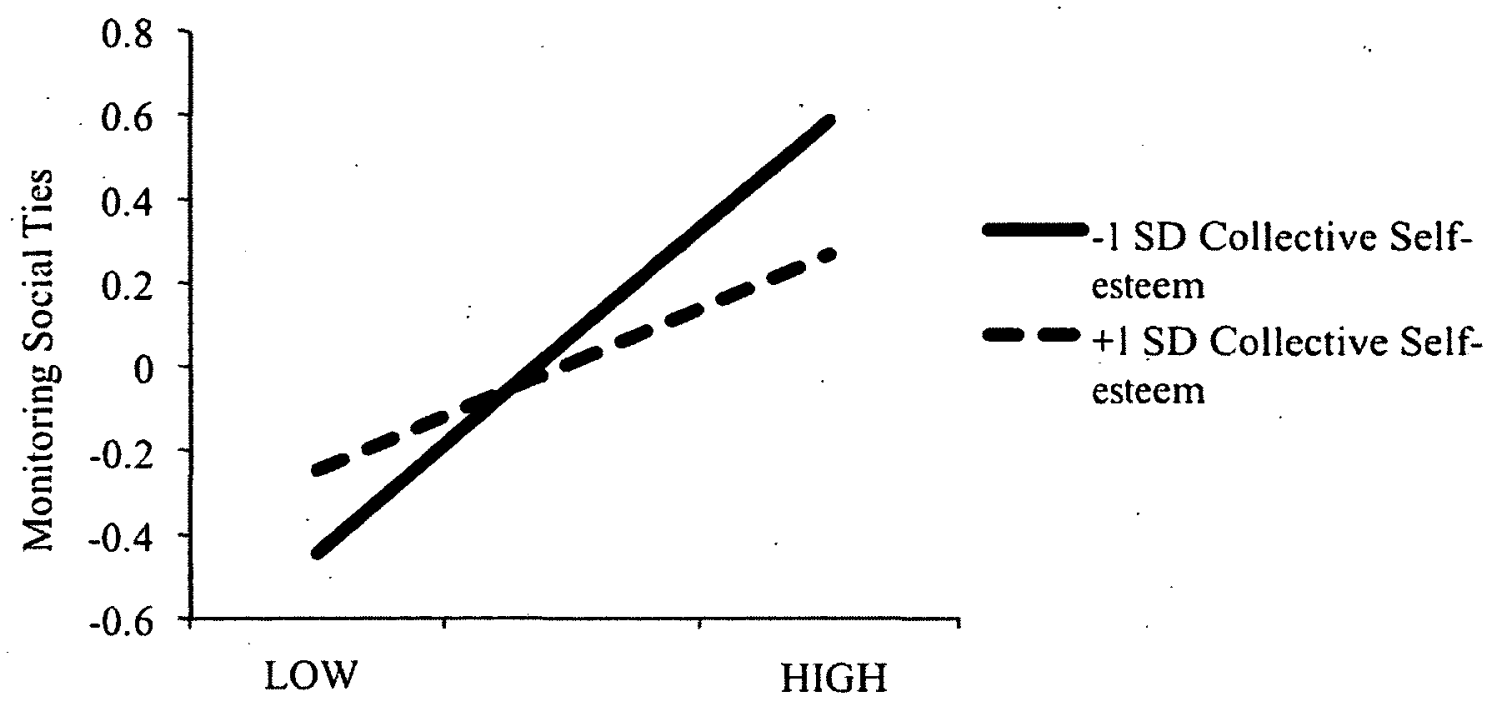

Facebook Importance

Figure 1. The relationship between Facebook Importance and Monitoring Social Ties on Facebook as a function of Collective self-esteem. 


\section{The relationship between Facebook Importance, Facebook Engagement and} indices of psychological well-being.

A second set of hierarchical regression analyses were performed to examine the amount of variance accounted for in negative aspects of psychological well-being outcomes (depression and loneliness) with respect to Facebook Importance, Facebook Engagement, and the moderating variable, collective self-esteem. Control variables were entered on Step 1. Facebook Importance was entered on step 2. All three Facebook Engagement Factors (Facebook Preference, Managing Conflict and Monitoring Social Ties) were entered on Step 3. Collective self-esteem was entered on Step 4. The four interactions variables (i.e., Collective self-esteem by Facebook Importance, by Facebook Preference, by Managing Conflict and by Monitoring Social Ties) were entered on Step $5^{1}$

Given the fact that self-worth and satisfaction with life, as outcome variables, were not correlated with Facebook Importance or any of the three Facebook Engagement Factors, no regression analyses were performed on these variables.

1 These analyses were run including gender as a predictor but gender did not play a significant role and there were no significant interactions present for any of the dependent variable outcomes. 
Predicting depression. On Step 1, consistent with hypotheses, both time spent on Facebook $(\beta=.14, p=.01)$ and number of Facebook friends $(\beta=.11, p=.05)$ were significant positive predictors of depression. On step 2, Facebook Importance was also a significant predictor $(\beta=.15, p=.01)$, indicating that Facebook Importance was positively associated with student depression. On Step 3, partially supporting initial predictions, Managing Conflict on Facebook (Factor 2) was a significant predictor of depression ( $\beta$ $=.18, p=.001$ ), Facebook Preference and Monitoring Social Ties were not. On Step 4, collective self-esteem was not a significant predictor of depression. On Step 5, there were two significant interactions: Facebook Importance by collective self-esteem $(\beta=.16$, $p=.05$ ), and Managing Conflict by collective self-esteem $(\beta=-.17, p=.01)$ (see Table 7$)$.

A follow up simple slopes analysis was conducted, using the low and high category values for collective self-esteem, as mentioned above. Simple slope analyses indicated that the treatment effect of Facebook Importance on depression was strongest for individuals high on collective self-esteem (see Figure 2.). However, the treatment effect of Managing Conflict on depression was strongest for individuals lower on collective self-esteem (see Figure 3.). 
Table 7

Hierarchical Regression Analyses of Facebook Importance and Facebook Engagement

Factors on depression scores and the Moderating Effects of Collective self-esteem

(controlling for Facebook variables).

Predictor Variable

Step 1

Time Spent Online

Facebook Friends

Step 2

Facebook Importance

Step 3

Facebook Preference

Managing Conflict

Monitoring Social Ties

Step 4

Collective self-esteem

Step 5

Facebook Importance X CSE

Facebook Preference X CSE

Managing Conflict X CSE

Monitoring Social Ties X CSE

\section{$\mathrm{R}^{2}$}

.04

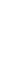


Summary. As predicted, time spent on Facebook and the number of Facebook friends were both significant predictors of depression. Also as predicted, Facebook Importance was a significant predictor of depression. Partially supporting initial hypothesis, in the regression model, only Managing conflict on Facebook was a significant predictor of depression. Contrary to predictions, collective self-esteem was not a significant predictor of depression. Finally, there were two significant interactions, between Facebook Importance and collective self-esteem and Managing Conflict and collective self-esteem. The relationship between Facebook Importance and depression was strongest for individuals higher on collective self-esteem. Individuals whose selfesteem is strongly tied to feeling part of a group may be particularly at risk for overvaluing the importance of Facebook in their daily life.

On the other hand, the relationship between Managing Conflict and depression was strongest for those lower on collective self-esteem. Thus, while managing conflict with friends online seems to be a generally non-adaptive relationship strategy, this way of engaging on Facebook is particularly problematic for those who do not feel secure about their social group status/membership. 


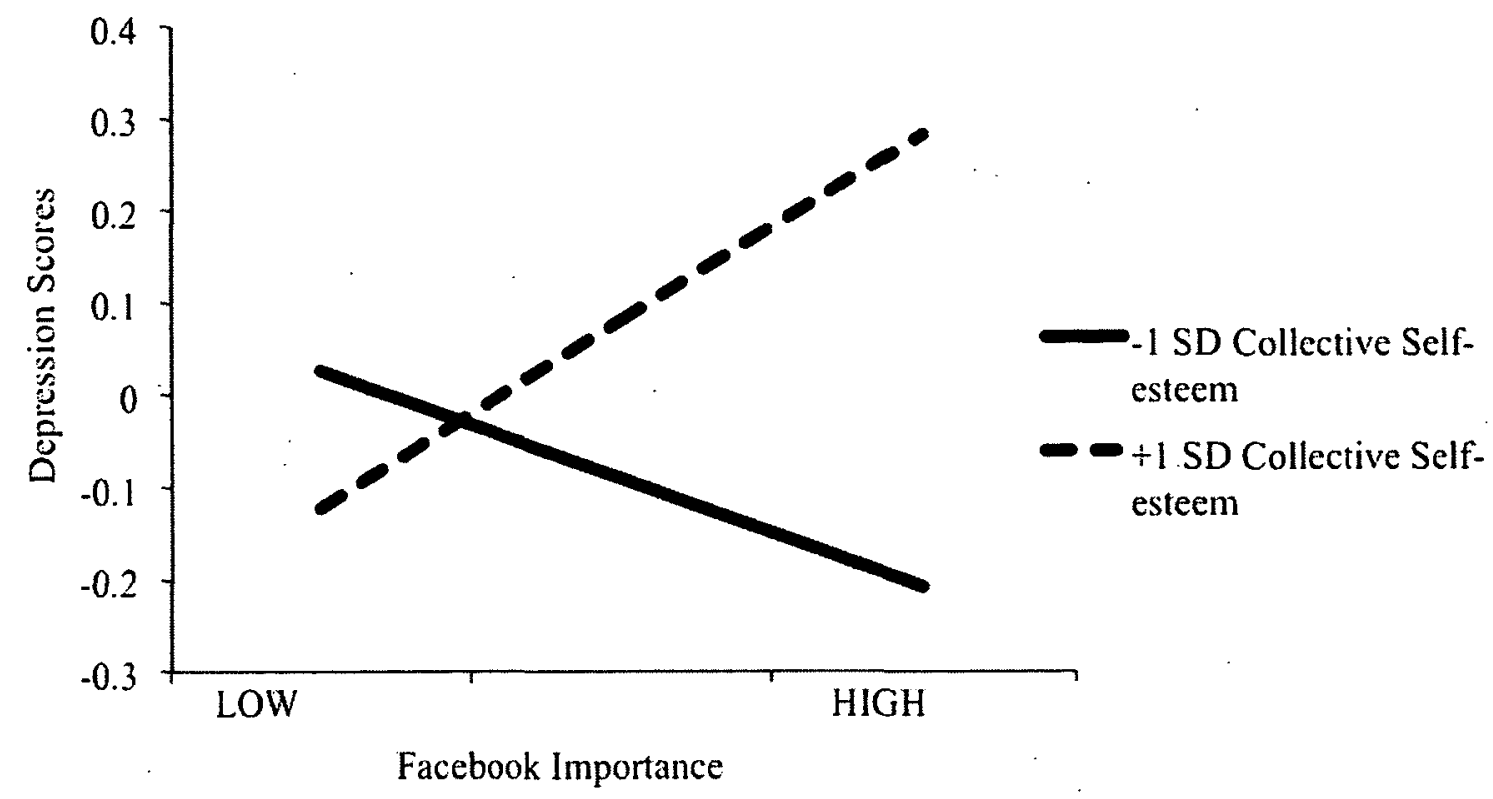

Figure 2. The relationship between Facebook Importance and depression scores as a function of Collective self-esteem (see page 70 for interpretation) 


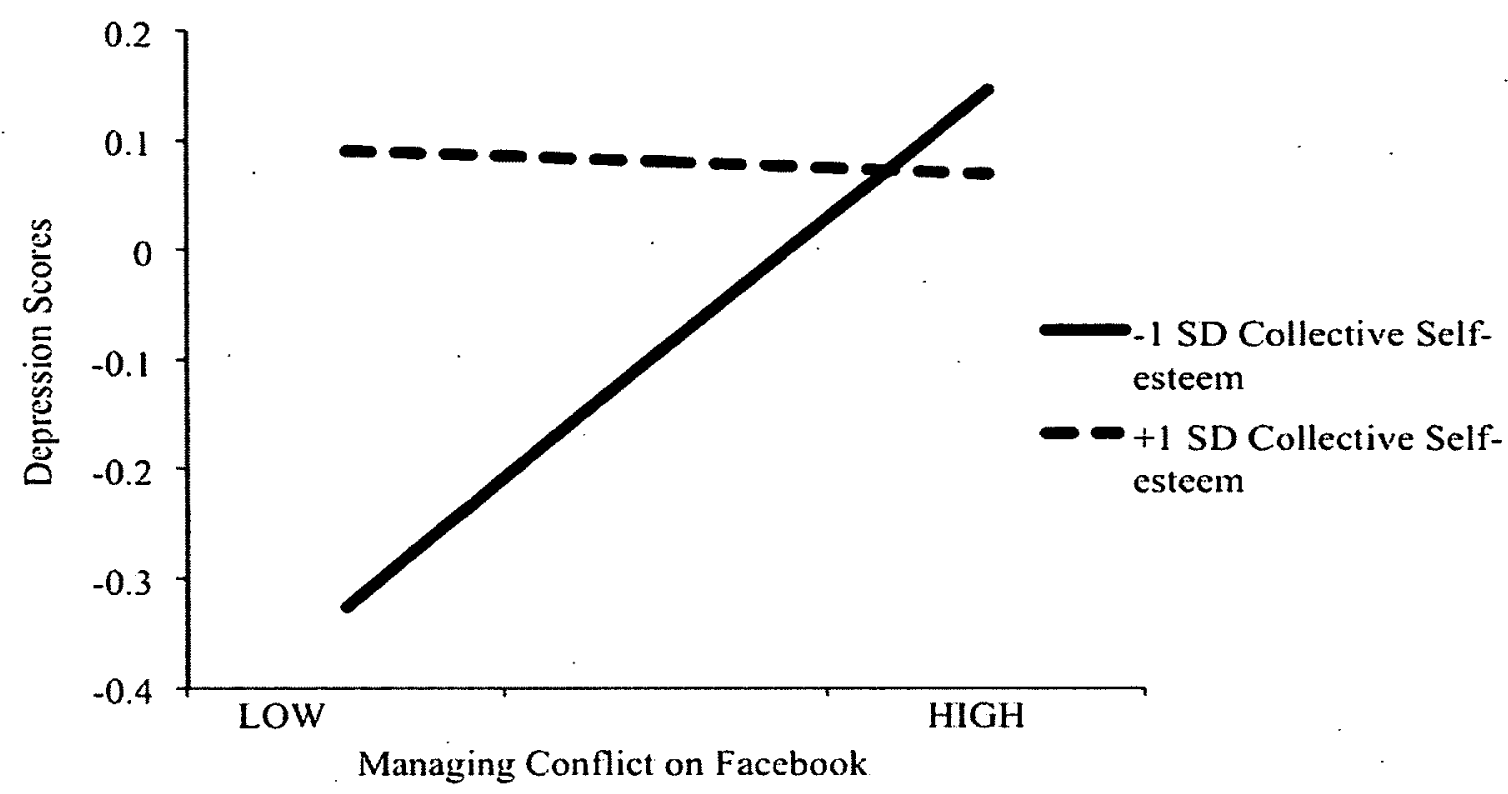

Figure 3. The relationship between Managing Conflict on Facebook and depression scores as a function of Collective self-esteem (see page 70 for interpretation). 
Predicting loneliness. Time spent on Facebook was entered on Step 1. Facebook Importance was entered on Step 2 of the regression. The three Facebook Engagement Factors were entered on Step 3. Collective self-esteem was entered on Step 4. It was expected that collective self-esteem might moderate the relationship between Facebook Importance and the three Facebook Engagement Factors and the second index of psychological well-being, loneliness. That is, Facebook Importance and Facebook Engagement might have a stronger influence on loneliness for students with a lower perceived sense of collective-self-esteem. As such, aforementioned interaction terms were entered in to the regression on Step 5.

On Step 1, contrary to predictions, time spent on Facebook was not a significant predictor of loneliness. On Step 2, as predicted, Facebook Importance was a significant predictor of loneliness $(\beta=-.11, p=.50)$. On Step 3 , partially supporting predictions, Monitoring Social Ties on Facebook was a significant predictor $(\beta=.12, p=.50)$ of loneliness, but Facebook Preference and Managing Conflict were not. On Step 4, as predicted, collective self-esteem was a significant predictor of loneliness $(\beta=.14, p=.10)$. On Step 5, partially supporting initial predictions, two significant interactions were found between Facebook Preference and $(\beta=-.16, p=.50)$ (see Figure 4), and Monitoring Social Ties and collective self-esteem $(\beta=-.14, p=.05)$ (see Figure 5). Interactions between Facebook Importance and collective self-esteem and Managing Conflict on Facebook and collective self-esteem were not significant (see Table 8).

A follow up simple slopes analysis was conducted, using the same two category values for collective self-esteem as aforementioned. Simple slope analyses indicated that the treatment effect of Facebook Preference on loneliness was the strongest for 
individuals higher on collective self-esteem. However, the treatment effect of Monitoring Social Ties on loneliness was the strongest for individuals lower on collective self-esteem. 
Table 8

Hierarchical Regression Analyses of Facebook Importance and Facebook Engagement Factors on loneliness and the Moderating Effects of Collective self-esteem (controlling for Facebook variables).

Predictor Variable

Step 1

Time Spent Online

Step 2

Facebook Importance

Step 3

Facebook Preference

Managing Conflict

Monitoring Social Ties

Step 4

Collective self-esteem

Step 5

Facebook Importance X CSE

Facebook Preference X CSE

Managing Conflict X CSE

Monitoring Social Ties X CSE
.07

.02

.01

$-.11^{*}$

.03

.01

.00

.08

$.12 *$

.05

.02

$.14^{* *}$

.10

.05

${ }^{* * *} \mathrm{p}<.001,{ }^{* *} \mathrm{p}<.01,{ }^{*} \mathrm{p}<.05$

.03

$-.16^{*}$

.03

$-.14^{*}$ 
Summary. Contrary to predictions, time spent on Facebook was not a significant predictor of loneliness. However, as expected, Facebook Importance was a significant predictor of loneliness, while only one of the three Facebook Engagement Factors significantly predicted loneliness, Monitoring Social Ties. Collective self-esteem was a significant predictor of loneliness, with individuals having a stronger sense of their group membership being particularly vulnerable to feelings of loneliness.

There were two significant interactions between Facebook Preference and collective self-esteem, and Monitoring Social Ties on Facebook and collective selfesteem. The relationship between Facebook Preference and loneliness was strongest for individuals higher on collective self-esteem, but the relationship between Monitoring Social ties and loneliness was strongest for individuals lower on collective self-esteem. Contrary to the analyses predicting depression, individuals with a stronger sense of group membership may be at risk for placing less emphasis on using Facebook for social interactions, leading to a greater vulnerability to loneliness. In contrast, spending significant amounts of time online, monitoring one's social ties, when one feels particularly dissatisfied with those social ties may invoke greater feelings of loneliness. 


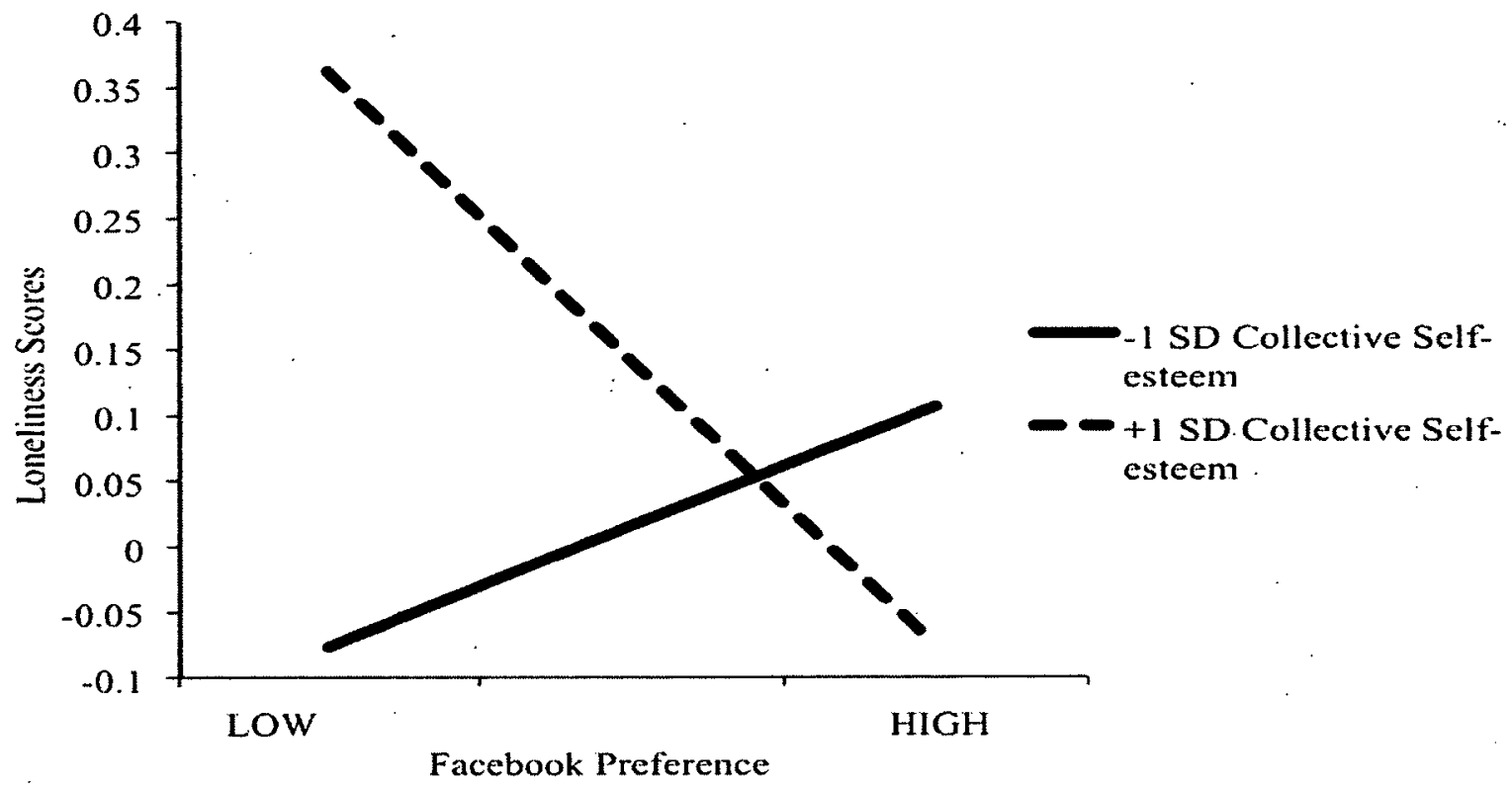

Figure 4. The relationship between Facebook Preference and loneliness scores as a function of Collective self-esteem (see page 76 for interpretation). 


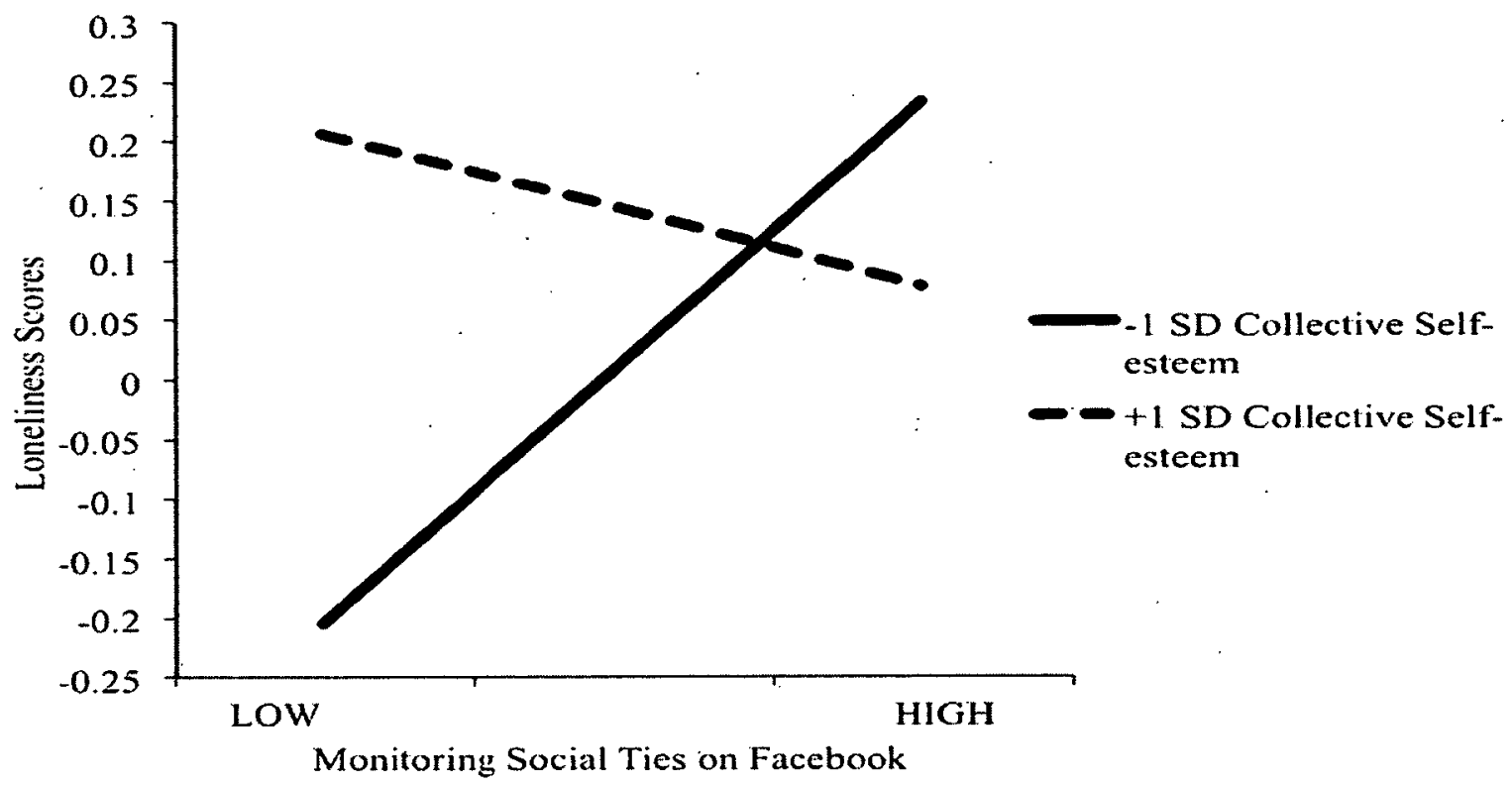

Figure 5. The relationship between Monitoring Social Ties and loneliness scores as a function of collective self-esteem (see page 76 for interpretation). 


\section{Overall summary.}

In this study, Facebook Importance was strongly related to both time spent online and the number of Facebook friends, such that the stronger the belief regarding the importance of Facebook, the more amount of time individuals spent on Facebook and the more Facebook friends they had. Similarly, collective self-esteem was also strongly related to amount of time spent online per day and number of Facebook friends. With respect to communication methods, Facebook importance was strongly related to the amount of time individuals private messaged their friends, but not wall posting between friends. Conversely, collective self-esteem was not related to either communication methods.

Results from the second part of this study indicated that the amount of time spent on Facebook was significantly related to Facebook Engagement. This means that the more time.people spend online, the more likely they are to be engaged on Facebook, to include a greater preference for interacting online, engaging in greater conflict with their friends and peers, and in monitoring the daily events in their acquaintances' lives. In addition, results showed that the more individuals rated Facebook as being important, the greater their overall engagement. Finally, results largely indicated that the construct of collective self-esteem did not impact the relationship between Facebook Importance and Facebook Engagement.

Part three examined how Facebook Importance and Facebook Engagement together impacted psychological well-being outcomes. With regard to depression scores, results showed that time spent on Facebook and the number of Facebook friends were both positively related to depression scores. Additionally, the greater the belief in the 
importance of Facebook the more likely individuals were to experience greater depressive symptoms.

Out of the three Facebook Engagement Factors, only Managing conflict on Facebook was a significant predictor of depression. Contrary to predictions, collective self-esteem was not directly related to depression, but indirectly contributed to two interaction relationships. There were two significant interactions, between Facebook Importance and collective self-esteem and Managing Conflict and collective self-esteem. The relationship between Facebook Importance and depression was strongest for individuals higher on collective self-esteem. Individuals whose self-esteem is strongly tied to feeling part of a group may be particularly at risk for over-valuing the importance of Facebook in their daily life. On the other hand, the relationship between Managing Conflict and depression was strongest for those lower on collective self-esteem. Thus, while managing conflict with friends online seems to be a generally non-adaptive relationship strategy, this way of engaging on Facebook is particularly problematic for those who do not feel secure about their social group status/membership.

With respect to loneliness, contrary to predictions, time spent on Facebook was not a significant predictor of loneliness. However, as expected, Facebook Importance was a significant predictor of loneliness, while only one of the three Facebook Engagement Factors significantly predicted loneliness, Monitoring Social Ties. Collective self-esteem was directly related to feelings of loneliness, with individuals having a stronger sense of their group membership being particularly vulnerable to feelings of loneliness. Results showed there were two significant interactions between Facebook Preference and collective self-esteem, and Monitoring Social Ties on Facebook 
and collective self-esteem. The relationship between Facebook Preference and loneliness was strongest for individuals higher on collective self-esteem, but the relationship between Monitoring Social ties and loneliness was strongest for individuals lower on collective self-esteem. Therefore, individuals with a stronger sense of group membership may be at risk for placing less emphasis on using Facebook for social interactions, leading to a greater vulnerability to loneliness. In contrast, spending significant amounts of time online, monitoring one's social ties, when one feels particularly dissatisfied with the membership between those social ties may invoke greater feelings of loneliness. 


\section{Discussion}

Over the past decade, the communication uses of the Internet have become a very important part of young people's lives (e.g., Gemmill \& Peterson, 2006; Jones, 2002; Lenhart \& Madden, 2007; Subrahmanyam \& Greenfield, 2008). Social networking sites are the latest online communication tool that allows users to create a public or semipublic profile, create and view their own as well as other users' online social networks (Boyd \& Ellison, 2007), and interact with people in their networks. Sites such as Facebook have well over 100 million users, many of them adolescents and emerging adults. Although research on young people's use of social networking sites is emerging (Boyd \& Ellison, 2007; Ellison et al., 2007; Valkenburg et al., 2006), research in this area has been limited to "blanketing" relationships (i.e., not separating peers, friendships, or close friendships), what people do on these sites, how much time they spend online, and who they are interacting with.

Given that Facebook usage is both unique to each user and difficult to operationalize, the present research first sought to examine the role of the belief in the importance Facebook plays (i.e. Facebook Importance) in maintaining relations online, particularly close friendships, and how this affects various ways of engaging online. Of additional interest was how, these variables in turn, predict well-being among users.

Additionally, the present study examined the moderating influence of collective self-esteem on the relationship between Facebook Importance and three distinct Facebook Engagement Factors, and then examined how these two concepts, together, affect indices of well-being, as measured by depression and loneliness.

Individual Difference Factors (Age and Gender) 
The current study revealed individual differences in terms of Facebook usage. For example, younger participants (aged 17-20) reported a significantly greater amount of time spent online as compared to individuals' aged 25-30 and those in the highest age category (aged 31 and older). Participants aged 17-20 and 21-24 did not significantly differ. In addition, younger participants reported a greater number of Facebook friends as compared to those all other age categories.

Furthermore, as indicated in the previous section, Facebook Importance and Facebook Engagement factors also differed by age, with the two youngest age groups placing greater importance on Facebook as a means to interact with their friends as compared to the two older age categories. Finally, Monitoring Social Ties, Facebook Engagement Factor 3, differed significantly by age, with participants aged 21-24 reporting a greater amount of Monitoring Social Ties as compared to all other age groups. In sum, younger participants spent more time on Facebook, had more Facebook friends, and generally rated Facebook as being more important than older age categories. Finally, younger participants also tended to have higher Facebook Engagement scores, such as greater time spent Monitoring Social Ties online, as compared to older participants.

Recent research has demonstrated that adolescents (Boneva, Quinn, Kraut, Kiesler, \& Shklovski, 2006) and young adults in university (Clark, Frith, \& Demi, 2004; Gemmill \& Peterson, 2006; Jones, 2002) are heavy users of the Internet relative to the general population, and use it extensively for communication with peers and friends. Research also suggests that young adults use instant messaging mainly to communicate with offline friends about events in school, gossip, and in keeping up to date on what is happening in their friends' lives (Boneva et al., 2006; Gross et al., 2002). Not 
surprisingly then, younger participants in the study tended to spend a great amount of time on Facebook and therefore have likely accumulated a larger friendship base online as compared to older participants who perhaps use different methods of communicating with their friends; given that they did not grow up in the generation where offline friendships transcended into the online world.

Finally, with respect to engagement, research on social networking sites is beginning to accumulate (Boyd \& Ellison, 2007) and indicates that social networking sites may be used to bridge online and offline social ties (Subrahmanyam et al., 2008). Relevant research has examined university students'. use of social networking sites to form and maintain interconnections with their offline peers. For instance, in a survey of all incoming first year students at a major Midwestern university, Lampe et al. (2007) found that students most often used Facebook for social purposes: to stay in touch with their friends from high school as well as to form interconnections with people they had met offline such as in their dormitories or in class. Similarly, Ellison et al. (2007) found that college students used Facebook to maintain or bolster existing offline connections rather than to form new relationships. Such ties appear to have some positive benefits and greater Facebook use was associated with more perceived social capital. As such, the younger participants in the current study spent more time on Facebook Monitoring Social Ties as compared to older participants to keep these strong and weak ties available and would do so by keeping in contact with their acquaintances and 'weaker' friendships to maintain a larger base of a social network. This finding may be in part due to the fact that, as research has shown (Lampe et al., 2007; Freiert, 2007; Boyd, 2008), Facebook users, particularly those in university settings, engage in Facebook usage for 'social 
searching', to find out information about offline contacts, peers and weak social ties, which appears to embody the concept behind the idea of Monitoring Social Ties. Older participants on the other hand, may not feel the need to engage in such behaviours as they may be more established within their social settings and are not in as much of a state of transition as younger participants socially or geographically.

It was also hypothesized that younger participants would differ with respect to their perceived Facebook Importance, and in their Facebook Engagement as compared to older participants. Adolescents' developmental concerns include formulating identity, adjusting to sexuality, and establishing intimate relations with peers, friends and romantic partners (Brown, 2004; Erikson, 1959; Weinstein \& Rosen, 1991), and recent research indicates that they use online contexts in the service of these important concerns. A qualitative study showed that adolescents adopted usernames and pictures for selfpresentation and used their blog entries for self-disclosure about their peers and everyday life (Subrahmanyam et al., 2008). They also used their online presence to create narratives about themselves and to reflect on the people and events in their lives (Subrahmanyam et al., 2008).

In the current study, younger participants, those falling within the defined age parameters of emerging adults, viewed Facebook as being of greater importance with respect to interacting with friends than older participants. This could be due to the fact that they are currently in a developmental phase of transition and interpersonal growth, and are seeking out online spaces to further enhance and share their experiences with friends, thereby making this online space undoubtedly important in their day-to-day interactions. Viewing users' online worlds as psychologically continuous with their 
offline ones enables us to start teasing apart the relation between online communication and development. Much of the research in support of this view has been done on adolescents, and it is an open question whether such connectedness and importance is present among emerging adults in university.

The relationship between Facebook Importance and Facebook Engagement Of particular interest to the present study was how Facebook Importance, the belief that Facebook is important in maintaining certain interpersonal relations/activities online, impacted Facebook Engagement and whether or not this was moderated by perceived level of social group membership, namely, collective self-esteem. While collective self-esteem was not a significant moderator for the relationship between Facebook Importance and Facebook Engagement, Facebook Importance was significantly related to all three Facebook Engagement Factors (Facebook Preference, Managing Conflict, Monitoring Social Ties). That is, the more likely students were to believe that Facebook is important in terms of interacting with your friends online, the more likely they were to prefer Facebook as the primary means for communicating with friends, manage conflict online, and to monitor social ties online.

Facebook Importance and Facebook Preference. With respect to the relationship between Facebook Importance and Facebook Preference, this finding is consistent with research that suggests that as the belief in the capability of a social networking site increases, so too does users' usage levels, preference and familiarity with the technology itself (Gangadharbatla, 2008). Furthermore, research has also shown that the greater the belief in the importance and capacity with which a person can perform those tasks online, the greater should be his or her ability to join and participate in user- 
generated interactions on such sites. Also, as importance beliefs increase, the attitudes toward the object of those beliefs also should increase (Ajzen \& Sexton 1999), which suggests that persons with higher levels of belief in the importance of a particular medium, should have more favorable behaviours and a preferences toward their social networking site of choice. Therefore, it makes sense that the more that individuals feel Facebook has the capacity to play an important role in maintain friendships online, the more time they spend on Facebook building up and communicating with their social network, and the more likely they will be to prefer Facebook as the primary means of communication with their friends.

Facebook Importance and Managing Conflict. Facebook Importance was also significantly related to Facebook Engagement Factor 2, Managing Conflict online. Research is quite limited with respect to managing conflict online, however, the results could be explained by the idea that social networking sites often invite more conflictmanipulative and disrespectful behavior that escalates anger and reduces productivitythrough the reduction of social cues and depersonalization of the other, which can lead to exchanges of negative communication between two or more people (Friedman \& Currall, 2003; Harrison \& Falvey, 2002; Landry, 2000; Markus, 1994; Moore, Kurtzberg, Thompson, \& Morris, 1999; O'Sullivan \& Flanagin, 2003). Landry (2000) and other scholars contend that the depersonalization of the other and the lack of social cues such as facial expressions, tone of voice, gestures, and other cues found in face-to-face communication create misunderstandings between communicators, which can lead to conflict-inducing behavior (Alonzo \& Aiken, 2004; O'Sullivan \& Flanagin, 2003; Walther, 1992). The speed factor, for instance; can be considered a double-edged sword; 
because of social networking site's "shoot from the hip" quality, people can fire off a message or engage in an interaction without thinking about the consequences (Baruch, 2005).

In a lengthy discussion, Friedman and Currall (2003) note aspects of the medium that make conflict more likely to escalate. Online communication, they argue, is inherently more "asocial", because people often forget that another human being is at the other end of the interaction. Online interactions are typically received and written while the writer is in isolation, staring at a computer screen-perhaps for hours at a time, so that awareness of the humanness of the counterpart may be diminished (Friedman \& Currall, 2003). Working from the conflict spiral model (Rubin \& Rubin, 1994), Friedman and Currall (2003) claim that once an interaction is misunderstood as negative or aggressive, it can lead to the other person reciprocating in kind, which leads to more negative responses, and so forth. Throughout the process, the parties' attitudes toward each other may change.

Attitudes and beliefs are not overt behaviors but rather dispositions that influence behavior (Allport, 1935). Therefore, this finding suggests that with respect to the relationship between Facebook Importance and Managing Conflict, an attitude or belief toward an action and subjective social norms influence a person's intention to perform an action, which in turn influences action behaviors (Ajzen \& Sexton, 1999; Ajzen \& Fishbein, 1980). As such, the greater the belief towards Facebook as being important, the more likely individuals are to engage in behaviours on Facebook that seem normative with respect to their interpersonal relations with friends online, one of which may be managing relational conflict. While individuals may feel as though Facebook is an 
important medium for interacting with their friends online, it may also be that they see it as a "buffer" in dealing with conflict within these important friendships. Research has also shown that due to the ease in accessing information about friends online (i.e., access to pictures, posts, events, etc.) there is a greater likelihood that it can lead to increased conflict online (Christofides et al., 2009). With individuals holding a strong belief in the importance of using Facebook every day, it is not surprising then that users would begin to feel "safer" managing conflict online.

Facebook Importance and Monitoring Social Ties. Generally, the more importance participants placed on Facebook, the more likely they were to engage with it, in many different ways. Although collective self-esteem did not play a significant role in predicting Facebook engagement, it did interact with Facebook Importance to predict one type of Facebook engagement, namely Monitoring Social Ties on Facebook. That is, Monitoring Social Ties on Facebook was a particularly important element of Facebook usage for individuals who felt less secure about their social group status/membership. Arguably, those who felt that Monitoring Social Ties was an important aspect of Facebook engagement, may have been attempting to increase their perceived group membership status by indirectly engaging with friends online to learn more about things that were going on in their lives. This particular finding coincides with past research which suggests that social networking sites offer a space in which people can address this need to belong to their social group by using services provided by Facebook that enables information gathering along with the possibility of gaining social approval (Gangadharbatla, 2008).

Need to belong within our social groups also can be understood on the basis of a 
fundamental interpersonal relations orientation, which suggests that three basic needs underlie people's group-seeking behavior: inclusion, which pertains to the need to belong to or include others in a circle of acquaintances; affection, or the need to love or be loved by others; and control, which encompasses the need to exert power over others or give power over the self to others (Schutz, 1966). Joining social networking sites can meet all three of these needs; specifically, people may join user-generated content sites such as Facebook to remain "in the loop" and up to date on the daily events in people's lives and maintain relationships with friends and others, or Monitoring Social Ties, irrespective of time and physical space.

\section{The Relationship between Facebook Importance, Facebook Engagement and Indices of Psychological Well-being}

Depression. Confirming initial hypotheses, Facebook usage, time spent on Facebook and the number of Facebook friends, were all significantly related to depression scores. A new study by Chou and Edge (2011) reports a correlation between a Facebook user's disposition about their life and happiness and the amount of time spent interacting with their friends on the social network. Seeing a pattern emerge, the two researchers discovered that as people spend more time on Facebook interacting with their friends, they start to believe that others have a better life than they do and begin to show symptoms of "Facebook depression" (Chou \& Edge, 2011). This finding suggests that in thinking that others have a better life than you do, you begin to feel as though your own doesn't compare in terms of excitement and quality and users start to exhibit depressive symptoms (Chou \& Edge, 2011). As young people are spending more and more time on Facebook and managing their friendships on Facebook, they may also be increasingly at 
risk for depression and loneliness. This is an important finding as maybe older individuals, even older university students, have a healthier relationship with Facebook and appear not to be taking it too seriously. Not surprisingly then, those who are spending more time on Facebook and interacting with a greater number of Facebook friends, as was shown in the current study, tend to have higher depression scores.

Also significantly related to depression scores among first year university students was the belief in the importance of Facebook to connect and interact with their friends. This was particularly true of individuals who were high on collective self-esteem. This finding might be best explained by the co-construction model, that highlights the fact that online and offline worlds are psychologically connected (Subrahmanyam et al., 2008). This model proposes that users bring expectations with regard to people and issues, from their offline worlds into their online ones (Subrahmanyam et al., 2008), and as such they over-emphasize the importance of consistently interacting online with their friends. This appears to be particularly true of individuals who have a high belief in the importance of their group membership and attempt to merge their two social groups to create a greater opportunity for increased connectedness. Many researchers, who argue for the greater benefits of offline relations, as opposed to online interactions (Tong et al., 2008; Donath \& Boyd, 2004), suggest that online friendships lack the necessary cues, physical proximity and closeness that accompany positive outcomes in friendships. Therefore, it may be that as the line between offline and online friendships begins to blur, individuals begin to hold unrealistic expectations about their online friendships, and as such, are not satisfied with the context and structure of the online relations and begin to experience symptoms of depression because their social expectations are not being met. 
People have a strong motivation to form and maintain social relationships (Baumeister \& Leary, 1995). One of the central tasks of the human self is to obtain social acceptance, and so many of its functions and activities are geared toward promoting that goal (Baumeister, 1998; Leary, Tambor, Terdal, \& Downs, 1995; Schlenker, 1980). Individuals who are high on collective self-esteem therefore, appear to be placing a greater emphasis on the importance that Facebook plays in maintaining their friendships, and are not necessarily adjusting their expectations to the limitations of online interactions and, as such, as are reporting higher depression scores, as compared to individuals lower on collective self-esteem.

While Facebook Importance predicted depression scores most strongly for those higher on collective self-esteem, it was the type of Facebook Engagement that was particularly damaging for individuals who were lower on collective self-esteem. While managing conflict with friends online seems to be a generally non-adaptive relationship strategy, this way of engaging on Facebook is particularly problematic for those who do not feel secure about their social group status/membership. Research in the area of managing conflict on Facebook is currently very limited. While some individuals may prefer to handle conflict without having to be face to face, past research suggests that friendships managed on the internet are generally perceived as less close and of lower quality than offline grounded relationships because the interactive physical cues are lacking (Kim et al., 2009; Lee \& Boyer, 2007). Scholars argue that students who communicate via computer mediated communication with other students use more direct “uncertainty reduction strategies" (Mazer, Murphy, \& Simonds, 2007, p. 3) (e.g., engage in more direct questioning and self-disclosures) than students in face-to-face 
conversations; making people more vulnerable when engaging in conflict online because it is not face to face so it is less intimidating to be forward and direct (Mazer et al., 2007). In addition, the medium itself allows for greater self-disclosure (Mazer et al., 2007) among friends and as such, people may be more inclined to share embarrassing or difficult information which may again make them more vulnerable to the possibility of conflict online.

People who are lower on collective self-esteem may feel that it's better to manage conflict on-line, rather than face-to-face, to avoid damaging the friendship. Facebook, by its very nature, provides easy and publicly acknowledged access to friends' information, including changes to their profile, additions of new contacts, status updates, and messages posted to and from their page (Christofides et al., 2009). In this regard then, overexposure to a friend's Facebook profile, when you are feeling insecure about your own group membership, may actually increase the likelihood of jealousy and thus increase the level of relational conflict as a result of online interactions (Christofides et al., 2009). Furthermore, Anderson (2005) also suggested that among university students, excessive Internet use might be related to interpersonal issues such as establishing new relationships and identity formation within closer relationships and that this can lead to decreased levels of happiness. This may be particularly problematic for individuals who are lower on collective self-esteem and too eager to interact excessively online with their friends to make these connections. Due to their perceived feelings of uncertainty within their social group, they may be interacting negatively with other users online unintentionally as a way to avoid real-life conflict, and this may be proving to have an impact on their levels of depression. 
Loneliness. Somewhat surprisingly, time spent on Facebook was not predictive of greater feelings of loneliness. It may be however, that the amount of time spent online is not what is directly impacting well-being, but generally, the belief in the importance that online mediums like Facebook play in maintaining friendships online; that is related to feelings of loneliness. The second hypothesis confirmed these assumptions, as Facebook Importance positively predicted feelings of loneliness among university students. Among those researchers who have studied the impact of Internet use on loneliness, Kraut et al. (1998), and Nie (2001) studied lonely people's preference for Internet use; or the idea of feeling that it was important to connect with people online. McKenna and her colleagues (2002) found that lonely people were more likely to use online chat rooms and newsgroups to form close relationships with those with whom they met online. Lou (2009) further suggests that university-aged students were found to be at high risk of loneliness during the transition to college when they were faced with the stresses of living away from their family and friends and lacked their previous social support system. Arguably then, it is no surprise that many first year students from the current study would be placing greater emphasis on the importance of the social medium to connect with others and in turn may be feeling a greater sense of loneliness without the opportunity to engage physically with their support system.

While it was anticipated that the three Facebook Engagement Factors would predict loneliness equally, only Monitoring Social ties proved to have a significant positive relationship with loneliness. This finding indicates that perhaps passively monitoring social ties on Facebook leads individuals to feel as though they are less connected to their friends then they would hope to be and are rather just sitting on the 
side lines, observing the daily events in their friends lives. Van der Aa, Overbeek, Engels, Scholte, Meerkerk, \& Van den Eijnden (2009) proposed that emerging adults who are socially marginalized and lonely are particularly vulnerable for developing compulsive internet usage, and in particular, engaging online passively (i.e. just simply looking on other's pages, and not directly interacting with their friends online) with their Facebook friends (Van der Aa et al., 2009). These individuals are prone to interacting negatively (i.e. demonstrating jealous tendencies and instigating conflict) online because they are often desperately seeking out ways to compensate for their lack of social experience offline (Van der Aa et al., 2009). Unfortunately, when people begin to interact excessively online, they have little to no time for engaging with social contacts in their daily lives, which places them at a greater risk for developing further feelings of loneliness (Van der Aa et al., 2009).

As predicted, there was a negative main effect of collective self-esteem on loneliness, where individuals with a stronger sense of their group membership were particularly vulnerable to feelings of loneliness. This finding is consistent with literature that states that the social lives and group memberships of people who self-disclose as being lonely have suggested that they often have fewer and less close relationships than non-lonely people (Jones, 1982; Stokes, 1985; Wheeler, Reis, \& Nezlak, 1983; Williams \& Solano, 1983). Not surprisingly then, it is fair to assume that the more likely you are to feel as through you have a strong group membership within your social circle, the more likely you are to have greater feelings of loneliness. The most important finding in considering levels of collective self-esteem however, came from two significant interactions. The relationship between Facebook Preference and loneliness, and 
Monitoring Social Ties and loneliness both varied as a function of collective self-esteem, albeit in different directions. The relationship between Facebook Preference and loneliness was strongest for individuals higher on collective self-esteem, but the relationship between Monitoring Social Ties was strongest for individuals lower on collective self-esteem.

Findings indicate that individuals with a stronger sense of group membership may be at risk for placing less emphasis on using Facebook as the primary means for social interactions, leading to a greater vulnerability to loneliness. While research is somewhat conflicted on the topic of social networking sites and loneliness, one study (Moody, 2001) found that with a high rate of time spent online, individuals may spend more energy cultivating a network of relations and support from other users and will begin to feel a sense of belonging to a community. Yet, arguably, if individuals feel as though they have a strong existing social membership offline, they may be less likely to choose to engage online to develop a network of social relations. Consistent with previous researchers (Ellison et al., 2007; Pempek et al., 2009), students mainly used Facebook for social purposes rather than any other purpose. It appears, therefore, that Facebook fulfills its role as it was intended by its creators: to support social networks (Kalpidou et al., 2011; Akyildiz \& Argan, 2011). It is also revealed that Facebook is not generally used for meeting new people as suggested by Ellison et al. (2007), but rather Facebook is used to keep contact with an existing friend or someone they met socially rather than use involving meeting new people and creating new social networks (Akyildiz \& Argan, 2011). As such, if individuals with higher collective self-esteem are not using Facebook as the primary means to interact with their friends and individuals from their social 
group, unless everyone else in their social group follows suit, they may begin to miss out on the different kinds of relations that occur online (i.e. being invited to special events, keeping in touch with close friends away from home, etc. (Moorman \& Bowker, 2011)), and as such, may begin to feel lonely.

While the current study did not break down loneliness into emotional or social loneliness, this particular finding from the current study could perhaps be explained by the fact that individuals who have a high sense of belonging with their social groups may be less likely to turn to the internet to further interact and connect with these social ties (Moody, 2001), as they feel that they have a well established support system within their existing social group. By not utilizing Facebook as the primary means to communicate, however, this decreased emphasis on their preference for this medium could be what is impacting their feelings of emotional loneliness, and causing them to feel as though they are not engaging in all opportunities to further intimate closeness with these friends within their strong social group (Moody, 2001). As such, it is no surprise that in not using Facebook as the preferred means of communication with friends, despite feeling a strong sense of group membership, greater feelings of loneliness and arguably, perceived social isolation could ensue.

Lastly, the result suggesting that the relationship between Monitoring Social Ties on Facebook and loneliness was strongest for individuals lower on collective self-esteem, is supported by research findings that suggest that individuals who turn to online relationships for social interaction may form unrealistic expectations regarding these relationships (Dowdell \& Bradley, 2010). Oftentimes, users can become fixated on the online friendship, believing that they can depend on these online friends for all social 
contact and support, as well as being active in their daily life events (Dowdell \& Bradley, 2010), yet often end up feeling a sense of isolation and loneliness (Dowdell \& Bradley, 2010).

Similarly with the findings from the current study, it may be that individuals are turning to Facebook to keep tabs on their weaker social ties because they perceive less intimacy and supportiveness in their existing friendships (La Greca \& Lopez, 1998), and may be using this site to enhance the connectedness within their relationships with existing friends within their established social groups to get closer to a connect with them online by viewing and "checking in" on what their friends are doing. As the results show, this is particularly problematic for individuals who not only do not have a satisfying social group, but who also do not feel a sense of belonging or social identity within their social group. Loneliness often occurs when one is dissatisfied with the strength and bond of existing relationships (Peplau, Russell, \& Heim, 1979), and the ease at which individuals can passively monitor what their social ties are doing online, may further increase their feelings of loneliness.

\section{Theoretical Implications}

In terms of theoretical implications, the present study contributes valuable and innovative research information to aid in the understanding of how friendships are maintained on Facebook. First, the current study provides support for Gangadharbatla's (2008) research on social networking sites and the idea that the belief towards the importance of such sites shapes interactions online among friends. Findings from the present study reinforce the notion that the belief towards the importance of online social mediums, in this case Facebook, impacts how people engage interpersonally with their 
friends online. Indeed, findings suggest that feeling as though Facebook is important to maintaining a friendship encourages users to prefer Facebook as the primary means of communication. With this finding, it appears that users have a preference towards using Facebook for the majority of their interactions and are using this method of communication to deal with both the positive and negative aspects of interpersonal relations. As a result of the user's strong belief in the importance that Facebook plays in maintaining friendships, users are looking to Facebook to managing conflict within their friendships online, as well as to passively monitor what is occurring within the daily lives of their friends. This has theoretical implications for future research which examines online interactions among close friends. As generations continue to use Facebook heavily in their daily lives, the results of this study indicate that further research Facebook and factors that influence an individuals' usage is warranted. These questions will have to be investigated in greater detail to obtain a better understanding of the ways in which people continue to use Facebook to engage with their friends online and what it is about the social medium that draws them in. As we begin to unravel these complex questions regarding the role of technology in our lives, we may find that we have to alter our use of these novel communication tools, or we may have to learn to develop online behaviours in ways that are more beneficial to our psychological health.

In addition to the finding that the belief in the importance of Facebook predicted Facebook usage and Engagement, the present study further built upon Gangadharbatla (2008)'s model by utilizing collective self-esteem as a moderator in these relationships. Findings from the present study reinforce the importance of group membership to individuals' self-concept, as well as their social behavior towards others (Luhtanen \& 
Crocker, 1992); thus helping to shape interactions between friends within their social group (Tajfel, 1982; Tajfel \& Turner, 1979, 1986). The current study's findings confirm that collective self-esteem indirectly influences outcomes and shapes the relationship between Facebook Importance and Facebook Engagement Factors, as well as their relationship to well-being. This is an important finding in that feeling secure in one's social group may actually relate to the kinds of interpersonal interactions that are occurring on Facebook, which in turn has implications for the social and psychological well-being of the user.

Due to the fact that researchers have struggled to identify factors that predict online friendship interactions and Facebook usage on Facebook, little consensus exists among researchers in terms of which factors play the most critical role. The present study fills a gap in that it pinpoints specific individual beliefs about Facebook Importance and the need to belong to a group, that directly predict and moderate Facebook Engagement Factors and indices of well-being. In addition to that, the findings of the current study point specifically at the fact that Facebook Importance and Engagement were significant predictors of negative aspects of well-being, contributing further to the findings of some of the existing literature on social networking sites and negative wellbeing (Valkenburg et al., 2006; Kim et al., 2009) most notably, depression and loneliness. What is imperative in the current study's findings is that there were moderating factors at play that haven't been incorporated into previous studies, and this enhances the potential to learn more empirically with respect to social networking, friendships and well-being. However, replication of these results, incorporating the same measures using other first year students at other Canadian universities remains essential. 


\section{Limitations and Future Research}

While this study does contribute important findings to the literature, several limitations of the study deserve mention. One such limitation was the use of a convenience sample, which included first year university students from Carleton University, and is therefore not representative of Canadian first year students in general. Thus, it is quite possible that the findings from this study could be either more or less pronounced in other first year student samples. A future study may benefit by including first-year students from different regions to permit a more diverse sample. This would result in a more representative sample and expand the generalizability of the current study's results.

A second limitation was the cross-sectional nature of the study, which prevents one from inferring a causal association between Facebook Importance and Facebook Engagement Factors, and this relationship in predicting indices of well-being. That is to say, while it is suspected that Facebook Importance predicts Facebook Engagement Factors, and subsequently, indices of well-being, other explanations should not be discounted. For example, it is possible that specific interpersonal events in a given day (i.e. a birthday or special event such as an engagement) may lead individuals to perceive Facebook as being highly important to maintaining their online friendships. Similarly, while it is suspected that Facebook Importance contributes to depression and loneliness among first year university students, an alternative explanation could be that the mechanisms involved in negative indices of well-being among students in transition, lead them to place a greater emphasis on Facebook as being an important means to consistently maintaining past and new friendships online. In a future study, it may be of 
interest to specifically study the bi-directional nature of the relationship between Facebook Importance and Facebook Engagement Factors and indices of well-being.

Further, self-report questionnaires were used to assess the main variables in the current study, and therefore results of the present study are hindered by common method variance that is associated with using self-report measures. It should be noted however that all self-report measures used in this study have strong psychometric properties that support their use and help validate the findings from this study. It is also important to acknowledge that perceptions of Facebook Importance can vary among members and that the self-reported questionnaire may not capture aspects of their belief in the importance of this social medium to communicate with their friends.

Future research may also consider incorporating more qualitative measures, particularly if beliefs and attitudes towards the importance of Facebook are to be fully investigated, as well as perceived social status within a social group. Qualitative responses may be able to capture information that simply cannot be quantified. For example, incorporating qualitative measures would allow students to provide explanations for their attitudes toward Facebook and experiences with dealing with their friendships online, in addition to how their sense of belonging within their social group may encourage them to participate in one online activity versus another. Such responses could provide important insight into emerging adult friendships on Facebook as it relates to usage, relational maintenance, and ultimately, well-being.

Finally, given that there are a large number of factors that may influence the relationship between Facebook Importance and Facebook Engagement Factors and wellbeing, it may be viewed as a limitation that only one moderating variable was considered 
in the present study. Including only one moderating variable was motivated by the fact that there does not appear to be any research examining potential moderating variables on the relationship between Facebook Importance and Facebook Engagement Factors and well-being, therefore examining perceived social belonging/group membership. Future work in this area may benefit by including other moderating variables. Since this study examined group belonging, a peer-based model for Facebook Engagement Factors, perhaps a further study could enhance this conceptualized model and examine similar moderating factors such as social capital or perceived peer social support when examining the relationship between Facebook Importance, Facebook Engagement Factors, and well-being. 


\section{Conclusion}

In spite of these limitations and the need for future research, the current study presented significant findings that build on the current body of literature. Firstly, it's important to note that the current study found that younger participants, those aged 17-24 reported the highest levels of Facebook involvement and reported the greatest number of Facebook friends. This has further implications for research into online friendships, as younger cohorts remain heavy users of Facebook and appear to be the most at risk for reduced well-being. This study also demonstrated that some aspects of Facebook use, Facebook Engagement Factors and subsequent well-being can be explained by an individual's belief towards the importance of Facebook, as well as the indirect relationship these variables had with collective self-esteem, or the perceived strength of one's social group membership. In the current study, the beliefs surrounding the importance of Facebook were significantly related to Facebook usage and engagement behaviours, while the varying levels of collective self-esteem played an indirect role alongside Facebook Importance and Engagement in predicting well-being for first year university students. Additionally, it's important to note that the Facebook variables in the current study were significant risk factors for greater negative indices of well-being, in particular, depression and loneliness, but were not significantly related to positive aspects of well-being. It is important that future research consider more in-depth and longitudinal studies that control for beliefs towards the importance of Facebook, collective self-esteem and belonging for incoming first year students and investigate these online interactions in order to better understand the phenomenon that is online friendships and its impact on long-term well-being. 


\section{References}

Ajzen, I., \& Fishbein, M. (1980). Understanding attitudes and predicting social behaviour. Englewood Cliffs, NJ: Prentice-Hall.

Ajzen, I., \& Sexton, J. (1999). Depth of Processing, Belief Congruence, and AttitudeBehavior Correspondence. In S. Chaiken \& Y.Trope, (Ed.), Dual-process theories in social psychology (pp. 117-138). New York: The Guilford Press.

Akyıldı,, M., \& Argan, M. (2011). Using Online Social Networking: Students' Purposes of Facebook Usage at the University of Turkey. (Unpublished doctoral dissertation).University of Istanbul, Turkey.

Allport, G.W. (1935). Attitudes. In C. Murchison (Ed.), Handbook of Social Psychology (pp. 107-132). Worcester, Mass: Clark University Press.

Alonzo, M., \& Aiken, M. (2004). Flaming in electronic communication. Decision Support Systems , 36, 205-213.

Anderson, T.L. (2005). Relationships among internet attitudes, internet use, romantic beliefs, and perceptions of online romantic relationships. Cyberpsychology and Behaviour, 8, 521-531.

Argyle, M. (2001). The psychology of happiness. London: Taylor \& Francis.

Arnett, J. J. (1998). Learning to stand alone: The contemporary American transition to adulthood in cultural and historical context. Human Development, 41, 295-315.

Arnett, J.J. (2000). Emerging adulthood: A theory of development from the late teens through the twenties. American psychologist, 55, 469-480.

Auhagen, A. (1996). The Diversity of human relations. New York, NY, US: Cambridge University Press. 
Barry, C. M., \& Madsen, S. D. (2009). Friendship and romantic relationship qualities in emerging adulthood: Differential associations with identity development and achieved adulthood criteria. Journal of Adult Development, 16, 209-222.

Bartlet, M.S. (1954). A note on the multiplying factors for various chi square approximation. Journal of the Royal Statistical Society, 16, 296-298.

Baumeister, R. F. (1998). The self. In D. T. Gilbert, S. T. Fiske, \& G. Lindzey (Ed.), The Handbook of social psychology (pp. 680-740). New York: McGraw-Hill.

Baumeister, R.F., \& Leary, M.R. (1995). The need to belong: Desire for interpersonal attachments as a fundamental human motivation. Psychology Bulletin, 117, 497529.

Berndt, T. J., \& Keefe, K. (1995). Friend's influence on adolescents' adjustment to school. Child Development, 66, 1312-1329.

Bingham, N., Holloway, S., \& Valentine, G. (1999). Proceedings from: The Royal Geographical Society with the Institute of British Geographers Annual Conference. Leicester, UK.

Blieszer, R., \& Adams, R. (1992). Adult Friendship. Newbury Park, CA: Sage Publications. Boase, J., Horrigan, J. B., Wellman, D., \& Rainie, L. (2006), The strength of Internet ties. Washington, DC: Pew Internet \& American Life Project.

Bohrnstedt, G.W., \& Felson, R.B. (1983). Examining the relationship between children's actual and perceived performances and self-esteem: A comparison of several causal models. The Journal of Personality and Social Psychology, 45, 43-56.

Boneva, B. S., Quinn, A., Kraut, R. E., Kiesler, S., \& Shklovski, I. (2006). Teenage communication in the instant messaging era. In R. Kraut M. Brynin \& S. Kiesler 
(Ed.), Information technology at home (pp. 612-672). Oxford University Press.

Bowker, A., \& Ramsay, K. (2012). Adolescent friendship. In R.J.R Levesque (Ed.), Encyclopedia of Adolescence.

Boyd, D. (2008). Why youth (heart) social network sites: The role of networked publics in teenage social life. In. D. Buckingham (Ed.), Youth, Identity, and Digital Media (pp. 119-1442). Cambridge, MA: MIT Press.

Boyd, D. \& Ellison, N. B. (2007). Social Networking sites: definite, history, and scholarship. Journal of Computer-Mediated Communication, 7(1), 99-122.

Brown, B. B. (2004). Adolescents' relationships with peers. In R. M. Lerner \& L. Steinberg (Ed.), Handbook of adolescent psychology (pp. 363-394). Hoboken, NJ: Wiley.

Buote, V. M., Pancer, S. M., Pratt, M. W., Adams, G., Lefcovitch, S. B., Polivy, J., \& Wintre, M. G. (2007). The importance of friends: Friendship and adjustment among 1st-year university students. Journal of Adolescent Research, 22, 665-689.

Buhrmester, D., \& Furman, W. (1987). The development of companionship and intimacy. Child Development, 58, 1101-1113.

Cattell, R. B. (1966). Handbook of multivariate experimental psychology. Chicago: Rand McNally. 
Chou, G.H.T., \& Edge, N. (2012). They Are Happier and Having Better Lives than I Am: The Impact of Using Facebook on Perceptions of Others' Lives. Cyberpsychology, Behavior, and Social Networking. 15(2), 117-121

Christofides, E., Muise, A., \& Desmarais, S. (2009). More information than you ever wanted: Does Facebook bring out the green-eyed monster of jealousy? CyberPsychology and Behavior, 12, 441-444.

Clark, D. J., Frith, K. H., \& Demi, A. S. (2004). The physical, behavioral, and psychosocial consequences of Internet use in college students. Computers, Informatics, Nursing, 22, 153-161.

Coley, T. (2006). Students and cyber communities. (Unpublished doctoral dissertation). University of South Carolina, South Carolina.

Crocker, J., \& Luhtanen, R. (1990). Collective self-esteem and in-group bias. Journal of Personality and Social Psychology, 58, 60-67.

Daugherty, T., Eastin, M., \& Gangadharbatla, H. (2005). e-CRM: Understanding Internet Confidence and Implications for Customer Relationship Management. In I. Clark III \& T. Flaherty (Ed.), Advances in Electronic Marketing (pp.67-82). Harrisonburg, VA: James Madison University, Idea Group Publishing, Inc.

Davis, K.E., \& Todd, M.J. (1985). Assessing friendship: Prototypes, paradigm cases and relationship description. Thousand Oaks, CA, US: Sage Publications, Inc.

DeAndrea, D.C., Ellison, N.B., LaRose, R., Steinfield, C., \& Fiore, A. (2011). Serious social media: On the use of social media for improving students' adjustment. Internet and Higher Education, 21, 241-263.

Demir, M., Ozdemir, M., \& Weitekamp, L. A. (2007). Looking to happy tomorrows with 
friends: Best and close friendships as they predict happiness. Journal of Happiness Studies, 8, 243-271.

Diener, E., Emmons, R. A., Larsen, R. J., \& Griffin, S. (1985). The Satisfaction With Life Scale. Journal of Personality Assessment, 49, 71-75.

Donath, J., \& Boyd, D. (2004). Public displays of connection. BT Technology Journal, 22(4), 71-82.

Dowdell, E.B. \& Bradley, P.K. (2010). Risky internet behaviors: A case study of online and offline stalking. The Journal of School Nursing, 26, 436-442.

Ellison, N. B., Steinfield, C., \& Lampe, C. (2007). The benefits of Facebook "friends:" Social capital and college students' use of online social network sites. Journal of Computer-Mediated Communication, 12(4), article 1.

Erikson, E. H. (1959). Identity and the life cycle: Selected papers. Oxford: International Universities Press.

Facebook (2012). Retrieved from http:// Facebook.com

Freiert, M. (2007). (December 2009). Facebook now ranked 3rd in page views; Myspace down nearly $20 \%$.Complete, Inc. Retrieved from http://blog.compete.com/2007/09/11/Facebook-third-biggest-site-page-viewsMyspace-down/

Friedman, R. A., \& Currall, S. C. (2003). Conflict escalation: Dispute exacerbating elements of e-mail communication conflict. Human Relations, 56(11), 1325-1347.

Gangadharbatla, H. (2008). Facebook me: Collective self-esteem, need to belong, and Internet self-efficacy as predictors of the IGeneration's attitudes towards social networking sites. Journal of Interactive Advertising, 8, 5-15. 
Gemmill, E., \& Peterson, M. (2006). Technology use among college students: Implications for student affairs professionals. NASPA Journal, 43(2), 280-300.

Golder, S., Wilkinson, D., \& Huberman, B. (2006). Rhythms of social interaction: Messaging within a massive online network. In C. Steinfield, B.T. Pentland, M. Ackerman \& Contractor (Ed.), Communities and Technologies 2007:Proceedings of the third international conference on communities and technologies (pp.41-66). London: Springer.

Gross, E. F., Juvonen, J., \& Gable, S. L. (2002). Internet use and well-being in adolescence. Journal of Social Issues, 58(1), 75-90.

Harrison, T. M., \& Falvey, L. (2002). Democracy and new communication technologies. Communication Yearbook, 25, 1-33.

Harter, S. (1988). Manual for the Self-Perception Profile for Adolescents. University of Denver.

Harter, S. (1999). The construction of the self: a developmental perspective. New York: Guilford Press.

Hays, R.D., \& DiMatteo, M.R. (1987). A short-form measure of loneliness. The Journal of Personality Assessment, 51, 69-81.

Hays, R. B. (1984). The development and maintenance of friendship. Journal of Social and Personal Relationships, 1, 75-98.

Hays, R. B. (1985). A longitudinal study of friendship development. Journal of Personality and Social Psychology, 48(4), 909-924. 
Hogg, M., \& Abrams, D. (1990). Social Motivation, Self-Esteem and Social Identity. In D. Abrams and M.A. Hogg, (Ed.), Social Identity Theory: Constructive and Critical Advances (pp. 28-47). London: John Wiley \& Sons.

Hoffman, P. (2008). But are we really friends? Online social networking in. undergraduate students (Unpublished doctoral dissertation). University of Akron, Ohio.

Jackson, L., Pancer, S.M., Pratt, M.W., \& Hunsberge, B.E. (2000). Great Expectations: The Relation Between Expectancies and Adjustment During the Transition to University Journal of Applied Social Psychology, 30, 2100-2125.

Joinson, A. (2008). Looking at', 'Looking up' or 'Keeping up with' people? Motives and uses of Facebook. 2008 Proceedings from CHI-Online Social Networks. Florence, Italy.

Jones, W.H. (1982). Loneliness and social behaviour. In L.A. Peplau \& D. Perlman (Ed.), Loneliness: A sourcebook of current theory, research, and therapy (pp. 238-254). New York: John Wiley.

Jones, S. (2002). The Internet goes to college. (June 2012). Retrieved from: http://www.pewinternet.org/pdfs/PIP_College_Report.pdf

Kaiser, H. (1970). A second generation Little Jiffy. Psychometrica, 35, 401-415.

Kaiser, H. (1974). An index of factorial simplicity. Psychometrica, 39, 31-36.

Kalpidou, M., Costin, D., \& Morris, J. (2011). The relationship between Facebook and the well-being of undergraduate college students. Cyberpsychology, Behavior and Social Networking, 14 (4), 183-189.

Keenan, A., \& Shiri, A. (2009). Sociability and social interaction on social networking 
websites. Library Review, 58 (6), 438-450.

Kenniston, K. (1970). Youth, a new stage of life. American Scholar, 39. 631-643.

Kenny, M. (1987). The extent and function of parental attachment among first year college students. Journal of Youth and Adolescence, 16, 17-29.

Kim, J., LaRose, R., \& Peng, W. (2009). Loneliness as the cause and effect of problematic Internet use: The relationship between internet use and psychological well-being. CyberPsychology and Behavior, 12, 451-455.

Knight, R.G.; Williams, S., McGee, R., \& Olaman, S. (1997). Psychometric properties of the Centre for Epidemiologic Studies Depression Scale (CES-D) in a sample of women in middle life. Behaviour Research and Therapy, 35, 373-380.

Kraut, R., Kiesler, S., Boneva, B., Cummings, J., Helgeson, V., \& Crawford, A. (2002). Internet paradox revisited. Journal of Social Issues, 58, 49-74.

Kraut, R., Patterson, M., Lundmark, V., Kiesler, S., Mukhopadhyay, T., \& Scherlis,W. (1998). The Internet paradox: A social technology that reduces social involvement and psychological well-being. American Psychologist, 53, 1017-1032.

La Gaipa, J.J. (1977) Testing a multi-dimensional approach to friendship. In S.W. Duck (Ed.), Theory and Practice in Interpersonal Attraction (pp. 249-270). New York: Academic Press.

La Greca, A.M. and Lopez, N. (1998). Social anxiety among adolescents: Linkage with peer relations and friendships. Journal of Abnormal Child Psychology, 26, 83-94.

Lampe, C., Ellison, N., \& Steinfield, C. (2006). A Face(book) in the crowd: Social searching vs. social browsing. Proceedings of CSCW-2006, New York. 
Lampe, C., Ellison, N., \& Steinfield, C. (2007). A familiar Face(book): Profile elements as signals in an online social network. Proceedings of Conference on Human Factors in Computing Systems, New York.

Landry, E. M. (2000). Scrolling around the new organization: The potential for conflict in the on-line environment. Negotiation Journal, 16(2), 133-142.

Leary, M. R., Tambor, E. S., Terdal, S. K., \& Downs, D. L. (1995). Self-esteem as an interpersonal monitor: The sociometer hypothesis. Journal of Personality and Social Psychology, 68, 518-530.

Lee, S.Y., \& Boyer L. (2007, October). A place of their own: an exploratory study of college students' uses of Facebook. Proceedings from the 57th International Communication Association Annual Meeting, San Francisco, CA.

Lou, L.L. (2009). Loneliness, friendship, and self-esteem: First year college students' experience of using Facebook. (Unpublished doctoral dissertation). University of Albany.

Lutahnen, R., \& Crocker, J. (1992). A Collective self-esteem scale: Self-evaluation of one's social identity. Society for Personality and Social Psychology, 18, 302-318.

Markus, M. L. (1994). Finding a happy medium: Explaining the negative effects of electronic communication on social life at work. ACM Transactions on Information Systems, 12(2), 119-149.

Mauk, A.J. (2011). Friendship and student engagement, achievement, and persistence in college. (Unpublished doctoral dissertation). Florida State University.

Mazer, J.P., R.E. Murphy, and C.J. Simonds. (2007). I'll see you on 'Facebook': The effects of computer-mediated teacher self-disclosure on student motivation, 
affective learning, and classroom climate. Communication Education 56, 1-17.

McKenna, K., \& Bargh, J. (2000). Plan 9 from cyberspace: The implications of the Internet for personality and social psychology. Personality and Social Psychology Review, 4, 57-75.

McKenna, K.Y.A., Green, A.S., \& Gleason, M.E.J. (2002). Relationship formation on the Internet: What's the big attraction? Journal of Social Issues, 58(1), 9-31.

Mesch, G. \& Talmud, I. (2006). The quality of online and offline relationships: The role of multiplexity and duration of social relationships. The Information Society, 22, $137-148$.

Mitrano, T. (2006). A Wider World: Youth, Privacy, and Social Networking Technologies. Educational Review, 41, 16-29.

Moody, J. (2001). Peer influence groups: identifying dense clusters in large groups. Social networks, 23, 261-283.

Moore, D. A., Kurtzberg, T. R., Thompson, L. L., \& Morris, M. W. (1999). Long and short routes to success in electronically mediated negotiations: Group affiliations and good vibrations. Organizational Behavior and Human Decision Processes, $77(1), 22-43$.

Moorman, J., \& Bowker, A. (2011). The university Facebook experience: Social networking and the quality of interpersonal relationships. The American Association of Behavioral and Social Sciences Journal, 15, 1-23.

Morahan-Martin, J., \& Schumacher, P. (2000). Incidence and correlates of pathological Internet use among college students. Computers in Human Behavior, 16, 13-29. 
Morgan, C., \& Cotton, S.R. (2003). The relationship between Internet activities and depressive symptoms in a sample of college freshmen. CyberPsychology and Behavior 6, 133-42.

Nelson, L.J., \& McNamara-Barry, C. (2005). Distinguishing Features of Emerging Adulthood: The Role of Self-Classification as an Adult. Journal of Adolescent Research, 20, 242-262.

Nie, N. (2001). Sociability, interpersonal relations, and the Internet: Reconciling conflicting findings. American Behavioral Scientist, 45, 420-435.

Osborn, J.L. (2000). A comparison of the defining characteristics, constitutive speech events, and relational provisions of online and offline friendships. (Unpublished doctoral dissertation).

O’Sullivan, P. B., \& Flanagin, A. J. (2003). Reconceptualizing "flaming" and other problematic messages. New Media \& Society, 5(1), 69-94.

Pancer, S. M., Hunsberger, B., Pratt, M.W., \& Alisat, S. (2005). Bridging troubled waters: Helping students to make the transition from high school to university. Guidance and Counselling, 19, 184-190.

Papacharissi, Z., \& Rubin, A. (2002). Predictors of Internet use. Journal of Broadcasting \& Electronic Media, 44,175-196.

Parks, M. R., \& Floyd, K. (1996). Making friends in cyberspace. Journal of Communication, 14, 85-108.

Parks, M., \& Roberts, L. (1998). Making MOOsic: The development of personal relationships on line and a comparison to their off-line counterparts. Journal of Social and Personal Relationships, 15, 517-537. 
Pavot, W., \& Diener, E. (1993). Review of the satisfaction with life scale. Psychological Assessment, 5, 164-172.

Pempek, T.A., Yermolayeva, Y.A., \& Calvert, S.L. (2009). College students' social networking experiences on Facebook. Journal of Applied Developmental Psychology, 30, 227-238.

Peplau, L.A., Russell, D. \& Heim, M. (1979). The experience of loneliness. In I. Frieze, D.Bar- Tal, \& J.S. Carroll (Ed.), New approaches to social problems: Applications of attribution theory (pp. 53-78). San Francisco: JosseyBass.

Perry, M. (2010). Face to face versus computer-mediated communication: Couples' satisfaction and experience across conditions. (Unpublished doctoral dissertation). University of Kentucky.

Pratt, M.W., Danso, H. A., Arnold, M. L., Norris, J. E., \& Filyer, R. (2001). Adult generativity and the socialization of adolescents: Relations to mothers' and fathers' parenting beliefs, styles, and practices. Journal of Personality, 69, 89119.

Radloff, L.S. (1977). The CES-D scale: a self-report depression scale for research in the General population. Applied Psychological Measurement 1, 385-401.

Reis, H. T., Sheldon, K. M., Gable, S. L., Roscoe, J., \& Ryan, R. M. (2000). Daily wellbeing: The role of autonomy, competence, and relatedness. Personality and Social Psychology Bulletin, 26, 419-435.

Reis, H. T., \& Shaver, P. (1988). Intimacy as an interpersonal process. In S. Duck (Ed.), Handbook of personal relationships (pp. 367-389). Chichester, UK: Wiley. 
Rheingold, H. (1993). The virtual community: homesteading on the electronic frontier.

New York: Addison- Wesley.

Richey, M.H, \& Richey, H.W. (2006) The significance of best-friend relationships in adolescence. Psychology in the school, 17, 536-540.

Ridings, C., \& Gefen, D. (2004). Virtual Community Attraction: Why People Hang Out Online. Journal of Computer-Mediated Communication, 10 (1).

Rindfuss, R. R. (1991). The young adult years: Diversity, structural change, and fertility. Demography, 28, 493512.

Roberts, R.E., Vernon, S.W., \& Rhoades, H.W. (1989). Effects of language and ethnic status on reliability and validity of the Center for Epidemiologic StudiesDepression Scale with psychiatric patients. Journal of Nervous and Mental Disease, 177, 581-592.

Rubin, A.M. (1981). An examination of television viewing motives. Communication Research, 8, 141-165.

Rubin, R.B., \& Rubin, A.M. (1994). Antecedents of interpersonal communication motivation. Communication Quarterly, 40, 305-317.

Schlenker, B. R. (1980). Impression management: The self-concept, social identity, and interpersonal relations. Monterey, CA: Brooks/Cole Publishing.

Schutz, W.C. (1966), The Interpersonal Underworld. Palo Alto, CA: Science and Behavior Books.

Seligman, M. (2011). Flourish. New York: Simon \& Schuster.

Sensales, G., \& Greenfield, P.M. (1995). Attitudes toward computers, science, and technology: A cross-cultural comparison between students in Rome and Los 
Angeles. Journal of Cross-Cultural Psychology, 26, 229-242.

Shamp, S.A. (1991). Mechanomorphism in perception of computer communication partners. Computers in Human Behavior, 7, 147-161.

Shaw, B., \& Gant, L. (2002). In defense of the Internet: The relationship between Internet communication and depression, loneliness, self-esteem, and perceived social support. CyberPsychology and Behavior, 5, 157-171.

Sheldon, P. (2008). The relationship between unwillingness-to-communicate and students' Facebook use. Journal of Media Psychology, 20, 67-75.

Steinfield, C., Ellison, N., \& Lampe, C. (2008). Social capital, self-esteem, and use of online social network sites: A longitudinal analysis. Journal of Applied Developmental Psychology, 29, 434-445.

Stokes, J. (1985). The relation of social network and individual difference variables and loneliness. Journal of Personality and Social Psychology, 48, 981-990.

Sullivan; H. S. (1953). The interpersonal theory of psychiatry. New York: Norton.

Subrahmanyam, K., \& Greenfield, P. M. (2008). Communicating online: Adolescent relationships and the media. The Future of Children: Children and Media Technology, 18, 119-146.

Subrahmanyam, K., Reich, S. M., Waechter, N., \& Espinoza, G. (2008). Online and offline social networks: use of social networking sites by emerging adults. Journal of Applied Developmental Psychology, 29(6), 420-433.

Suler, J. (1996). Bringing online and offline living together: the integration principle. Retrieved from: www.rider.edu/ suler/psycyber/integrate.html. 
Tajfel, H. (1981). Human Groups and Social Categories. Cambridge: Cambridge University Press.

Tajfel, H., \& Turner, J. C. (1979). An integrative theory of intergroup conflict. In W. G.

Austin \& S. Worchel (Ed.), The social psychology of intergroup relations (pp. 33-47). Monterey, CA: Brooks/Cole.

Tajfel, H., \& Turner, J. C. (1986). The social identity theory of intergroup behavior. In W. G. Austin \& S. Worchel (Ed.), The social psychology of intergroup relations (pp. 7-24). Chicago: Nelson-Hall.

Tidwell, L.C., \& Walther, J.B. (2002). Computer-Mediated Communication Effects on Disclosure, Impressions, and Interpersonal Evaluations. Human Communication Research, 28, 317-348.

Tokuno, K. A. (1986). The early adult transition and friendships: Mechanisms of support. Journal of Adolescence, 21, 593-606.

Tong, S.T., Van Der Heide, B., \& Langwell, L. (2008). Too much of a good thing? The relationship between number of friends and interpersonal impressions on Facebook. Journal of Computer-Mediated Communication, 13, 531-549.

Valkenburg, P. M., Peter, J., \& Schouten, A. P. (2006). Friend networking sites and their relationship to adolescents' well being and social self-esteem. CyberPsychology and Behavior, 9, 584-590.

Valkenburg, P. M., \& Peter, J. (2007). Preadolescents' and adolescents' online communication and their closeness to friends. Developmental Psychology, 43, $267-277$. 
Van der Aa, N., Overbeek, G., Engels, R.C.M. E., Scholte, R.H.J., Ron H. J. Scholte, Meerkerk, G.J., \& Van den Eijnden, R. J. J. M. (2009). Daily and compulsive internet use and well-being in adolescence: A diathesis-stress model based on big five personality traits. Journal of Youth and Adolescence, 38, 765-776.

Vasalou, A., Joinson, A.N., \& Courvoisier, D. (2010). Cultural differences, experience with social networks and the nature of true commitment in Facebook. International Journal of Human-Computer Studies, 68, 719-728.

Vitak, M. (2008). Facebook "Friends": How Online Identities Impact Offline Relationships. Retrieved from http:// michiganstate.academica.edu/vitak/Papers/390880/Facebook_Friends_How_Onli ne_Identities_Impact_Offline_relations.

Voss, K., Markiewicz, D., \& Doyle, A.B. (1999). Friendship, marriage and self-esteem. Journal of Social and Personal Relationships, 16, 103-122.

Walther, J. B. (1992). Interpersonal effects in computer-mediated interaction: A relational perspective. Communication Research, 19, 52-90.

Walther, J.B. (1993). Impression development in computer-mediated interaction. Western Journal of Communication, 57, 381-398.

Walther, J.B. (1996). Computer-mediated communication: impersonal, interpersonal, and hyperpersonal interaction. Communication Research, 23, 3-43.

Walther, J. B., \& D'Addario, K. P. (2001). The impacts of emoticons on message interpretation in computer-mediated communication. Social Science Computer Review, 19, 323-345. 
Way, N., \& Greene, M. (2006). Trajectories of perceived friendship quality during adolescence: The patterns and contextual predictors. Journal of Research on Adolescence, 16, 293-320.

Weinstein, E., \& Rosen, E. (1991). The development of adolescent sexual intimacy: Implications for counseling. Adolescence, 26, 331-339.

Weiss, R. S. (1974). The provisions of social relationships. In Z. Rubin (Ed.), Doing unto others (pp. 17-26). Englewood Cliffs, NJ: Prentice-Hall.

Wellman, B., \& M. Gulia (1999). The Network Basis of Social Support: A Network is more than the sum of its ties. In B. Wellman (Ed.), Networks in the Global Village: Life in Contemporary Communities (pp.83-118). Boulder, CO: Westview Press.

Wellman, B., Salaff, J., Dimitrova, D., Garton, L., Gulia, M., \& Haythornthwaite, C. (1996). Computer networks as social networks: Collaborative work, telework, and virtual community. Annual Review of Sociology, 22, 213-238.

Wheeler, L., Reis, H., \& Nezlak, J. (1983). Loneliness, social interaction, and sex roles. Journal of Personality and Social Psychology, 45, 943-953.

Williams, J.G., \& Solano, C.H. (1983). The social reality of feeling lonely: Friendship and reciprocation. Personality and Social Psychology Bulletin, 9, 237-242.

Zhao, S., Grasmuck, S., \& Martin, J. (2008). Identity construction on Facebook: Digital empowerment in anchored relationships. Computers in Human Behavior, 24, $1816-1836$. 


\section{Appendix A. Informed Consent}

\section{Consent Form}

The purpose of an informed consent is to ensure that you understand the purpose of the study and the nature of your involvement. The informed consent must provide sufficient information so that you have the opportunity to determine whether you wish to participate in the study.

Study Title: How Facebook Gave Me 'Friends': The Impact of Facebook Importance on Engagement and Psychological Well-Being

Study Personnel: Dr. Anne Bowker (Faculty Sponsor, anne bowker@carleton.ca ) Jessica Moorman (M.A.Candidate, Jessica_moorman@carleton.ca )

Should you have any ethical concerns about this study please contact Dr. Monique Senechal, Chair of the Carleton University Ethics Committee for Psychology Research, at 520-2600 ext. 1155; monique_senechal@carleton.ca. For any other concerns about this research or how the study was conducted, please contact Dr. Anne Bowker, Chair of the Department of Psychology, at 520-2600 ext. 8218 or at anne bowker@arleton.ca.

Purpose and Task Requirements: We are interested in your Facebook use, as well as your attitudes towards the importance of Facebook in maintaining friendships and how this impacts psychological well-being. We will ask you to complete a questionnaire regarding some basic demographic information about yourself as well as your Facebook acvitities, Facebook usage and a questionnaire concerning your opinions on the importance of certain Facebook activities with regards to staying in contact with your friends. In addition, we also want to know how you feel about your social group and how accepted you feel by your friends. By participating in this study you are greatly assisting us to obtain basic knowledge about friendships online and how Facebook may aid in staying in touch with those friends. Be assured that your name will not be associated in any way with the research findings. Completion of this study should not take more than 45 minutes of your time and you will be given .5\% toward your final grade in any Introductory Psychology course.

Potential risk/discomfort: We can anticipate no physical discomfort to you as a result of your participation in this study. Your participation is solicited but is completely voluntary. The information collected in this study will be used only by the study investigators. Questions about this study should be directed to either of the researchers listed above.

Anonymity/Confidentiality: All information collected in this study will remain confidential. All questionnaires collected by the researcher will be kept secure and confidential, and will be used only by the study investigators. We will be asking you for your name and student number, in order to assign your credit for participation. However, your name and student number will not be associated in any way with your data, and all your responses will be anonymous. 
Right to Withdraw: Your participation in this study is entirely voluntary. At any point during the study you have the right not to complete certain questions or to withdraw from the current study with no penalty whatsoever.

I have read the above description of the study entitled "Friendship 2.0: How Managing Friendships Online Affects the Relationship Between Friendship Quality and Psychological Well-Being-Study 1" The data collected will be used for research and/or teaching purposes. By clicking the "Yes" link below, I indicate that I am at least 18 years of age and that I agree to participate in the study, and this in no way constitutes a waiver of my rights.

$$
\text { Yes - I grant consent No - I do not grant consent }
$$


Appendix B. Debriefing

\section{Debriefing}

Thank you for participating in this study! This post-survey information is provided to inform you of the exact nature of the research you just participated in.

What are we trying to learn in this research? The purpose of this research is to examine online friendships in first year university students. More specifically, the current study aimed to explore the characteristics of friendships by highlighting the important role that online networks play in supporting and fostering continued interactions among friendships. Of particular interest is what people are doing online with their friends and their perceived importance of these online interactions on Facebook. We are also interested in determining if there are other factors involved that may influence this relationship such as how accepted the person feels and their perceived group status.

In our study, participants are asked to share their beliefs regarding the importance of Facebook and how this impacts their engagement online (i.e. how they maintain friendships through Facebook). In the second half of the study, participants' beliefs regarding the importance of Facebook and their level of engagement was then used to predict their psychological well-being. The Facebook measures were created by the researchers, to capture the range of Facebook activities and purposes for engaging online, as well as popular online interactions online between friends. We were also interested in how other factors, such as collective self-esteem may impact this relationship.

\section{What are our hypotheses and predictions?}

We predicted that higher scores on Facebook Importance will predict greater Facebook usage and Facebook Engagement and that this relationship would be strongest for those higher on collective self-esteem. In turn, we expected this model to then predict greater psychological well-being.

Why is this important to scientists or the general public?

This research will contribute to psychologists' knowledge and understanding of friendships in an online context. Specifically, findings from this study will shed light on how people maintain friendships online using Facebook and what factors affect their engagement online with their friends and overall psychological well-being.

\section{What if I have questions later?}

If you have any further questions about this project or concerns about how it was conducted please contact Jessica Moorman (email: Jessica_moorman@carleton.ca), or Dr. Anne Bowker (Department of Psychology Carleton University, email: anne_bowker@carleton.ca, 520-2600 ext. 8218).

For ethical concerns regarding your treatment as a participant during this study, please contact Dr. Monique Senechal, Chair of the Carleton University Ethics Committee for Psychology Research, at 520-2600 ext. 1155; monique_senechal@carleton.ca. For any 
other concerns about this research, you may contact Dr. Anne Bowker, Chair of the Department of Psychology, at 520-2600 ext. 8218; psychchair@carleton.ca

Is there anything that I can do if I found this experiment to be emotionally draining?

We realize that some of the questions regarding friendship quality may have produced feelings of anxiety. If as a result of participating in this study you are currently feeling any anxiety or distress, or if you experience any such feelings in the future, we suggest that you make an appointment with the Carleton University Health and Counselling Services, 520-6674.

Thank you for participating in this study! We greatly appreciate your participation, but we ask that you refrain from discussing this study with potential participants (i.e., other PSYC 1001/1002/2001/2002 students) because their responses may be influenced. 


\section{Appendix C. Measures}

\section{Demographics Questionnaire}

In order to assign you credit for your participation, we require your name and student number. This information will be separated from the rest of your questionnaire data, and will not be associated with your responses in any way. This information will be held in strict confidentiality, and will not be used for any purpose other than to assign you credit for participating.

Name:

Student \#:

Age:

Gender: $\mathbf{M}$ $\mathrm{F}$

Are you from Ottawa: Yes/ No

If no, please answer where you are from: 
Part A:

\section{Appendix D. Facebook Engagement Questionnaire}

1. In the past week, approximately how much time per day have you spent on Facebook?

\begin{tabular}{|l|l|l|l|}
\hline Less than $10 \mathrm{~min}$ & & $2-3$ hours & \\
\hline $10-30 \mathrm{~min}$ & & $3-4$ hours & \\
\hline $31-60 \mathrm{~min}$ & & $4-5$ hours & \\
\hline $1-2$ hours & & More than 5 hours & \\
\hline
\end{tabular}

2. About how many total Facebook friends do you have?

\begin{tabular}{|l|l|l|l|}
\hline 10 or less & & $400-499$ & \\
\hline $11-50$ & & $500-599$ & \\
\hline $51-100$ & & $600-699$ & \\
\hline $100-199$ & & $700-799$ & \\
\hline $200-299$ & & $800-899$ & \\
\hline $300-399$ & & Greater than 900 & \\
\hline
\end{tabular}

3. How many times a day, on average, would you post on friends' walls on Facebook?

\begin{tabular}{|l|l|l|l|}
\hline Less than 5 times & $15-20$ times & \\
\hline $5-10$ times & & $20-25$ times & \\
\hline $10-15$ times & & More than 25 times & \\
\hline
\end{tabular}

4. How many times a day, on average, would you private message friends on

Facebook?

\begin{tabular}{|l|l|l|l|}
\hline Less than 5 times & & $15-20$ times & \\
\hline $5-10$ times & & $20-25$ times & \\
\hline $10-15$ times & & More than 25 times & \\
\hline
\end{tabular}

5. How many friends each day, on average, would you spend on interacting with on Facebook chat?

\begin{tabular}{|l|l|l|l|}
\hline $1-2$ & & $9-10$ & \\
\hline $3-4$ & & Over 10 & \\
\hline $5-6$ & & & \\
\hline $7-8$ & & & \\
\hline
\end{tabular}


Part B:

Directions: The following statements reflect various ways in which you may describe your experiences/situations with friends/significant others on Facebook. Rate the degree to which you agree or disagree with each statement using the following scale $(1=$ Strongly Disagree and $6=$ Strongly Agree). There is no right or wrong answer.

$\begin{array}{lllllc}\text { Strongly } & & \text { Mildly } & \text { Mildly } & & \text { Strongly } \\ \text { Disagree } & \text { Disagree } & \text { Disagree } & \text { Agree } & \text { Agree } & \text { Agree } \\ \mathbf{1} & \mathbf{2} & \mathbf{3} & \mathbf{4} & \mathbf{5} & \mathbf{6}\end{array}$

Strongly

Strongly

Disagree

\section{$\underline{\text { Agree }}$}

1. I would rather message someone on Facebook than phone them or text them.........

$\begin{array}{llllll}1 & 2 & 3 & 4 & 5 & 6\end{array}$

2. When I have something difficult to tell someone I prefer to private message them on Facebook....

3. I don't call my friends about something important, I often just message them privately on Facebook....

4. I find it easier to get a hold of my friends through Facebook

$\begin{array}{llllll}1 & 2 & 3 & 4 & 5 & 6\end{array}$

5. I have blocked a friend when we have been in a fight with each other..

$\begin{array}{llllll}1 & 2 & 3 & 4 & 5 & 6\end{array}$

6. I have removed a relationship status when in a fight with a significant other...

$\begin{array}{llllll}1 & 2 & 3 & 4 & 5 & 6\end{array}$

7. I have had a fight with a friend/significant other over something I saw on Facebook.

$\begin{array}{llllll}1 & 2 & 3 & 4 & 5 & 6\end{array}$

8. I have engaged in a argument with a friend or $\begin{array}{llllllllll}\text { significant other through Facebook messages/chat... } & 1 & 2 & 3 & 4 & 5 & 6\end{array}$

9. I feel that I can learn things about my friends or significant other through Facebook

$\begin{array}{llllll}1 & 2 & 3 & 4 & 5 & 6\end{array}$


10. Facebook is the easiest way to communicate with my friends

$\begin{array}{llllll}1 & 2 & 3 & 4 & 5 & 6\end{array}$

11. I feel the need to "status update" so my friends know what I am up to.................................................

$\begin{array}{llllll}1 & 2 & 3 & 4 & 5 & 6\end{array}$

12. I choose to "hide" some people's status updates on my news feed.

$\begin{array}{llllll}1 & 2 & 3 & 4 & 5 & 6\end{array}$

13. I would rather have a fight with a friend or

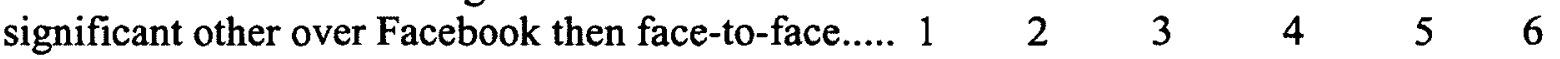

14. Initially, I feel that it is easier for me to talk to

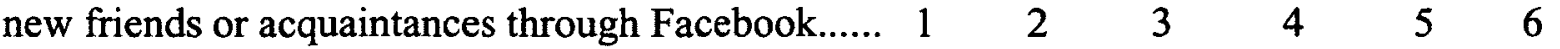

15. I have Facebook friends who I don't talk

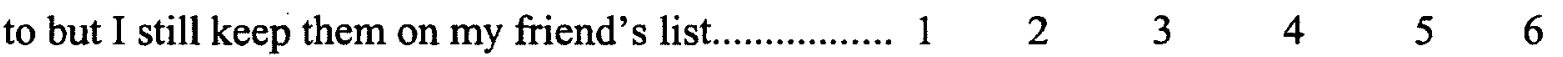

16. I receive more invites to do things with my friends through Facebook than over the phone...

$\begin{array}{llllll}1 & 2 & 3 & 4 & 5 & 6\end{array}$




\section{Appendix E. Facebook Importance Questionnaire}

Directions: The following statements reflect various ways in which you may describe your feelings of importance with engaging with your peer group of friends/on Facebook. Rate the degree to which you agree or disagree with each statement using the following scale $(1=$ Strongly Disagree and $6=$ Strongly Agree $)$. There is no right or wrong answer.

$\begin{array}{llll}\text { Strongly } & & \text { Mildly } & \text { Mildly } \\ \text { Disagree } & \text { Disagree } & \text { Disagree } & \text { Agree } \\ \mathbf{1} & \mathbf{2} & \mathbf{3} & \mathbf{4}\end{array}$

1. I feel that Facebook is an important way to keep in touch with friends

2. I feel that it's important that my friends post on my Facebook wall

3. I feel that it's important that my friends respond back to my Facebook wall posts

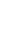

4. I feel that it's important that my friends "like" my updated Facebook status

5. I think it's important that my friends comment on my updated profile/Facebook pictures

6. I think it's important that my close friends private message me to share things

1

7. I think it's important to respond in a timely manner to wall posts and private messages from my friends

8. I think it's important that when I'm in a bad/upset mood my friends reassure me on Facebook

9. I think it's important that when I'm celebrating something good my friends support me and give me positive feedback on Facebook.

$\begin{array}{lllll}2 & 3 & 4 & 5 & 6\end{array}$

10. I think it's important that my friends post on my Facebook wall regarding special events (birthdays, graduations, good grades, etc.)

$\begin{array}{lllll}2 & 3 & 4 & 5 & 6\end{array}$


11. I think it's important to share things about myself through my Facebook status so my friends can see what I'm up to

3

45

56

12. I think it's important that I comment on a friends wall if all my other friends have because it shows I'm an equally good friend

1

23

$\begin{array}{lll}4 & 5 & 6\end{array}$

13. I think it's important to have closer friends comment on my pictures, statutes and updates than acquaintances

14. I think it's important to comment or "like" a status of someone I'm not as close with to try and maintain good social connections

3

15. I think it's important to be aware of my acquaintances

Facebook updates to I can sometimes comment/"like"

them to keep the friendship going

1

16. If different groups of my friends meet I think it's important that they should then connect on Facebook

$\begin{array}{llllll}1 & 2 & 3 & 4 & 5 & 6\end{array}$

17. If I see something that I like on my friend's Facebook wall I think that it's important that I comment on it

$1 \cdot 2$

2

3

4

56

18. I think that it's important that I "like" or comment on my friends' profile and updated Facebook pictures

19. I think that it's important that I connect with my group of friends regularly on Facebook

20. I think that it's important that my friends invite me to things through Facebook so people know what I'm doing

21. I think it's important that once I meet someone I add them to Facebook

22. I think it's important that I actively communicate with newly added friends on Facebook in the beginning of our friendship 


\section{Appendix F. Collective self-esteem Scale}

Directions: The following statements reflect various ways in which you may describe your perceptions and feelings related to your social group memberships. Rate the degree to which you agree or disagree with each statement using the following scale $(1=$ Strongly Disagree and $7=$ Strongly Agree). There is no right or wrong answer.

$\begin{array}{lcccccc}\begin{array}{l}\text { Strongly } \\ \text { Strongly }\end{array} & & \text { Mildly } & \text { Neutral } & \text { Mildly } & & \\ \begin{array}{l}\text { Disagree } \\ \text { Agree }\end{array} & \text { Disagree } & \text { Disagree } & & \text { Agree } & \text { Agree } & \\ 1 & 2 & 3 & 4 & 5 & 6 & 7\end{array}$

\section{Membership}

I am a worthy member of the social groups I belong to. (1)

I feel I don't have much to offer to the social groups I belong to. (5)

1 am a cooperative participant in the social groups $I$ belong to. (9)

1 often feel I'm a useless member of my social groups. (13)

\section{Private}

I often regret that I belong to some of the social groups I do. (2) ${ }^{b}$

In general, I'm glad to be a member of the social groups I belong to. (6)

Overall, I often feel that the social groups of which I am a member are not worthwhile. (10)

I feel good about the social groups I belong to. (14)

\section{Public}

Overall, my social groups are considered good by others. (3)

Most people consider my social groups, on the average, to be more ineffective than other social groups. ( 7$)^{b}$

In general, others respect the social groups that I am a member of. (11)

In general, others think that the social groups I am a member of are unworthy. (15)

\section{Identity}

Overall, my group memberships have very little to do with how I feel about myself. $(4)^{b}$

The social groups I belong to are an important reflection of who I am. (8)

The social groups I belong to are unimportant to my sense of what kind of a person I am. (12) ${ }^{b}$ In general, belonging to social groups is an important part of my self-image. (16) 


\section{Appendix G. Centre for Epidemiological Studies Depression Scale}

Directions: Below is a list of the ways you might have felt or behaved. Please indicate how often you have felt this way during the past week by writing the appropriate letter in the blank.

\begin{tabular}{|c|c|c|}
\hline $\begin{array}{l}\text { Rarely or none } \\
\text { of the time }\end{array}$ & $\begin{array}{l}\text { Some of } \\
\text { the time }\end{array}$ & Occasionally \\
\hline $\mathbf{A}$ & B & C \\
\hline
\end{tabular}

During the past week:

1. I was bothered by things that usually don't bother me.

A $\quad$ B $\quad$ C $\quad$ D

2. I did not feel like eating; my appetite was poor.

A $\quad$ B $\quad$ C $\quad$ D

3. I felt that I could not shake off the blues even with help from my family or friends.

A $\quad$ B $\quad$ C $\quad$ D

4. I felt that I was just as good as other people.

A $\quad$ B $\quad$ C $\quad$ D

5. I had trouble keeping my mind on what I was doing.

A $\quad$ B $\quad$ C $\quad$ D

6. I felt depressed.

A $\quad$ B $\quad$ C $\quad$ D

7. I felt that everthing I did was an effort.

A $\quad$ B $\quad$ C $\quad$ D

8. I felt hopeful about the future.

A $\quad$ B $\quad$ C $\quad$ D

9. I thought my life had been a failure.

A $\quad$ B $\quad$ C $\quad$ D

10. I felt fearful.

A $\quad$ B $\quad$ C $\quad$ D

11. My sleep was restless.

A $\quad$ B $\quad$ C $\quad$ D

12. I was happy.

A $\quad$ B $\quad$ C $\quad$ D

13. I talked less than usual.

$\begin{array}{llll}\text { A } & \text { B } & \text { C } & \text { D }\end{array}$

14. I felt lonely.

$\begin{array}{llll}\text { A } & \text { B } & \text { C } & \text { D }\end{array}$

15. People were unfriendly.

$\begin{array}{llll}\text { A } & \text { B } & \text { C } & \text { D }\end{array}$

16. I enjoyed life.

$\begin{array}{llll}\text { A } & \text { B } & \text { C } & \text { D }\end{array}$ 
17. I had crying spells.

18. I felt sad.

19. I felt that people disliked me.

20. I could not get "going".

21. I felt like eating all the time.

$\begin{array}{cccc}\text { A } & \text { B } & \text { C } & \text { D } \\ \text { A } & \text { B } & \text { C } & \text { D } \\ \text { A } & \text { B } & \text { C } & \text { D } \\ \text { A } & \text { B } & \text { C } & \text { D }\end{array}$

A $\quad$ B $\quad$ C $\quad$ D 


\section{Appendix H. The Self-Perception Scale for Adolescents-Self Worth Subscale}

Directions: For each statement, please choose which side (A or B) applies to you. Choose only one side of each statement. Then mark whether it is "Sort of true for you' or 'Really true for you'.

Here is an example:

\begin{tabular}{|c|c|c|c|c|c|c|c|}
\hline & $\begin{array}{l}\text { Reall } \\
\text { y true } \\
\text { for } \\
\text { me }\end{array}$ & $\begin{array}{l}\text { Sort of } \\
\text { true } \\
\text { for me }\end{array}$ & A & & B & $\begin{array}{c}\text { Sort of } \\
\text { true for } \\
\text { me }\end{array}$ & $\begin{array}{l}\text { Really } \\
\text { true } \\
\text { for me }\end{array}$ \\
\hline 1. & & & $\begin{array}{l}\text { Some teenagers like } \\
\text { ice-cream }\end{array}$ & But & $\begin{array}{l}\text { Other teenagers } \\
\text { prefer fresh fruit }\end{array}$ & & $X$ \\
\hline
\end{tabular}




\section{What I Am Like}

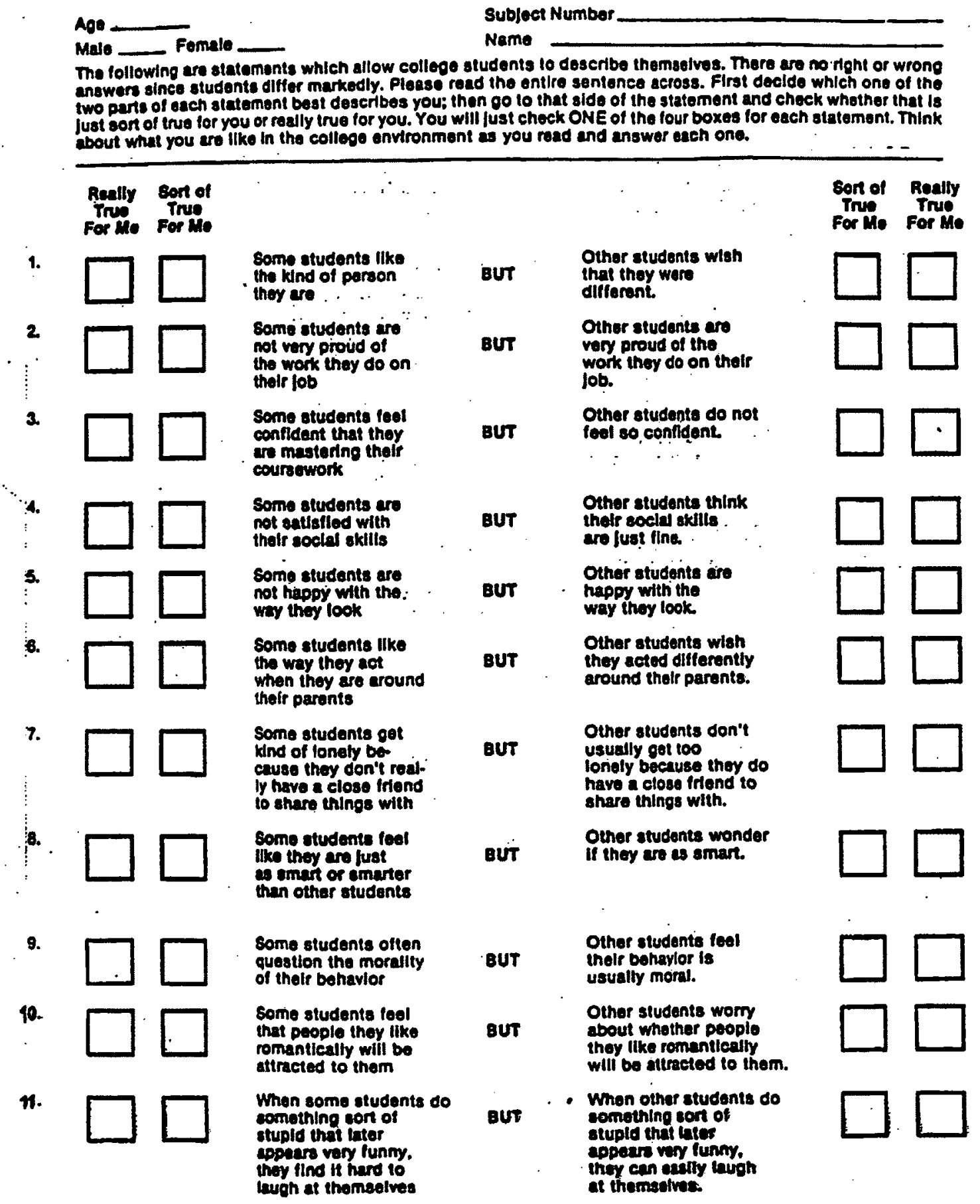




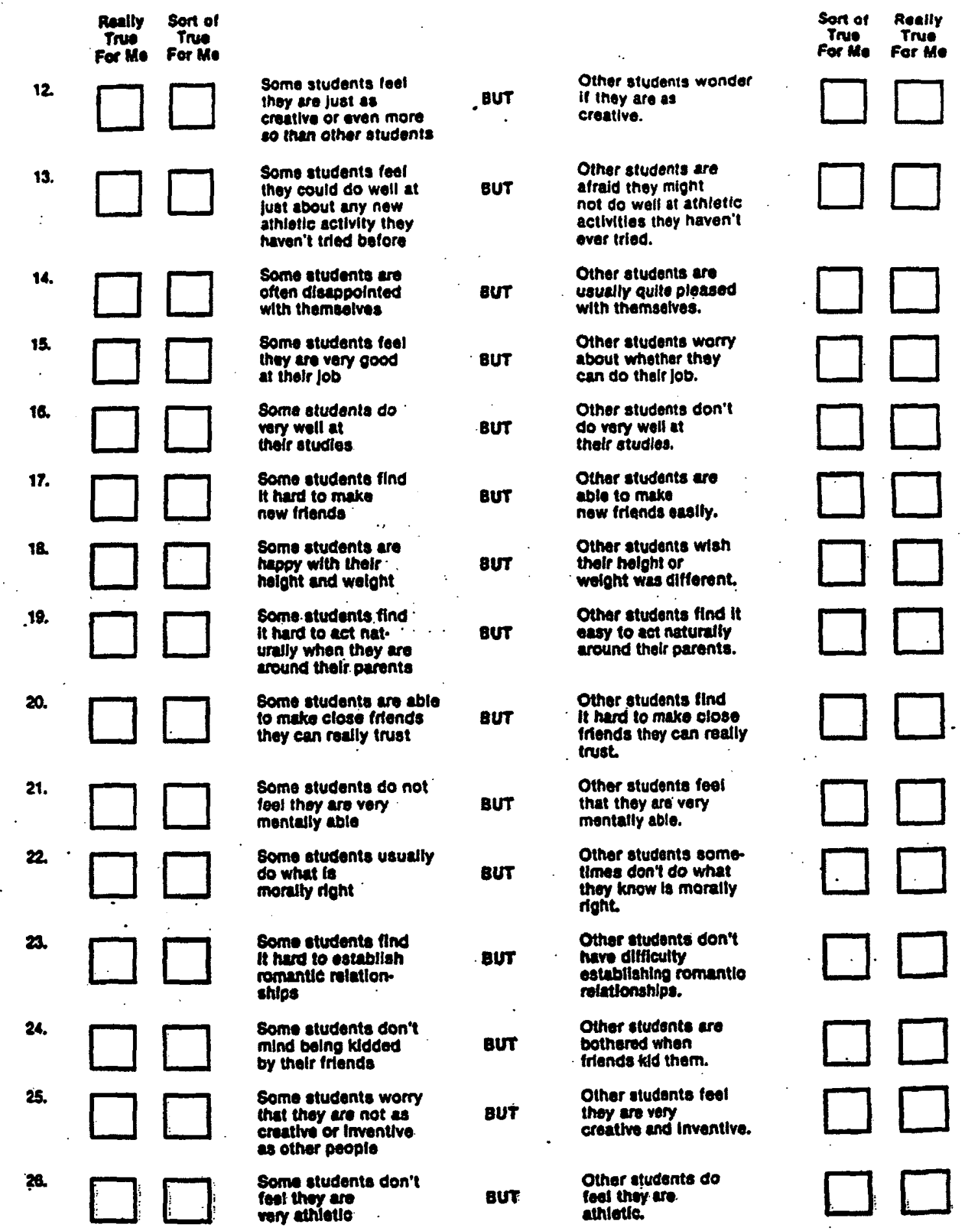




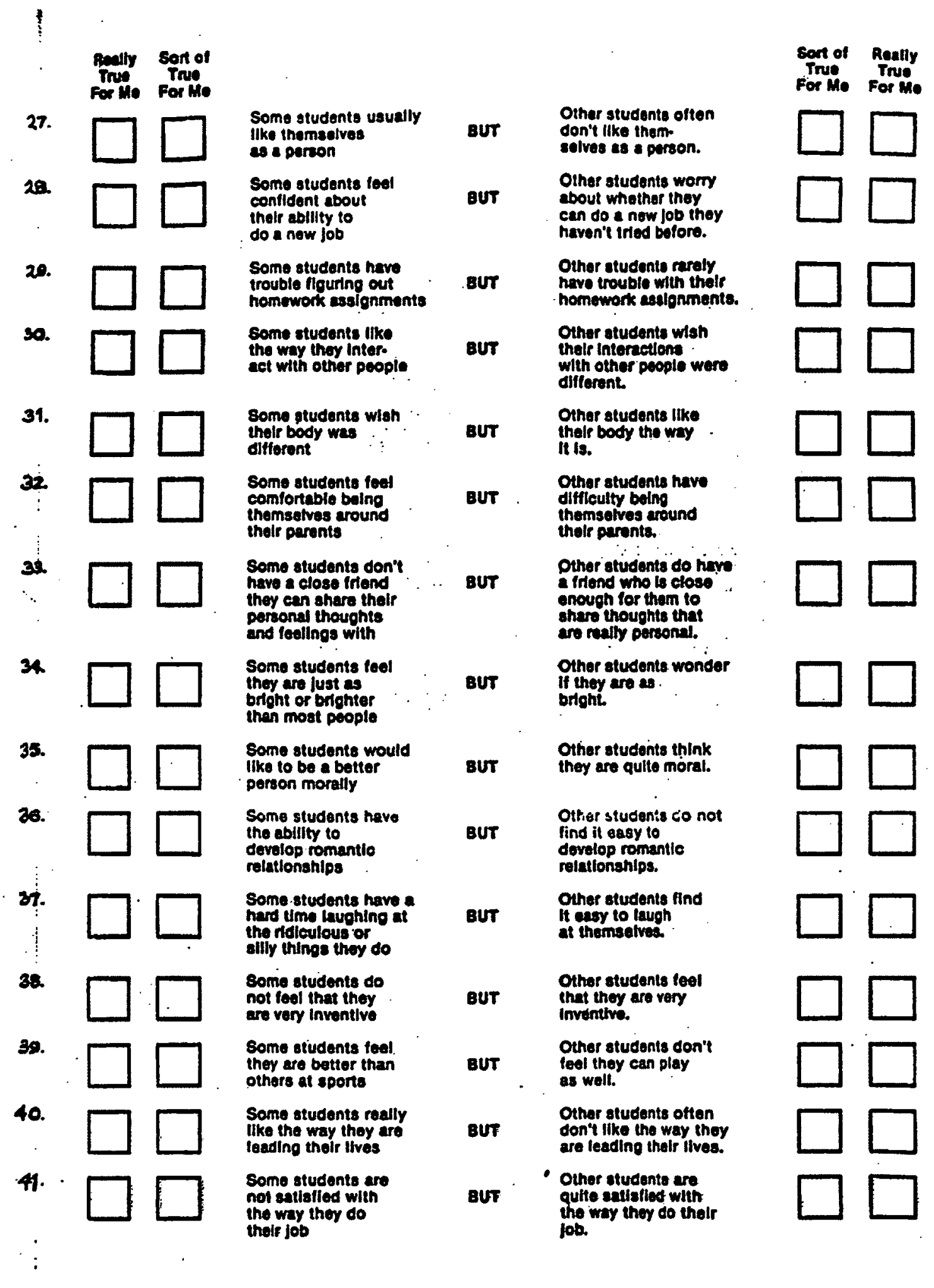




\begin{tabular}{|c|c|c|c|c|c|c|c|}
\hline & $\begin{array}{l}\text { Roally } \\
\text { True } \\
\text { For Me }\end{array}$ & $\begin{array}{l}\text { Sort of } \\
\text { True } \\
\text { For Me }\end{array}$ & & & & $\begin{array}{l}\text { sort of } \\
\text { True: } \\
\text { for the }\end{array}$ & $\begin{array}{l}\text { Really } \\
\text { True } \\
\text { For He }\end{array}$ \\
\hline 12 & & & $\begin{array}{l}\text { Some students some } \\
\text { limes do not teal } \\
\text { intellectualiy competent } \\
\text { at thair studies }\end{array}$ & ตUT & $\begin{array}{l}\text { Other students usualiy } \\
\text { do leal intellec. } \\
\text { tually competent at } \\
\text { their studies. }\end{array}$ & & \\
\hline 43. & & & $\begin{array}{l}\text { Somo students feal } \\
\text { that they aro so- } \\
\text { clally accepted by : } \\
\text { many people }\end{array}$ & BUT & $\begin{array}{l}\text { Other students wlsh } \\
\text { more people } \\
\text { acespted them. }\end{array}$ & & \\
\hline 4. & & & $\begin{array}{l}\text { Some students like } \\
\text { ineir phydeal tp. } \\
\text { peerenes the wiey it is }\end{array}$ & But & $\begin{array}{l}\text { Other students do } \\
\text { not like thelp } \\
\text { physical appearance. }\end{array}$ & & \\
\hline 45. & & & $\begin{array}{l}\text { Some sludents find } \\
\text { mat thay are unable } \\
\text { to get along with } \\
\text { thoir parents }\end{array}$ & BUT & $\begin{array}{l}\text { Other studante get } \\
\text { along wilh ineir } \\
\text { parents quite welt. }\end{array}$ & & \\
\hline 46. & & & $\begin{array}{l}\text { Some students are } \\
\text { sble to make really } \\
\text { close friends }\end{array}$ & 8UT & $\begin{array}{l}\text { Other stidents find } \\
\text { it hard to make } \\
\text { really close friends. }\end{array}$ & & \\
\hline 47. & & & $\begin{array}{l}\text { Some students would } \\
\text { really raihor bo } \\
\text { dilferent }\end{array}$ & eut & $\begin{array}{l}\text { Other studenta are } \\
\text { very haopy boing } \\
\text { the way thoy are. }\end{array}$ & & \\
\hline 48. & & & $\begin{array}{l}\text { Some itudents gues. } \\
\text { ulon whother they } \\
\text { art very Inteligent. }\end{array}$ & BUT & $\begin{array}{l}\text { Othar students foel } \\
\text { thoy are } \\
\text { Intelligent. }\end{array}$ & & \\
\hline 49. & & & $\begin{array}{l}\text { Some itudents ilve } \\
\text { up lo inolr own } \\
\text { morl standerds. }\end{array}$ & BUT & $\begin{array}{l}\text { Other atudents have } \\
\text { trouble living up to } \\
\text { their mord standards. }\end{array}$ & & \\
\hline 50. & & & $\begin{array}{l}\text { Some students worry } \\
\text { thit when they like. } \\
\text { someone romuntleally. } \\
\text { that person won't tike } \\
\text { Ilke them back }\end{array}$ & BUt & $\begin{array}{l}\text { Other students foel } \\
\text { that when they are } \\
\text { romanticelfy intersested } \\
\text { in someone, that perseon } \\
\text { will like them beck. }\end{array}$ & & \\
\hline 51. & & & $\begin{array}{l}\text { Some students can } \\
\text { readly laugh at cer-. } \\
\text { taln things they do }\end{array}$ & BUT & $\begin{array}{l}\text { Other students have a } \\
\text { hard time laughing } \\
\text { at themselves. }\end{array}$ & & \\
\hline 52. & & & $\begin{array}{l}\text { Some atudents foel } \\
\text { ther have lot of } \\
\text { orfoinal toeas. }\end{array}$ & BUT & $\begin{array}{l}\text { Other gtudents ques- } \\
\text { tion whother their ldeas } \\
\text { are very orlginal. }\end{array}$ & & \\
\hline 53. & & & $\begin{array}{l}\text { Some students don't } \\
\text { do weil at activitios } \\
\text { requilning physical } \\
\text { okill. }\end{array}$ & BUT & $\begin{array}{l}\text { Other sludants are } \\
\text { good et acthitios } \\
\text { requifing phyoleal } \\
\text { skilt. }\end{array}$ & & \\
\hline S4. & & & $\begin{array}{l}\text { Some students are } \\
\text { often diasatlisfled } \\
\text { with themselves }\end{array}$ & & $\begin{array}{l}\text { Other studente are } \\
\text { uaually sallsfied } \\
\text { with thernselves. }\end{array}$ & & \\
\hline
\end{tabular}




\section{Appendix I. Revised UCLA Loneliness Scale}

Directions: Indicate how often you feel the way described in each of the following statements.Circle one number for each.

Often this way

1
Sometimes

2

$\underset{3}{\text { Rarely }}$

3
Never

4

- I feel in tune with people around me

2

3

4

- I lack companionship

2

3

4

- There is no one I can turn to

2

3.

4

- I do not feel alone

2

3

4

- I feel part of a group of friends

2

3

4

- I have a lot in common with people around me

- I am no longer close to anyone

2

3

4

- My interests and ideas are not shared by those around me

- I am an outgoing person

2

3

4

- There are people I feel close to

\section{1}

2

3

4

- I feel left out

- My friendships are superficial

\section{1}

2

3

4

- No one really knows me well

- I feel isolated from others

- I can find companionship when I

- want it

- There are people who really understand me

- I am unhappy being so withdrawn 
- People are around me but not with me 1
2

2
3

3

3
4 4

- There are people I can turn to
1

1

$\mathbf{1}$ 


\section{Appendix J. Satisfaction With Life Scale}

Directions: Below are five statements with which you may agree or disagree. Using the 1-7 scale below, indicate your agreement with each item by placing the appropriate number on the line preceding that item. Please be open and honest in your responding. The 7-point scale is:

1 =strongly disagree, 2 = disagree, 3 = slightly disagree, $4=$ neither agree nor disagree, $5=$ slightly agree, 6 =agree, $7=$ strongly agree.

1. In most ways my life is close to my ideal

2. The conditions of my life are excellent

3. I am satisfied with my life

4. So far I have gotten the important things I want in life

5. If I could live my life over, I would change almost nothing 